\title{
ESTIMATIVA DA EVAPOTRANSPIRAÇÃO DE REFERÊNCIA PELO USO DA TERMOMETRIA AO INFRAVERMELHO
}

\section{SELMA REGINA MAGGIOTTO}

Eng. Agrônoma

Orientador: Prof. Dr. Marcos Vinícius Folegatti

Dissertação apresentada à Escola Superior de Agricultura "Luiz de Queiroz", da Universidade de São Paulo, para obtenção do título de Mestre em Agronomia, Área de Concentração: Irrigação e Drenagem.

\author{
Piracicaba \\ Estado de São Paulo - Brasil \\ Julho de 1996
}


Dados Internacionais de Catalogação na Publicação (CIP)

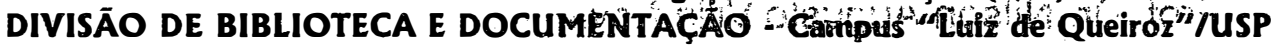

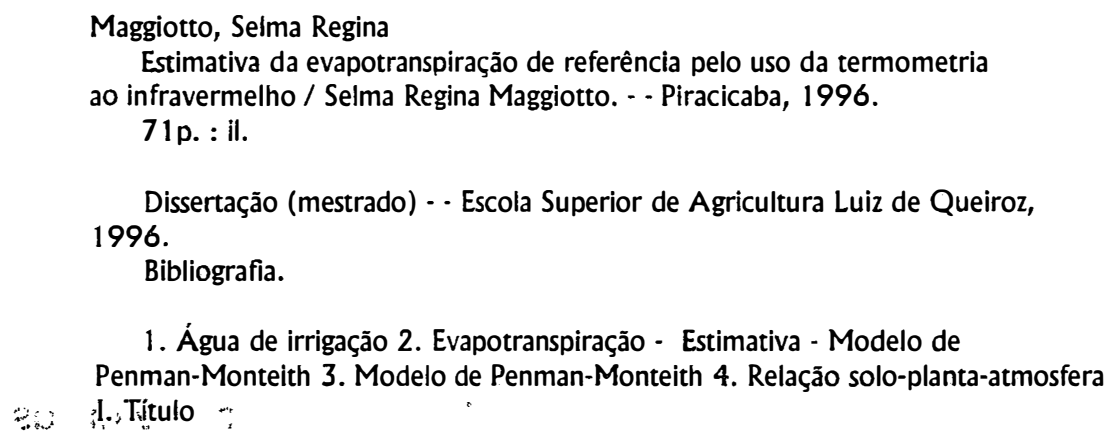

1. Água de irrigação 2. Evapotranspiração - Estimativa - Modelo de Penman-Monteith 3. Modelo de Penman-Monteith 4. Relação solo-planta-atmosfera I.: Titulo :

CDD $\quad 551.572$ 


\title{
ESTIMATIVA DA EVAPOTRANSPIRAÇĀO DE REFERÊNCIA PELO USO DA TERMOMETRIA AO INFRAVERMELHO
}

\author{
SELMA REGINA MAGGIOTTO
}

Aprovada em 06 de setembro de 1996.

Comissão julgadora:

Prof. Dr. Marcos Vinícius Folegatti

ESALQ/USP

Rrof. Dr Nilson Angusto Wilano va

ESALQ/USP

Prof. Dr. Antonio Roberto Pereira

ESALQ/USP

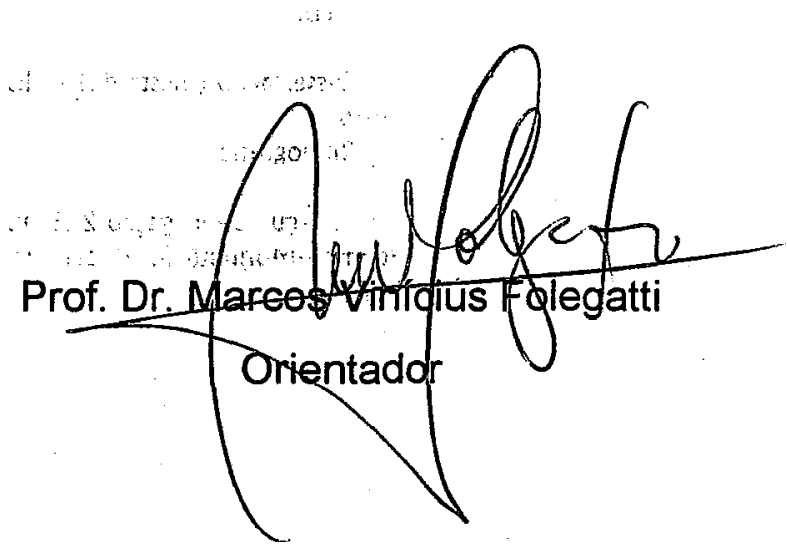


Aos meus pais,

José Maggiotto e Tereza de Souza Maggiotto,

e à minha irmã,

Sonia Cristina Maggiotto,

OFEREÇO. 


\section{AGRADECIMENTOS}

Ao Prof. Dr. Marcos Vinícius Folegatti, pela orientação e pela confiança em mim depositada para execução deste trabalho.

Aos professores dos Departamentos de Engenharia Rural e de Física e Meteorologia da ESALQ/USP, pelos ensinamentos e pela amizade.

Aos professores Antonio Roberto Pereira e Nilson Augusto Villa Nova, pelas idéias e pela colaboração na análise e discussão dos dados e resultados.

À Coordenação de Aperfeiçoamento de Pessoal de Nivel Superior (CAPES), pela bolsa de estudo concedida.

Aos funcionários do Departamento de Engenharia Rural, Hélio Toledo Gomes, José Figueiredo, Gilmar Batista Grigolon, Renato Benedito Nicolau, Antonio Cesar Souza Rocha, pela colaboração.

Aos colegas do curso, pelo companheirismo e agradável convivência.

Aos amigos Regina Célia de Matos Pires, Fabiano Chaves da Silva e Antonio Carlos Andrade Gonçalves, pela colaboração e pelo apoio.

A Axel Garcia y Garcia, em especial, pelo apoio e carinho sempre presentes.

A todos que de uma forma ou de outra colaboraram na realização deste trabalho. 


\section{SUMÁRIO}

Página

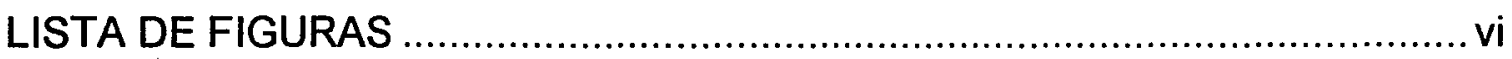

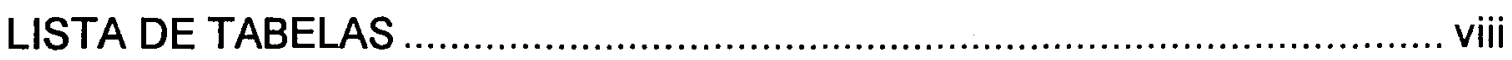

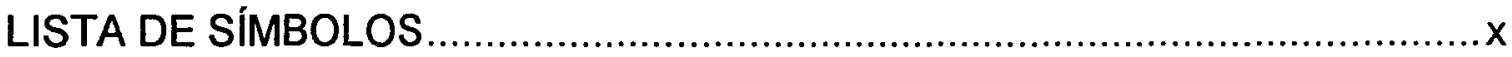

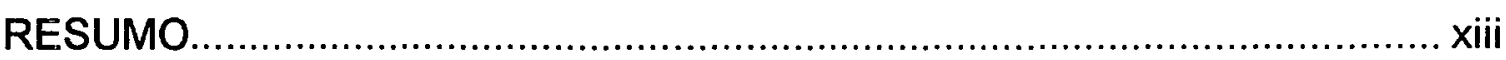

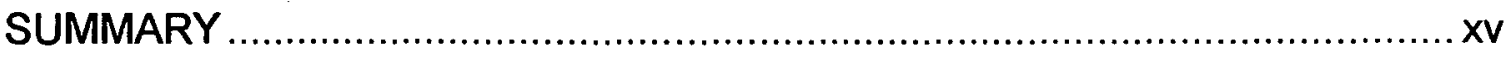

1. INTRODUÇÃO

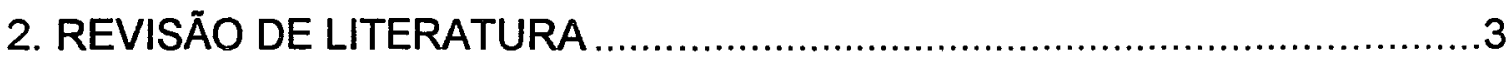

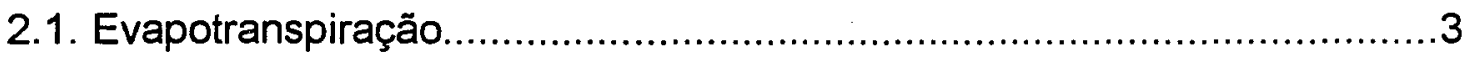

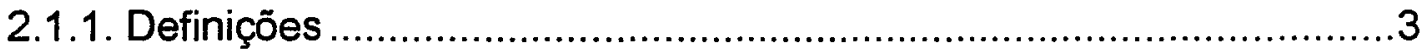

2.1.2. Métodos de estimativa da evapotranspiração .................................4

2.1.3. Método combinado - modelo de Penman-Monteith ..........................5

2.2. Temperatura de folhas e da cobertura vegetal......................................

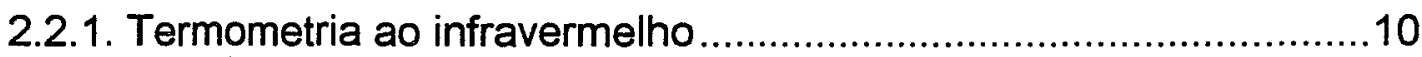

2.2.2. Fatores que influenciam na detecção da temperatura radiante

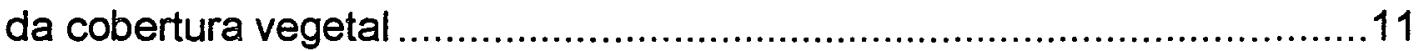

2.3. Uso da temperatura da cobertura vegetal na detecção do estresse

hídrico

2.4. Uso da temperatura da cobertura vegetal na estimativa da

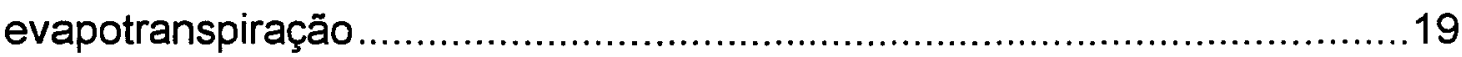

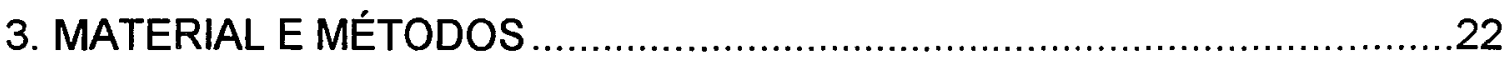

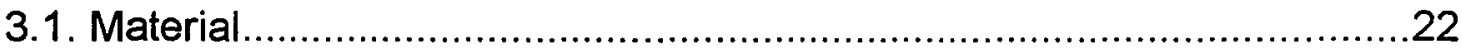

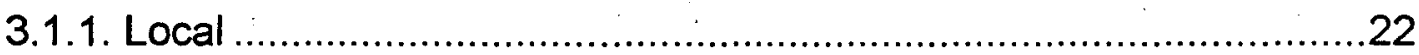

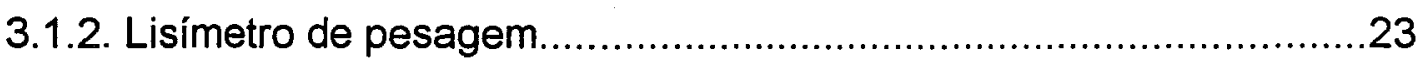

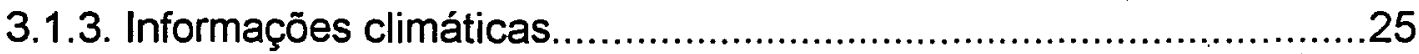

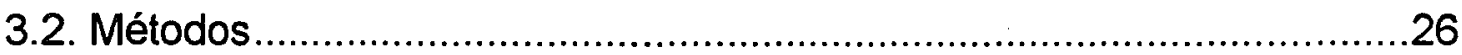

3.2.1. Determinação direta da evapotranspiração ...................................26 
3.2.2. Estimativa da evapotranspiração de referência pelo modelo

Penman-Monteith com o uso da termometria ao infravermelho.

3.2.3. Estimativa da evapotranspiração de referência pelo modelo

Penman-Monteith Padronizado pela FAO/91 ….....................................30

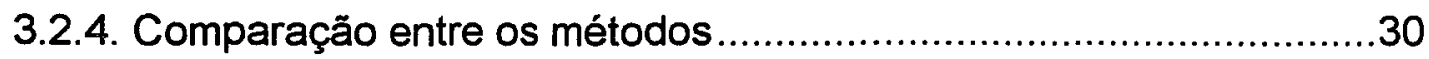

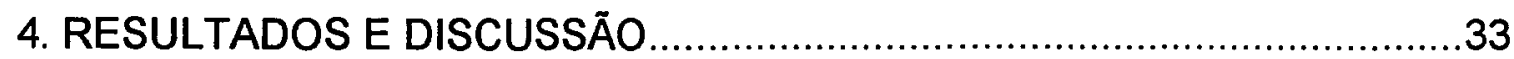

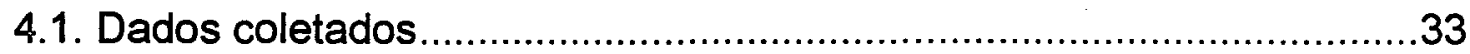

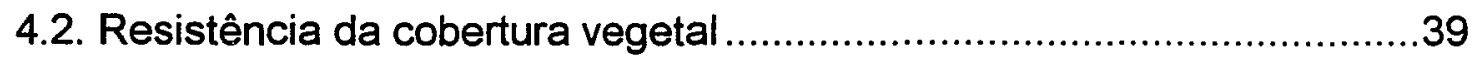

4.2.1. Cálculo de rc em períodos de $30 \mathrm{~min}$..........................................40

4.2.2. Cálculo de rc em períodos de 24 horas .......................................43

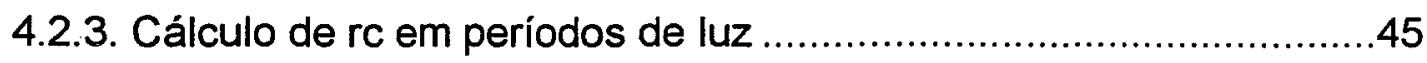

4.2.4. Considerações sobre o cálculo de rc..........................................46

4.2.5. Escolha do valor de $\mathrm{rc}_{\mathrm{Tc}}$ a ser utilizado na estimativa da

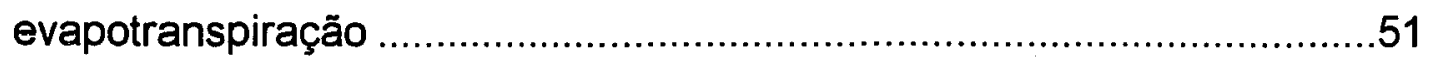

4.3. Estimativa da evapotranspiração de referência ..................................51

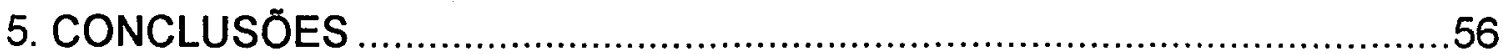

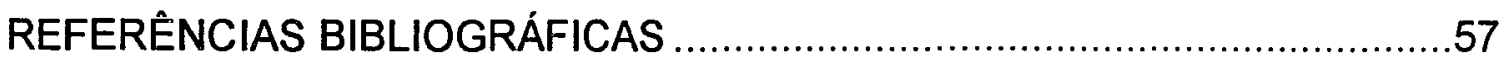

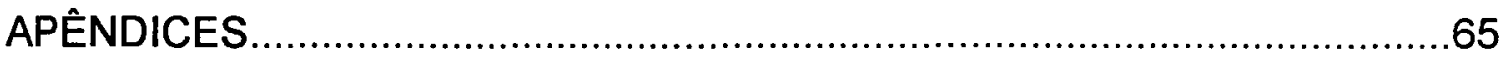

Apêndice I. Calibração do lisímetro de pesagem .......................................66

Apêndice II. Calibração do Termômetro ao Infravermelho ...........................69

Apêndice III. Comparação entre as médias mensais dos últimos 10 anos e as médias mensais do período de estudo 


\section{LISTA DE FIGURAS}

Página

Figura 1. Croqui da área em estudo.

23

Figura 2. Temperatura média diária $\left({ }^{\circ} \mathrm{C}\right)$ e umidade relativa média diária (\%) dos dias em análise.

Figura 3. Radiação líquida total no período de $24 \mathrm{~h}\left(\mathrm{~kJ} \mathrm{~m}^{-2} \mathrm{~d}^{-1}\right)$ dos dias em análise.

Figura 4. Variação da radiação líquida ao longo de um dia sem a ocorrência de nuvens (28/01) e de um dia encoberto (02/05).

Figura 5. Variação da radiação líquida ao longo de um dia com presença de nuvens.

Figura 6. Velocidade do vento média diária $\left(\mathrm{m} \mathrm{s}^{-1}\right)$ dos dias em análise

Figura 7. Variação da resistência da cobertura vegetal calculada como resíduo ( $\mathrm{rc}_{\mathrm{res}}$ ) e pelo uso da temperatura da cobertura vegetal ( $\mathrm{rc}_{\mathrm{Tc}}$ ) e variação da radiação líquida: a) e c) ao longo de um dia sem a ocorrência de nuvens; b) e d) ao longo de um dia com a ocorrência de nuvens.

Figura 8. Variação da relação entre a densidade de fluxo de calor latente medido e a radiação líquida, e variação da velocidade do vento: a) e c) em um dia sem a ocorrência de nuvens; b) e d) em um dia com a ocorrência de nuvens.

Figura 9. Resistência da cobertura vegetal ( $\mathrm{rc}_{\mathrm{res}}$ e $\mathrm{rc}_{\mathrm{Tc}}$ ) calculada com valores médios de $24 \mathrm{~h}$, para os dias em análise.

Figura 10. Resistência da cobertura vegetal ( $\mathrm{rc}_{\mathrm{res}}$ e $\mathrm{rc}_{\mathrm{Tc}}$ ) calculada com valores médios dos períodos de luz, para os dias em análise.

Figura 11. Resistência da cobertura vegetal ( $r \mathrm{C}_{\text {res }}$ e $r \mathrm{C}_{\mathrm{Tc}}$ ) calculada para os dias em análise, com dados médios diários de $R n$ e $G$, e dados instantâneos de temperatura da cobertura vegetal: a) às 12:00 $h ; b)$ às $15: 00 h$ 
Figura 12. Evapotranspiração medida ( $\left.E T_{\text {lis }}\right)$, e estimadas pela parametrização proposta pela $\mathrm{FAO} / 91\left(\mathrm{ET}_{\mathrm{FAO}}\right)$ e pelo uso da temperatura da cobertura vegetal $\left(\mathrm{ET}_{\mathrm{Tc12}}\right.$ e $\left.E \mathrm{~T}_{\mathrm{Tc15}}\right)$, para os dias em análise.

Figura 13. Comparação entre os valores medidos da evapotranspiração (linha 1:1), e os valores estimados pela parametrização proposta pela $\mathrm{FAO} / 91$ ( $E \mathrm{~T}_{\mathrm{FAO}}$ ), e pelo uso da temperatura da cobertura vegetal $\left(E T_{T c 12}\right.$ e $\left.E T_{T c 15}\right)$.

Figura 14. Variação da massa do lisimetro e da temperatura na altura das células de carga durante o período de calibração. 66

Figura 15. Relação entre valores reais e medidos pelo lisimetro de pesagem, em comparação com a reta 1:1.

Figura 16. Esquema de montagem do sistema para calibração do termômetro ao infravermelho.

Figura 17. Representação gráfica da calibração do termômetro ao infravermelho. 


\section{LISTA DE TABELAS}

Página

Tabela 1. Valores médios de temperatura do ar ( $\mathrm{Ta})$, umidade relativa (UR), velocidade do vento (U), temperatura da cobertura vegetal (Tc), e valores totais de radiação líquida $(R n)$, densidade de fluxo de calor no solo $(G)$ e evapotranspiração medida pelo lisimetro ( $E T_{\text {lis }}$ ), em periodos de $24 \mathrm{~h}$.

Tabela 2. Valores de resistência da cobertura vegetal calculados pelo uso de informações médias de $24 \mathrm{~h}$.

Tabela 3. Valores médios de temperatura do ar ( $\mathrm{Ta}$ ), umidade relativa (UR), velocidade do vento (U), temperatura da cobertura vegetal $(T c)$, e valores totais de radiação líquida (Rn), densidade de fluxo de calor no solo $(G)$ e evapotranspiração medida pelo lisimetro ( $E T_{\text {isis }}$ ), em periodos de luz.

Tabela 4. Valores de resistência da cobertura vegetal calculada pelo uso de informações médias de períodos de luz.

Tabela 5. Valores da resistência da cobertuta vegetal calculados pelo uso da temperatura da cobertura vegetal obtida em horários de maior radiação, para os dias analisados.

Tabela 6. Parâmetros das equações de regressão entre $\mathrm{rc}_{\mathrm{res}}$ e $\mathrm{rc}_{\mathrm{Tc}}$ calculados nos horários de maior radiação $(y=a+b x)$.

Tabela 7. Valores medidos de evapotranspiração ( $E T_{\text {lis }}$ ), estimados pela parametrização proposta pela $\mathrm{FAO} / 91$ ( $E T_{\mathrm{FAO}}$ ), e pelo uso da temperatura da cobertura vegetal $\left(E T_{T_{c 12}}\right.$ e $\left.E T_{T c 15}\right)$.

Tabela 8. Parâmetros para comparação entre os métodos de estimativa da evapotranspiração, tomando como padrão a evapotranspiração medida pelo lisímetro $(y=a x+b)$ : indice $d$ (Id). erro sistemático (Es, em $\mathrm{mm} \mathrm{d}^{-1}$ ), erro não sistemático ( $E$, em $\mathrm{mm} \mathrm{d}^{-1}$ ) e média do erro absoluto (MAE, em $\mathrm{mm} \mathrm{d}^{-1}$ ). 
Tabela 9. Massa medida e massa real durante 0 procedimentos de acréscimo e decréscimo de peso.

Tabela 10. Parâmetros das equações de regressão linear $(y=a x+b)$ entre pesos reais e medidos, e índice $d$ (Id).

Tabela 11. Comparação entre dados climáticos médios mensais dos últimos 10 anos e a média mensal durante o período de coleta de dados: temperatura do ar (Ta), umidade relativa (UR), velocidade do vento (U) e chuva (C). 


\section{LISTA DE SÍMBOLOS}

\begin{tabular}{|c|c|c|}
\hline símbolo & descrição & unidade \\
\hline$\varepsilon$ & emissividade da superfície de um corpo & \\
\hline$\sigma$ & constante de Stefan-Boltzmann & $\mathrm{J} \mathrm{m}^{-2} \mathrm{~s}^{-1} \mathrm{~K}^{-4}$ \\
\hline$\rho$ & massa específica do ar atmosférico & $\mathrm{kg} \mathrm{m}^{-3}$ \\
\hline$\gamma$ & constante psicrométrica & $\mathrm{kPa}{ }^{\circ} \mathrm{C}^{-1}$ \\
\hline$\lambda E$ & densidade fluxo de calor latente & $\mathrm{J} \mathrm{m}^{-2} \mathrm{~s}^{-1}$ \\
\hline $\mathrm{cp}$ & calor especifico do ar a pressão constante & $\mathrm{J} \mathrm{kg}^{-1} \circ \mathrm{C}^{-1}$ \\
\hline CTV & variabilidade da temperatura da cobertura vegetal & \\
\hline CWSI & índice de estresse hídrico da cultura & \\
\hline \multirow[t]{2}{*}{ d } & deslocamento do plano zero do perfil de velocidade do & \\
\hline & vento & $\mathrm{m}$ \\
\hline DPV & déficit de pressão de vapor & $\mathrm{kPa}$ \\
\hline$e^{*} a$ & pressão de saturação de vapor à temperatura do ar & $\mathrm{kPa}$ \\
\hline \multirow[t]{2}{*}{$e^{*} \mathrm{C}$} & pressão de saturação de vapor à temperatura da & \\
\hline & cobertura vegetal & $\mathrm{kPa}$ \\
\hline ea & pressão atual de vapor & $\mathrm{kPa}$ \\
\hline Es & erro sistemático da estimativa da evapotranspiração & $\mathrm{mm} \mathrm{d}^{-1}$ \\
\hline ETo & evapotranspiração de referência & $\mathrm{mm} \mathrm{d}^{-1}$ \\
\hline \multirow[t]{2}{*}{$E T_{F A O}$} & evapotranspiração estimada a partir da parametrização & \\
\hline & proposta pela FAO/91 & $\mathrm{mm} \mathrm{d}^{-1}$ \\
\hline$E T_{\text {lis }}$ & evapotranspiração medida pelo lisímetro de pesagem & $\mathrm{mm} \mathrm{d}^{-1}$ \\
\hline $\mathrm{ET}_{\mathrm{Tc}}$ & $\begin{array}{l}\text { evapotranspiração estimada a partir do uso da } \\
\text { temperatura da cobertura vegetal }\end{array}$ & $\mathrm{mm} \mathrm{d}^{-1}$ \\
\hline \multirow[t]{2}{*}{ Eu } & erro não sistemático da estimativa da & \\
\hline & evapotranspiração & $\mathrm{mm} \mathrm{d}^{-1}$ \\
\hline G & densidade de fluxo de calor no solo & $\mathrm{J} \mathrm{m}^{-2} \mathrm{~s}^{-1}$ \\
\hline $\mathrm{H}$ & densidade de fluxo de calor sensivel & $\mathrm{J} \mathrm{m}^{-2} \mathrm{~s}^{-1}$ \\
\hline
\end{tabular}




\begin{tabular}{|c|c|c|}
\hline he & altura média da vegetação & $\mathrm{m}$ \\
\hline IAF & índice de área foliar & $\mathrm{m}_{\text {folha }}^{2} / \mathrm{m}_{\text {terreno }}^{2}$ \\
\hline Id & índice d de concordância & \\
\hline k & constante de von Karman & \\
\hline MAE & média do erro absoluto & $m m d^{-1}$ \\
\hline $\mathbf{N}$ & número de pares de dados analisados & \\
\hline O & valor médio observado (medido) da evapotranspiração & $m m d^{-1}$ \\
\hline $\mathrm{Oi}$ & valor observado (medido) da evapotranspiração & $m m d^{-1}$ \\
\hline$P$ & pressão atmosférica local & $\mathrm{kPa}$ \\
\hline \multirow[t]{2}{*}{$\mathrm{Pi}$} & valor previsto (estimado pelo modelo) da & \\
\hline & evapotranspiração & $\mathrm{mm} \mathrm{d}^{-1}$ \\
\hline \multirow[t]{2}{*}{ Pri } & $\begin{array}{l}\text { valor da evapotranspiração calculado a partir dos } \\
\text { coeficientes da equação de regressão entre valores }\end{array}$ & \\
\hline & medidos e estimados & $\mathrm{mm} \mathrm{d}^{-1}$ \\
\hline $\mathbf{R}$ & constante universal dos gases para o ar úmido & $\mathrm{J} \mathrm{kg}^{-1} \mathrm{~K}^{-1}$ \\
\hline ra & $\begin{array}{l}\text { resistência aerodinâmica à difusão de calor sensível e } \\
\text { de vapor d'água }\end{array}$ & $s \mathrm{~m}^{-1}$ \\
\hline Rad & radiação emitida por um corpo & $\mathrm{J} \mathrm{m}^{-2} \mathrm{~s}^{-1}$ \\
\hline$r a_{h}$ & resistência aerodinâmica à difusão de calor sensível & $s \mathrm{~m}^{-1}$ \\
\hline $\mathrm{ra}_{\mathrm{v}}$ & resistência aerodinâmica à difusão de vapor d'água & $s \mathrm{~m}^{-1}$ \\
\hline \multirow[t]{2}{*}{ rc } & resistência da cobertura vegetal à difusão de calor & \\
\hline & latente & $s \mathrm{~m}^{-1}$ \\
\hline $\mathrm{rC}_{\text {res }}$ & resistência da cobertura vegetal residual & $\mathrm{s} \mathrm{m}^{-1}$ \\
\hline $\mathrm{rC}_{\mathrm{Tc}}$ & $\begin{array}{l}\text { resistência da cobertura vegetal calculada a partir da } \\
\text { temperatura da cobertura vegetal }\end{array}$ & $s \mathrm{~m}^{-1}$ \\
\hline $\mathrm{RI}$ & média diária da resistência estomática de uma folha & $s \mathrm{~m}^{-1}$ \\
\hline $\mathrm{Rn}$ & radiação líquida & $\mathrm{J} \mathrm{m}^{-2} \mathrm{~s}^{-1}$ \\
\hline \multirow[t]{2}{*}{ s } & inclinação da tangente à curva de pressão de & \\
\hline & saturação de vapor no ponto da temperatura do ar & $\mathrm{kPa}{ }^{\circ} \mathrm{C}^{-1}$ \\
\hline
\end{tabular}




$\begin{array}{lll}\text { SDD } & \text { graus dias de estresse } & { }^{\circ} \mathrm{C} \mathrm{d} \\ T & \text { temperatura de um corpo } & \mathrm{K} \\ \text { Ta } & \text { temperatura do ar } & { }^{\circ} \mathrm{C} \\ \text { TC } & \text { temperatura da cobertura vegetal } & { }^{\circ} \mathrm{C} \\ \text { TSD } & \text { temperatura de estresse diário } & { }^{\circ} \mathrm{C} \\ \text { TV } & \text { temperatura virtual do ar } & \mathrm{K} \\ \mathrm{U} & \text { velocidade do vento } & \mathrm{m} \mathrm{s}^{-1} \\ \text { UR } & \text { umidade relativa do ar } & \% \\ \text { Uz } & \text { velocidade do vento à altura z } & \mathrm{m} \mathrm{s}^{-1} \\ \text { zh } & \text { altura de determinação da temperatura e umidade } & \\ & \text { relativa } & \mathrm{m} \\ \text { zm } & \text { altura de medida da velocidade do vento } & \mathrm{m} \\ \text { zoh } & \text { comprimento de rugosidade equivalente para } & \\ & \text { transferência de calor sensivel e calor latente } & \mathrm{m} \\ \text { zom } & \text { comprimento de rugosidade equivalente para } & \\ & \text { transferência de momento } & \mathrm{m}\end{array}$




\title{
ESTIMATIVA DA EVAPOTRANSPIRAÇÃO DE REFERÊNCIA PELO USO DA TERMOMETRIA AO INFRAVERMELHO
}

\author{
Autora: Selma Regina Maggiotto \\ Orientador: Prof. Dr. Marcos Vinícius Folegatti
}

\section{RESUMO}

O uso eficiente da água na irrigação depende cada vez mais de estudos na área de monitoramento do consumo de água pelo sistema solo-plantaatmosfera. O modelo de Penman-Monteith é considerado o mais adequado para a estimativa da evapotranspiração nas diversas condições climáticas. Porém, sua adoção implica no desenvolvimento de pesquisas adicionais para se determinar valores de resistência da cobertura vegetal, sendo esta a principal dificuldade na aplicação do modelo.

O cálculo da relação entre os parâmetros de resistência pode ser feito pelo uso da temperatura radiante da cobertura vegetal, determinada com o termômetro infravermelho.

Este trabalho objetivou avaliar o uso da temperatura radiante da cobertura vegetal como auxiliar no cálculo da evapotranspiração de referência pelo modelo de Penman-Monteith, comparando os resultados com o cálculo pela mesma equação, mas utilizando a parametrização sugerida pela FAO/91, e com medidas diretas obtidas em lisímetro de pesagem.

Os fatores climáticos e a temperatura da cobertura vegetal foram determinados e analisados em periodos de $30 \mathrm{~min}, 24 \mathrm{~h}$ e períodos de luz. Os dados foram coletados por uma estação meteorológica automática instalada em área de grama, e a evapotranspiração ocorrida foi medida por um lisímetro de pesagem baseado em células de carga, instalado na mesma área. 
Foi feito o estudo dos valores de resistência da cobertura vegetal calculados nos diferentes períodos de tempo, e concluiu-se que para o uso da temperatura da cobertura vegetal no cálculo da relação entre os parâmetros de resistência, o valor da radiação líquida deve ser o total diário, enquanto que a temperatura do ar e da cobertura vegetal, a umidade relativa e a velocidade do vento devem ser leituras instantâneas, nas horas de maior radiação. Quando foram utilizadas informações médias de mesmos periodos de tempo, o cálculo resultou em valores negativos de resistência da cobertura vegetal.

A resistência da cobertura vegetal, quando calculada como residuo, apresentou valor médio de $144 \mathrm{~s} \mathrm{~m}^{-1}$, bastante superior ao proposto pela FAO/91 para uma cultura de referência. Apesar disso, a estimativa da evapotranspiração pelo uso da equação de Penman-Monteith parametrizada pela $\mathrm{FAO} / 91$, apresentou ótima performance, assim como a evapotranspiração estimada pelo uso de valores de rc calculados com medidas das 12:00 h, quando comparadas com a evapotranspiração medida pelo lisímetro. 


\title{
REFERENCE EVAPOTRANSPIRATION ESTIMATIVES USING INFRARED THERMOMETRY
}

\author{
Author: Selma Regina Maggiotto \\ Adviser: Prof. Dr. Marcos Vinícius Folegatti
}

\begin{abstract}
SUMMARY
The efficient use of water in irrigation depends even more on the researchs about the water use by the soil-plant-atmosphere system. The Penman-Monteith method is the most adequate to estimate the evapotranspiration in different climatic conditions. But its addoption requires additional studies about the canopy resistance determination, the parameter most difficult to measure.

The ratio between the resistance factors can be calculated by the use of the canopy temperature, determinated by infrared thermometry.

The objective of this study was to evaluate the use of the canopy temperature as a tool on the reference evapotranspiration estimative using the Penman-Monteith method, comparing its results with the estimative by the FAO/91 proposal, and with the evapotranspiration determinated by a weighing lysimeter.

The climatic factors and the canopy temperature were determined and analysed in $30 \mathrm{~min}, 24 \mathrm{~h}$, and day light periods of time. The data were collected by an automatic station installed over grass, and the evapotranspiration was measured by a weighing lysimeter in the same area.

The canopy resistance values calculated in different periods of time were analysed, and it was concluded that for the use of the canopy temperature on the ratio of the resistance factors, the value of the net radiation should be the
\end{abstract}


total of the day, while the air and canopy temperatures, relative humidity and wind speed should be instantaneous values, during the period of higher radiation. When were used the average of these factors at the same period of time, the canopy resistance resulted in negative values.

The canopy resistance calculated as residue, presented an average of $144 \mathrm{~s} \mathrm{~m}^{-1}$, higher than the FAO/91 proposal for a reference crop. Although, the estimative of evapotranspiration by that proposal presented a very good performance, as the evapotranspiration estimated by the use of rc calculated with measures at 12:00 $\mathrm{h}$, when compared with the evapotranspiration measured by the lysimeter. 


\section{INTRODUÇÃO}

O monitoramento do consumo de água pelo sistema solo-plantaatmosfera é uma das áreas que exige estudos cada vez mais detalhados, quando se busca o aumento da eficiência do uso da água para a irrigação.

A viabilidade e o uso correto das diversas técnicas existentes para quantificar o consumo de água dependem de seus custos, disponibilidade de dados, praticidade e facilidade de cálculos. Várias são as técnicas utilizadas para a obtenção de informações necessárias à estimativa da evapotranspiração, baseadas em dados de solo, clima ou planta. Determinações diretas de alguns parâmetros da planta, como temperatura radiante da cobertura vegetal, potencial de água na folha ou resistência estomática, apresentam-se como os métodos mais adequados à estimativa da necessidade de água, uma vez que a planta é o objetivo final dos estudos e ela responde tanto às condições atmosféricas quanto de solo.

A determinação da evapotranspiração pode ser feita diretamente, pelo uso de lisímetros. As medidas diretas são mais precisas, porém, devido ao maior custo e às complexas condições de manejo, são de uso restrito à pesquisa. Assim, o uso de modelos que possam estimar a evapotranspiração de uma cultura é mais adequado.

Atualmente existem inúmeros modelos para a estimativa da evapotranspiração. Os mais utilizados não são necessariamente os mais exatos, e calculam a evapotranspiração de referência para posteriormente, com o uso de coeficientes empíricos adequados, estimar a lâmina evapotranspirada pela cultura e que deve ser reposta pela irrigação. 
O método de Penman-Monteith é considerado como o mais preciso e exato na estimativa da evapotranspiração. Porém, para sua aplicação são necessárias pesquisas adicionais, visando testar sua validade para as diversas condições climáticas, e para a determinação de valores adequados de resistências aerodinâmica e da cobertura vegetal.

A relação entre esses fatores pode ser calculada pela utilização da temperatura radiante da cobertura vegetal, determinada com o auxílio da técnica da termometria ao infravermelho. Este procedimento pode facilitar a aplicação do método de Penman-Monteith na estimativa da evapotranspiração direta da cultura, sem necessidade da utilização de coeficientes de cultura.

Este trabalho objetivou avaliar o uso da temperatura da cobertura vegetal como auxiliar no cálculo da evapotranspiração de referência pelo modelo de Penman-Monteith, comparando os resultados com o cálculo pela mesma equação, mas utilizando a parametrização sugerida pela FAO/91, e com medidas diretas obtidas em lisímetro de pesagem. 


\section{REVISÃO DE LITERATURA}

\subsection{Evapotranspiração}

Há necessidade de se fazer a estimativa do consumo de água pelas culturas, ou seja, da evapotranspiração que ocorre no sistema solo-plantaatmosfera, visando estimar a quantidade de água que deve ser reposta por irrigação. Para tal estimativa, foram estudadas diversas formas de cálculo, utilizando diferentes informações, de solo, da planta ou meteorológicos, cada qual apresentando vantagens e desvantagens. A escolha de um ou outro método de estimativa da evapotranspiração da cultura está sempre relacionada com a disponibilidade de dados e com a precisão necessária na estimativa.

\subsubsection{Definições}

No estudo de evapotranspiração, ao longo dos anos foram relatadas diversas definições para este termo. Peres (1994) apresentou resumidamente a definição dos termos que podem ser utilizados.

Evapotranspiração potencial (ETp) é a quantidade máxima de água utilizada por uma extensa área vegetada, em crescimento ativo, sob condições ótimas de umidade do solo. Evapotranspiração real (ETa) ocorre quando as condições de contorno citadas anteriormente não forem verificadas, ou seja, independente da área e das condições de umidade do solo. Evapotranspiração da cultura (ETc) é a evapotranspiração de uma cultura agronômica, livre de doenças, desenvolvendo-se em uma área cultivada de um ou mais hectares, 
sob condições otimizadas de solo, incluindo água e fertilidade. Evapotranspiração de referência (ETo) é a evapotranspiração que ocorre em uma extensa superfície de grama, com porte de 8 a $15 \mathrm{~cm}$, em desenvolvimento ativo, cobrindo totalmente o solo e sem restrição de água; ou em alfafa (ETr), que é a evapotranspiração que se verifica em uma cultura de alfafa, com 30 a $50 \mathrm{~cm}$ de altura, e bordadura mínima de $100 \mathrm{~m}$, cultivada sem deficiência hídrica.

Buscando uma denominação geral, Smith (1991) relatou os resultados de uma discussão entre diversos pesquisadores, que então definiram evapotranspiração de referência. Basicamente foi a mesma definição apresentada anteriormente para ETo, porém considerando uma cultura hipotética, em extensa área, com 8 a $15 \mathrm{~cm}$ de altura, cobrindo totalmente o solo, em desenvolvimento ativo, sem restrição hídrica, com as seguintes características fixas: resistência da cobertura vegetal (rc) de $69 \mathrm{~s} \mathrm{~m}^{-1}$ e poder refletor (albedo) de $23 \%$.

\subsubsection{Métodos de estimativa da evapotranspiração}

Com o objetivo de sistematizar os procedimentos para estimativa da evapotranspiração de referência para grama (ETo), Doorenbos \& Pruitt (1975) estudaram os diferentes métodos de estimativa da evapotranspiração. Os autores selecionaram os modelos de Penman, de Blaney-Criddle, da radiação e do tanque Classe $A$, calibrando-os com os valores medidos da evapotranspiração de grama, coletados em lisímetros, nos mais diferentes climas e regiões. Segundo os autores, o método de Penman foi o que melhor estimou ETo, seguido do tanque Classe A.

No documento reportado por Smith (1991) foi feita uma reavaliação das recomendações feitas anteriormente, levando em consideração a eficiência dos métodos nas diversas condições climáticas e os problemas de disponibilidade de dados climáticos. Os métodos considerados adequados foram: método 
combinado (Penman-Monteith); método da radiação, com a aproximação sugerida por Priestley-Taylor; método da temperatura, indicando o uso da aproximação de Hargreaves; método do tanque de evaporação. Mais uma vez foram recomendadas pesquisas para que fosse possivel a comparação entre os diversos métodos.

Além disso, Smith (1991) apresentou uma nova proposta para o direcionamento dos estudos na área de evapotranspiração. Considerando que a equação combinada de Penman-Monteith é mais precisa e exata na estimativa da evapotranspiração, seria ideal que esta fosse utilizada diretamente para estimar a evapotranspiração das culturas. A maior dificuldade se encontra na definição de valores adequados das resistências da cobertura vegetal e aerodinâmica.

\subsubsection{Método combinado - modelo de Penman-Monteith}

O trabalho original de Penman (1948), propôs um método que permite uma estimativa da evapotranspiração de uma cultura de referência a partir de dados climáticos de temperatura, umidade relativa, radiação solar e vento. Este modelo apresenta problemas na estimativa da evapotranspiração nas diversas condições climáticas. Várias modificações foram propostas buscando superar a falta de universalidade do modelo original.

Doorenbos \& Pruitt (1975) propuseram o método de Penman Modificado, utilizado mundialmente. Porém há evidências que o método superestima a evapotranspiração em condições não advectivas. $O$ modelo então recomendado em Smith (1991) como a melhor equação combinada foi o modelo Penman-Monteith. A modificação proposta por Monteith (1965) apresentou uma equação geral, válida para qualquer tipo de vegetação, sob qualquer condição de estresse hídrico. $O$ autor generalizou o modelo de Penman através de uma analogia com a Lei de Ohm para os circuitos elétricos. Assim, introduziu no termo aerodinâmico da equação de Penman duas 
resistências à transferência do vapor d'água: a resistência da cobertura vegetal (rc) e a resistência aerodinâmica (ra). A primeira descreve as características fisiológicas da planta, e a segunda descreve o papel da turbulência atmosférica no processo de transporte do vapor d'água (Oke, 1992). A superioridade do modelo de Penman-Monteith em relação às demais formas derivadas da equação original de Penman está em que ele leva em conta, além da resistência aerodinâmica à difusão turbulenta do calor sensível e do vapor d'água, a resistência estomática ao transporte do vapor d'água (Allen et al, 1992).

Atualmente, faz-se o uso de duas etapas para o cálculo da evapotranspiração das culturas: estima-se a evapotranspiração de uma cultura de referência, e a seguir multiplica-se por um coeficiente de cultura empírico (Doorenbos \& Pruitt, 1975). De acordo com Smith (1991), uma forma mais vantajosa de cálculo seria conduzir 0 processo de estimativa da evapotranspiração real da cultura em uma só etapa, descartando-se a utilização dos coeficientes de cultura. Para tanto, seria necessário assumir um modelo de estimativa da evapotranspiração que fosse adequado a diferentes situações. O autor sugeriu então que o modelo de Penman-Monteith seja adotado como padrão, mediante utilização de valores adequados de resistência aerodinâmica e de resistência da cobertura vegetal, especificas para cada cultura.

Para que este objetivo seja alcançado, foi proposto o seguinte direcionamento à pesquisas em evapotranspiração: primeiramente, a estimativa do consumo de água por uma cultura seria feita estimando a evapotranspiração de referência pelo modelo combinado e aplicando os coeficientes de cultura. Uma segunda fase seria estimar diretamente a evapotranspiração da cultura pelo modelo de Penman-Monteith, através da aplicação de valores adequados de resistência aerodinâmica e resistência da cobertura vegetal. O problema é a determinação dos valores experimentais de resistência da cobertura vegetal 
confiáveis, nas diferentes fases de desenvolvimento das culturas e diferentes condições de clima e solo.

O modelo de Penman-Monteith, embora tenha uma formulação teórica rigorosamente física, é de fácil entendimento e demanda para a sua utilização informações climatológicas padronizadas, normalmente coletadas em estações meteorológicas padrões. Sua aplicação prática é limitada pelas dificuldades de se obter valores confiáveis e representativos para a resistência da cobertura vegetal, conforme relatado por Monteith (1985), Hatfield (1988), Luchiari Jr. \& Riha (1991) e Oke (1992). Autores como Ben-Asher et al (1989) afirmaram que o modelo de Penman-Monteith será de pouco valor prático, a não ser que a resistência da cobertura vegetal venha a ser parametrizada a partir de propriedades conhecidas e de fácil mensuração da planta, do solo e da atmosfera. Esta dificuldade operacional faz com que este modelo seja utilizado principalmente como uma ferramenta para estimativa da resistência da cobertura vegetal, quando a evapotranspiração é conhecida e não, como seria desejável, a situação inversa (Russel, 1980; Jackson et al, 1981; Monteith, 1985).

A estimativa da resistência da cobertura vegetal pode ser feita a partir de medidas diretas da resistência estomática média, pelo uso de porômetros de difusão, e do índice de área foliar da planta, estimado por amostragem. No entanto, esta é uma tarefa árdua e trabalhosa e, por esta razão, dentro dos limites dos erros experimentais, a resistência da cobertura vegetal pode ser determinada como residuo da aplicação do modelo de Penman-Monteith, desde que se conheça a evapotranspiração, obtida pelo uso de lisimetros, ou pela razão de Bowen, e as variáveis climáticas envolvidas no processo (Monteith, 1980; Sharma, 1983; Monteith, 1985; Luchiari Jr. \& Riha, 1991; Oke, 1992).

As pesquisas desenvolvidas com o objetivo de estudar a resistência da cobertura vegetal, apresentando sua relação com elementos de solo e do clima, relatam valores bastante variados. 
Hatfield (1988) evidenciou a necessidade de se pesquisar a variação da resistência da cobertura vegetal em função da disponibilidade de água no solo, dizendo que valores conhecidos de rc para as diferentes culturas estão ao redor de $20 \mathrm{~s} \mathrm{~m}^{-1}$ para solos próximos à capacidade de campo, aumentando à medida que a umidade do solo diminui.

Monteith (1985) sugeriu que se adote $r c=50 \mathrm{~s} \mathrm{~m}^{-1}$ para a determinação da evapotranspiração potencial das plantas cultivadas. Este valor coincide com o valor apresentado por Oke (1992) para culturas agrícolas.

Para a cultura do trigo irrigado na região de Planaltina - DF, Luchiari Jr. \& Riha (1991) encontraram valores de rc geralmente pequenos e pouco variáveis entre as 8 e 13:30 h. A resistência da cobertura vegetal variou de 50 a $100 \mathrm{~s} \mathrm{~m}^{-1}$ no dia imediatamente anterior à irrigação, enquanto a variação foi de 15 a $50 \mathrm{~s} \mathrm{~m}^{-1}$ um dia após. Em ambos os casos, rc cresceu rapidamente a partir do meio da tarde, chegando a valores superiores a $200 \mathrm{~s} \mathrm{~m}^{-1}$ após as 16 horas. Esse comportamento da rc foi atribuído à habilidade da planta em fornecer água à superfície evaporativa, em taxa suficiente à demanda. Os autores encontraram valores de evapotranspiração superestimados em $6 \%$ quando utilizaram o modelo combinado.

Russel (1980), trabalhando com cevada e pastagem durante 3 anos, no verão, encontrou que rc teve grande variação nesse periodo, oscilando de 15 a $200 \mathrm{~s} \mathrm{~m}^{-1}$, sendo maior nos anos mais secos e crescente à medida que as plantas amadureciam.

Também com cevada, Grant (1975) observou que no início da implantação da cultura, quando esta não cobria totalmente o solo, rc foi da ordem de $100 \mathrm{~s} \mathrm{~m}^{-1}$, valor este também verificado quando a cultura entrou em fase de amadurecimento. No intervalo destas condições, quando a cultura cobria totalmente o solo, determinou $\mathrm{rc}=35 \mathrm{~s} \mathrm{~m}^{-1}$.

Numa cultura de soja, Bailey \& Davies (1981) observaram que rc variou exponencialmente com a radiação solar global. Sob condições não restritivas de água no solo, eles encontraram valores de rc entre 25 e $50 \mathrm{~s} \mathrm{~m}^{-1}$, até 
quando a radiação solar global foi i gual ou superior a $200 \mathrm{~J} \mathrm{~m}^{-2} \mathrm{~s}^{-1}$ $\left(\sim 400 \mathrm{cal} \mathrm{cm}^{-2} \mathrm{dia}^{-1}\right)$. Abaixo deste valor, rc cresceu exponencialmente com a diminuição da disponibilidade de energia.

Analisando a variação da rc em relação à radiação solar, Hatfield (1985) observou que a resistência da cobertura vegetal para trigo respondeu rapidamente a variações na incidência de radiação solar, diminuindo exponencialmente com 0 aumento da radiação solar global incidente. Para valores de radiação global entre 250 e $300 \mathrm{~kJ} \mathrm{~m}^{-2} \mathrm{~h}^{-1}$, rc variou de 25 a $230 \mathrm{~s} \mathrm{~m}^{-1}$.

Uma vez estabelecido o valor da resistência da cobertura vegetal, o modelo de Penman-Monteith tem se mostrado superior aos demais métodos combinados na estimativa da evapotranspiração potencial, para uma ampla variedade de climas e localidades (Allen, 1986; Allen et al, 1989; Luchiari Jr. \& Riha, 1991). Allen et al (1989) apresentaram inclusive, equações para estimativa de rc, que foram utilizadas para comparar os resultados de diferentes localidades.

Uma função relacionando a resistência da cobertura vegetal ao índice de área foliar e ao déficit de umidade no solo foi derivada por Grant (1975). Utilizando-a no modelo de Penman-Monteith, o autor obteve boa concordância com os valores medidos diretamente em lisímetros de pesagem e pela razão de Bowen.

\subsection{Temperatura de folhas e da cobertura vegetal}

A utilização da temperatura da cobertura vegetal para detecção do estresse hídrico baseia-se no fato de que ao transpirar, a folha se resfria. $\grave{A}$ medida que 0 teor de água no solo diminui, a transpiração diminui e a temperatura da folha se eleva. Se pouca água é transpirada, as folhas ficarão mais quentes que o ar devido a absorção da radiação. 
Jackson (1982) fez uma revisão sobre a evolução do uso da técnica da temperatura de folhas e da cobertura vegetal como indicador do estresse hídrico. Citou que, na literatura, vários autores argumentaram que a temperatura das folhas é sempre maior que a temperatura do ar circundante. Outros argumentaram que as folhas podem tornar-se muito mais frias que 0 ar. O primeiro argumento prevaleceu por vários anos e numerosas citações deste ponto de vista foram apresentadas como evidência de que a temperatura das folhas não é um sensivel indicador de estresse hídrico. $O$ oposto também foi observado analisando a perspectiva histórica. $O$ avanço da tecnologia para a determinação da temperatura da cobertura vegetal possibilitou a comprovação de sua adequabilidade na detecção do estresse hídrico, e mesmo na estimativa da evapotranspiração, apesar de existirem ainda muitos pontos de discussão.

\subsubsection{Termometria ao infravermelho}

A temperatura de uma cobertura vegetal é o resultado da interação entre esta e a energia radiante que atinge o sistema. A radiação líquida de um sistema se divide em diversos processos: evaporativo (fluxo de calor latente); de aquecimento do ar e do solo (fluxos de calor sensivel); além de participar de outros processos, como a fotossíntese. Desta forma, uma cobertura vegetal tem sua temperatura determinada pelo balanço de energia entre sua superfície e a camada de ar logo acima.

Sendo uma resposta às trocas de energia, a temperatura da superficie da cobertura vegetal pode ser expressa em termos da radiação por ela emitida. Segundo a lei de Stefan-Boltzmann, a energia emitida por um corpo qualquer é proporcional à quarta potência da temperatura absoluta de sua superfície:

$$
\operatorname{Rad}=\varepsilon \sigma \mathrm{T}^{4}
$$


onde Rad é a radiação emitida por um corpo $\left(\mathrm{J} \mathrm{m}^{-2} \mathrm{~s}^{-1}\right) ; \varepsilon$ é a emissividade da superfície do corpo; $\sigma$ é a constante de Stefan-Boltzmann $\left(\mathrm{J} \mathrm{m}^{-2} \mathrm{~s}^{-1} \mathrm{~K}^{-4}\right)=$ $5,67410^{-8} \mathrm{~J} \mathrm{~m}^{-2} \mathrm{~s}^{-1} \mathrm{~K}^{-4} ; \mathrm{T}$ é a temperatura do corpo considerado (K). Assim, conhecendo-se o fluxo de radiação emitido pela superfície do corpo pode-se determinar sua temperatura.

Embora temperaturas de folhas tenham sido determinadas por mais de 100 anos, somente a partir dos anos 70 a determinação da temperatura da cobertura vegetal tornou-se uma técnica usual. Isto foi resultado do desenvolvimento de termômetros ao infravermelho portáteis, que determinam a radiação emitida de todas as partes da cobertura vegetal sob o campo visual do instrumento (Heermann et al, 1990). Nos anos 60 a tecnologia que utiliza termômetros ao infravermelho avançou rapidamente, e instrumentos que podem ser utilizados no campo tornaram-se disponíveis. Os instrumentos evoluíram desde os que exigiam energia externa fornecida por cabos até os portáteis com baterias. A termometria ao infravermelho é portanto um método remoto de estimativa da temperatura de um objeto, determinando a radiação emitida pelo mesmo.

\subsubsection{Fatores que influenciam na detecção da temperatura radiante da cobertura vegetal}

Vários são os fatores que têm influência sobre a detecção da temperatura radiante de uma superfície, e que devem ser observados quando em sua utilização em pesquisas ou mesmo em sua aplicação prática. A distância entre o sensor e a superfície em estudo, a emissividade da superfície, a posição do sensor em relação à posição do sol e a variabilidade da superfície são alguns deles, merecendo estudos específicos.

A emissão de energia radiante dos corpos ocorre dentro da faixa espectral de 8 a $14 \mu \mathrm{m}$. A absorção de radiação pelo vapor d'água do ar nestes comprimentos de onda é bastante alta, tornando-se uma preocupação na 
determinação da temperatura de uma superfície pela energia por ele irradiada. Porém Lorenz (1968) apresentou um estudo que conclui que se a distância entre o sensor e o alvo for inferior a $154 \mathrm{~m}$, essa influência do vapor d'água pode ser negligenciada.

Quanto à emissividade térmica ao infravermelho, Gates (1964) estabeleceu que todas as superfícies de plantas têm uma emissividade de 0,95 ou maior, com muitos valores ficando entre 0,97 e 0,98. A emissividade de uma cobertura vegetal deve ser maior que a de folhas individuais devido às cavidades formadas pela arquitetura foliar. A exposição de porções de solo pode influenciar na quantidade de energia que alcança o sensor devido à diferença de emissividade entre a cobertura vegetal e o solo (Heilman et al, 1981), podendo ser fonte de erro.

Fuchs \& Tanner (1966) mostraram que existe influência da radiação emitida pelo entorno da superfície em estudo e então refletida pela superfície para o sensor. Se a emissividade da superfície for menor que 1 e a radiação do entorno for desprezada, pode-se estar superestimando a temperatura da cobertura. Porém considerando que os sensores ao infravermelho utilizados na determinação da temperatura de superficies fazem leituras na faixa espectral de 8 a $14 \mu \mathrm{m}$, a temperatura calculada a partir da radiação é geralmente muito próxima da temperatura real da superfície.

Boissard et al (1990) apresentaram a influência da elevação do sol na temperatura da cobertura vegetal, provocando um aumento da energia que chega ao sistema, e alterando a situação de penetração e distribuição dos raios solares ao longo da cobertura vegetal.

A presença de nuvens provoca alterações da temperatura da superfície, alterando o equilíbrio do balanço de radiação, que leva algum tempo para ser restabelecido. Pennington \& Heatherly (1989) observaram que foram necessários cerca de $100 \mathrm{~s}$ para que a diferença entre a temperatura da cobertura vegetal e a temperatura do ar entrasse novamente em equilibrio após a radiação direta ser encoberta por nuvens. 
O ângulo zenital de visada é a inclinação do sensor em relação à perpendicular, e tem influência sobre a temperatura observada, pois a energia radiante de uma cobertura vegetal é função de sua geometria.

A variabilidade espacial que ocorre dentro de uma área vegetada leva à necessidade de um maior número de amostragens. Hatfield et al (1983) encontraram maior variabilidade no campo quando em solos nus e secos, em comparação com coberturas uniformes e completas.

As características arquitetônicas da cultura, sua forma de cultivo, a posição das linhas de cultivo também têm grande influência na temperatura da cobertura vegetal obtida por termometria ao infravermelho.

\subsection{Uso da temperatura da cobertura vegetal na detecção do estresse hídrico}

Utilizando termopares, Ehrler (1973) sugeriu que as diferenças entre as temperaturas da folha e do ar poderiam ser utilizadas no monitoramento da irrigação. Ele encontrou que as diferenças de temperatura variaram de -3 a $2^{\circ} \mathrm{C}$, com os menores valores ocorrendo a altas umidades do solo.

O uso de termopares tem como desvantagem a determinação da temperatura de folhas individualizadas, podendo estas não representar a situação da cultura como um todo. O uso da termometria ao infravermelho, que fornece a temperatura de uma área da superfície formada pelo dossel de plantas, torna-se mais adequado.

Buscando relacionar diretamente a temperatura da cobertura com seu estado de estresse hídrico, Sumayao et al (1980) observaram que folhas de milho e sorgo, quando irrigados apresentaram temperatura mais altas do que a temperatura do ar, quando esta era menor do que $33^{\circ} \mathrm{C}$ e mais baixas quando maiores. Estes resultados estão de acordo com Linacre $(1964,1967)$ que foi o primeiro a propor $33^{\circ} \mathrm{C}$ como a temperatura limite. Esta constante foi discutida por Blad \& Rosenberg (1976) que encontraram que a temperatura limite para a 
alfafa ocorria entre 23 e $30^{\circ} \mathrm{C}$. Idso et al (1981b) argumentaram que esta constante de temperatura não existe, mas ao contrário é um ponto dinâmico e depende do déficit de pressão de vapor.

A influência do clima e do solo na temperatura da cobertura vegetal direcionou o estudo da relação entre o estresse hídrico e a temperatura da cobertura vegetal e da determinação de índices que os relacionassem.

Segundo Hatfield (1983), três diferentes aproximações foram propostas para a avaliação do déficit hídrico pelo uso da temperatura da cobertura vegetal: alguns autores propuseram que o estresse hídrico pode ser avaliado pelo exame das diferenças da temperatura da cobertura vegetal entre o campo em questão e uma área bem molhada da mesma cultura; outros sugeriram que pode-se esperar que a variabilidade das determinações de temperatura da cobertura vegetal dentro de um campo tratado similarmente aumente com o aumento da necessidade de água; outra proposta que surgiu é que fossem utilizadas as diferenças de temperatura entre 0 ar e a cobertura vegetal.

Aston \& van Bavel (1972) propuseram um método que utiliza a variabilidade da temperatura da cobertura vegetal como um indicativo do início do estresse hídrico da planta. A partir dos dados de Clawson \& Blad (1982) determinou-se a variabilidade da temperatura da cobertura vegetal da cultura (CTV), definida como a diferença entre a máxima e a mínima de todas as temperaturas determinadas com termômetros ao infravermelho. Concluíram que as irrigações deveriam ser iniciadas quando CTV atingisse o valor de $0,8^{\circ} \mathrm{C}$. Afirmaram também que estes valores somente foram válidos quando a cobertura do solo pela cultura foi próxima da total. A partir dos mesmos dados, determinaram também a diferença de temperatura entre as parcelas irrigada e sob estresse; este índice foi chamado de temperatura de estresse diário (TSD).

Jackson (1982) explica que o uso de parcelas bem irrigadas como referência compensa efeitos do meio, tais como temperatura do ar e déficit de pressão de vapor. Observou que as irrigações ocorreram quando a 
temperatura da copa de parcelas sob estresse eram $1{ }^{\circ} \mathrm{C}$ superiores às irrigadas. Estes resultados mostraram que os dois índices, CTV e TSD poderiam ser utilizados como técnica de programação de irrigação.

Pazzetti et al (1993) utilizaram plantas de feijoeiro cultivadas em condições de campo, com o propósito de estabelecer uma relação entre as variações da temperatura da cobertura vegetal determinada com termômetro ao infravermelho e a produtividade da cultura. Concluíram que a evolução da temperatura de copa e os diferenciais de temperatura da copa entre as parcelas sob diferentes estados de estresse mostraram-se estritamente relacionados. Além disso, os resultados permitiram indicar que a temperatura da copa e os diferenciais de temperatura da copa podem ser empregados no monitoramento da irrigação.

Também trabalhando com a cultura do feijoeiro, foram avaliados os desempenhos de dois índices: o primeiro baseado na diferença das temperaturas das superfícies entre uma parcela de referência e a área que se pretende irrigar, e o segundo baseado no desvio padrão da diferença das temperaturas. Ambos os índices se mostraram adequados para indicar 0 momento de iniciar a irrigação (Costa \& Steinmetz, 1995; Steinmetz \& Costa, 1995).

Idso et al (1977) determinaram a temperatura da copa da cultura do trigo todos os dias durante o ciclo vegetativo. O objetivo foi desenvolver uma técnica para avaliar o déficit hídrico com um número mínimo de medidas, e assumiram que os fatores ambientais pressão de vapor do ar, radiação líquida e vento poderiam ser expressos na temperatura da copa. Estes autores definiram graus dias de estresse (SDD) como a diferença de temperatura da cobertura vegetal (Tc) e a temperatura do ambiente (Ta). Argumentaram ainda que o SDD aumenta com o aumento do déficit hídrico, ou seja, para uma menor disponibilidade de água para a transpiração corresponde o maior valor de SDD. 
O somatório dos valores de SDD, segundo Jackson et al (1977) pode ser utilizado como indicador do momento de irrigação. Para tal somatório, os autores sugeriram que quando o valor de (Tc-Ta) fosse negativo, dever-se-ia considerar o valor 0 , acumulando apenas os valores positivos. Desta forma, pelos resultados por eles obtidos, quando o somatório de SDD atingisse o valor 10 , deveria ser iniciada a irrigação para a cultura do trigo.

Os diversos índices propostos baseados nas relações entre a temperatura da cobertura vegetal e do ar apresentam limitações por não levarem em conta outros elementos climáticos na ocorrência do processo transpiratório, como a radiação solar e a umidade relativa do ar.

Wiegand \& Nanken (1966) propuseram que a diferença entre a temperatura da cobertura vegetal e a temperatura do ar está relacionada com o estado de água da cultura. Mostraram que a temperatura da folha aumentou linearmente com o aumento da insolação e decresceu linearmente com o aumento da turgidez relativa das folhas. Concluiram que a determinação da temperatura da folha requer determinações simultâneas da radiação solar.

A diferença entre a temperatura do ar e da cobertura vegetal foi combinada com dados de radiação líquida e de pressão de vapor, e utilizada por Geiser et al (1982) como uma forma de determinar o momento de irrigação. Os autores compararam este método com o balanço hídrico e concluíram que o uso de água para irrigação foi menor quando a diferença de temperatura foi utilizada como critério, não ocorrendo diferença significativa na produção.

Idso et al (1981c) demonstraram que o índice de estresse hídrico determinado pela temperatura da cobertura e do ar, e umidade relativa do ar é função única do déficit de potencial da água na folha de alfafa, induzido pelo potencial da água no solo. Entretanto, para a comparação entre os dados obtidos em dois locais, o potencial de água na folha teve que ser corrigido em função do déficit de pressão de vapor. Tal correção permitiu uma discriminação precisa entre os tratamentos, utilizando somente determinações de ( $\mathrm{TC}-\mathrm{Ta}$ ). 
A combinação do balanço de energia e a fórmula aerodinâmica usados para estimar a evaporação de superfícies naturais (Penman, 1948) pode descrever a temperatura da superfície em função da radiação líquida e do déficit de pressão de vapor (DPV) (Monteith \& Szeicz, 1962). Jackson et al (1981) desenvolveram de forma teórica os limites para a relação entre (Tc-Ta) "versus" DPV, definindo um índice de estresse hídrico, denominado CWSI.

Vários experimentos envolvendo determinações de (Tc-Ta) e DPV foram conduzidos para diferentes culturas (Idso et al, 1981a). Eles mostraram que para grande parte do período do dia, a relação (Tc-Ta) "versus" DPV apresenta relações lineares para plantas transpirando à taxa potencial, a despeito de outros elementos climáticos, exceto quando sob presença de nuvens. Os dados foram utilizados para determinar o que os autores denominaram como "linhas básicas" de estresse e de não estresse hídrico. Este fato foi utilizado para desenvolver, agora empiricamente, o CWSI.

Em trabalho posterior, Idso et al (1990) conduziram experimentos para determinar os efeitos de diferentes locais de determinação da temperatura do ar e do DPV na avaliação das "linhas básicas" do CWSI empírico. Foi verificado que os diferentes locais dé determinação (dentro do dossel vegetativo, logo acima da cobertura vegetal, e $10 \mathrm{~m}$ distante da área cultivada, a 1,6 m de altura) tiveram pouco efeito na determinação da linha.

Clawson et al (1989) fizeram um estudo que se propôs a demonstrar a dependência do TSD (índice baseado nas diferenças de temperatura entre duas áreas, sendo uma delas bem irrigada) da radiação líquida, temperatura do ar e do déficit de pressão de vapor, e avaliaram a substituição do índice pelo CWSI. Os autores comprovaram a dependência do TSD desses elementos, e sugeriram que seja feito o uso da temperatura da cobertura vegetal de uma área bem molhada como referência no CWSI empírico ou teórico, diminuindo as dificuldades para seu cálculo.

A partir de dados de campo e simulados, Stockle \& Dugas (1992) fizeram uma análise da adequabilidade dos índices CWSI teórico e empírico 
para diferentes condições ambientais. Os resultados indicaram restrições do uso do índice para monitoramento da irrigação sob variações de clima, particularmente sob condições de baixo déficit de pressão de vapor, pois o indice apresentou grande variabilidade.

Hatfield et al (1985) utilizaram a aproximação empirica do CWSI e observaram que a chamada "linha básica de não estresse" obtida foi muito diferente quando em situação de cobertura parcial do solo, provocando erros substanciais no cálculo do índice, superestimando o estado de estresse. Consideraram que em cobertura parcial, ocorreram mudanças nos parâmetros que são utilizados para cálculo da resistência aerodinâmica (deslocamento do plano zero e comprimento de rugosidade da superfície).

Avaliando duas formas de interpretar a diferença entre a temperatura da cobertura vegetal e a temperatura do ar, O'Toole \& Real (1986) entenderam que seria possivel o uso da relação linear entre (Tc-Ta) e o DPV, e da equação do balanço de energia, para calcular a resistência da cobertura vegetal e a resistência aerodinâmica. Os autores puderam calcular valores da resistência da cobertura vegetal e da resistência aerodinâmica de diversas culturas, em situação potencial.

Uma das primeiras pesquisas desenvolvidas no Brasil com o uso da termometria ao infravermelho para a detecção de estresse hídrico foi desenvolvida por Folegatti $(1988,1995)$. O autor conduziu um trabalho com o objetivo de determinar os diferentes índices de estresse hídrico (SDD, TSD, CWSI teórico e empírico) para a cultura do feijoeiro sob diferentes lâminas de irrigação. Concluiu, entre outras coisas, que as condições climáticas variáveis dificultam o cálculo do CWSI, ocorrendo influência de outros elementos climáticos, além do DPV, nos valores de (Tc-Ta). Concluiu também que a utilização de parcelas bem irrigadas como referência compensam efeitos de temperatura e DPV, desde que a radiação líquida e a velocidade do vento não variem durante as leituras. 
Amorim Neto et al (1995a e 1995b) submeteram a cultura do feijoeiro a diferentes tensões de água no solo, e observaram que a diferença entre a temperatura da cobertura vegetal e do ar poderia ser útil para a avaliação do estado hídrico da cultura. E a determinação do CWSI indicou ser este um índice adequado para programar a irrigação da cultura.

Ferreira et al (1995) utilizaram a metodologia sugerida por O'Toole \& Real (1986) para a determinação da resistência da cobertura vegetal e da resistência aerodinâmica, e encontraram valores de rc coerentes com os medidos com porômetros.

\subsection{Uso da temperatura da cobertura vegetal na estimativa da evapotranspiração}

Monteith \& Szeicz (1962), a partir de considerações sobre o balanço de energia, chegaram a uma expressão que relaciona a diferença entre a temperatura da cobertura vegetal e a temperatura do $a r$, com a radiação líquida, a velocidade do vento, o déficit de pressão de vapor $e$ as resistências aerodinâmica e da cultura.

O balanço de energia para uma cobertura vegetal pode ser escrito como:

$$
\mathrm{Rn}-\mathrm{G}-\mathrm{H}-\lambda \mathrm{E}=0
$$

onde $\mathrm{Rn}$ é a radiação líquida $\left(\mathrm{J} \mathrm{m}^{-2} \mathrm{~s}^{-1}\right) ; \mathrm{G}$ é a densidade de fluxo de calor no solo $\left(\mathrm{J} \mathrm{m}^{-2} \mathrm{~s}^{-1}\right) ; \mathrm{H}$ é a densidade de fluxo de calor sensível $\left(\mathrm{J} \mathrm{m}^{-2} \mathrm{~s}^{-1}\right)$; e $\lambda E$ é a densidade de fluxo de calor latente $\left(\mathrm{J} \mathrm{m}^{-2} \cdot \mathrm{s}^{-1}\right)$. Convencionando-se que a energia que chega ao nivel do solo é uma entrada de energia no sistema, e portanto positivo, e o que a energia que sai da superfície do solo é uma saída de energia do sistema, e portanto negativo, de uma forma simplificada, $\mathrm{H}$ e $\lambda \mathrm{E}$ podem ser expressos como (os sinais das variáveis determinarão se está ocorrendo entrada ou saída de energia do sistema): 


$$
\begin{gathered}
H=\frac{\rho c p(T c-T a)}{r a_{h}} \\
\lambda E=\frac{\rho c p\left(e^{*} c-e a\right)}{\gamma\left(r a_{v}+r c\right)}
\end{gathered}
$$

onde $\rho$ é a massa específica do ar atmosférido $\left(\mathrm{kg} \mathrm{m}^{-3}\right)$; $\mathrm{cp}$ é a calor específico do ar a pressão constante $\left(\mathrm{J} \mathrm{kg}^{-1}{ }^{\circ} \mathrm{C}^{-1}\right)$; Tc é a temperatura da cobertura vegetal $\left({ }^{\circ} \mathrm{C}\right)$; Ta é a temperatura do $\operatorname{ar}\left({ }^{\circ} \mathrm{C}\right)$; $e^{*} \mathrm{C}$ é a pressão de saturação de vapor à temperatura da cobertura vegetal ( $\mathrm{kPa})$; ea é a pressão atual de vapor $(\mathrm{kPa}) ; \gamma$ é a constante psicrométrica $\left(\mathrm{kPa}{ }^{\circ} \mathrm{C}^{-1}\right) ; \mathrm{ra}_{\mathrm{h}}$ é a resistência aerodinâmica à difusão de calor sensível $\left(\mathrm{s} \mathrm{m}^{-1}\right)$, ra $\mathrm{r}_{\mathrm{v}}$ é a resistência aerodinâmica à difusão de vapor d'água $\left(\mathrm{s} \mathrm{m}^{-1}\right)$; e rc é a resistência da cultura à difusão de vapor d'água (s $\mathrm{m}^{-1}$ ). Considera-se que $r \mathrm{a}_{\mathrm{h}} \approx r \mathrm{ra}_{\mathrm{v}}=\mathrm{ra}$, sendo portanto, ra, a resistência aerodinâmica à difusão de calor sensivel e de vapor d'água $\left(\mathrm{s}^{-1}\right)$. Uma discussão mais detalhada das hipóteses feitas é apresentada por Monteith (1973).

Uma forma de utilizar a temperatura da cobertura vegetal na estimativa da evapotranspiração é a substituição da equação (3) na equação (2), ou seja, estimar a densidade de fluxo de calor sensivel pelo uso da temperatura da cobertura vegetal, e calcular a evapotranspiração como resíduo da equação (2):

$$
\lambda E=R n-G-\frac{\rho c p(T c-T a)}{r a}
$$


Pelo uso desta equação, Choudhury et al (1986) e Ben-Asher et al (1992) encontraram boa relação entre os valores de evapotranspiração estimados e valores medidos, porém o uso da termometria ao infravermelho subestimou os valores medidos por Ben-Asher et al (1992) em 12\%.

Utilizando a temperatura da cobertura vegetal para estimar a densidade de fluxo de calor sensivel e a pressão de vapor para estimar a densidade de fluxo de calor latente (eq. (3) e (4) ), pode-se encontrar uma equação que descreva a diferença entre a temperatura da cobertura vegetal e a temperatura do ar em função da radiação líquida, da velocidade do vento, do déficit de pressão de vapor e das resistências aerodinâmica e da cultura. Combinando as equações anteriores (2), (3) e (1), e rearranjando, pode-se obter uma equação que calcula o valor da relação entre rc e ra:

$$
\frac{r c}{r a}=\frac{\rho c p\left(e^{*} c-e a\right)}{\gamma r a\left[(R n-G)-\frac{\rho c p(T c-T a)}{r a}\right]}-1
$$

O resultado desta equação pode ser utilizado como entrada na equação de Penman-Monteith, substituindo as diversas formas de estimativa da resistência da cobertura vegetal, maior problema encontrado na utilização do modelo. 


\section{MATERIAL E MÉTODOS}

\subsection{Material}

\subsubsection{Local}

A área em estudo estava localizada no posto agrometeorológico da área experimental de irrigação do Departamento de Engenharia Rural ESALQ/USP, na Fazenda Areão, em Piracicaba - SP (Lat. 2242' S; Long. $47^{\circ} 39^{\prime} \mathrm{W}$; altitude: $520 \mathrm{~m}$ ). Nesta área encontravam-se instalados: uma estação meteorológica automática, com sensores de temperatura e umidade relativa do ar, radiação solar global e radiação líquida, chuva, densidade de fluxo de calor no solo e temperatura da cobertura vegetal; uma bateria de 5 lisímetros, sendo um de pesagem, dois de drenagem e dois de nível de lençol freático constante; e um tanque Classe $\mathrm{A}$ de nivel constante (Figura 1).

O solo da área do posto agrometeorológico foi classificado como Terra Roxa Estruturada (Alfisol), série Luiz de Queiroz, e tem declividade média de 2,3\%. A área possuia $3.150 \mathrm{~m}^{2}$ vegetados com grama batatais (Paspalum notatum), mantida a uma altura de 8 a $12 \mathrm{~cm}$, através de cortes periódicos, e irrigada por um sistema de gotejamento enterrado.

O clima de Piracicaba é classificado como Cwa, pela classificação de Köppen, especificado como subtropical com chuvas no verão e inverno seco. A temperatura média anual é de $21,1^{\circ} \mathrm{C}$, e a chuva total anual é, em média, de $1.247 \mathrm{~mm}$ (Ometto, 1989). 
Os dados de peso do lisímetro e dos dados climáticos utilizados neste trabalho foram coletados no periodo de 15/12/95 a 25/05/96.

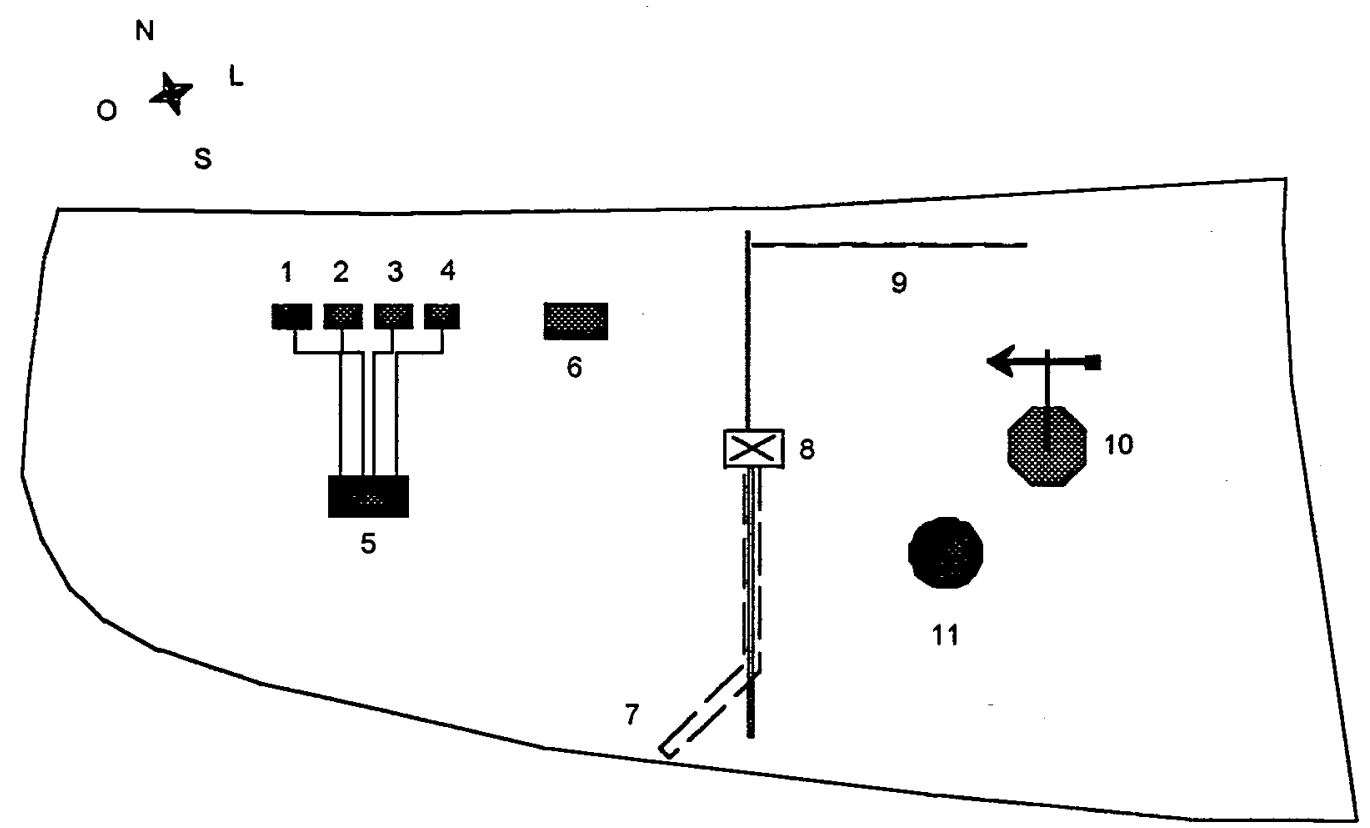

1) Lisimetro de drenagem

2) Lisimetro de drenagem

3) Lisímetro de lencol freático constante

4) Lisímetro de lençol freático constante

5) Caixa de observaçăo

6) Lisimetro de pesagem

7) Adutora

8) Cabeçal de controle

9) Linha secundária de gotejadores

10)Estaçáo agrometeorológica automatizada

11)Tanque Classe $A$

Figura 1. Croqui da área em estudo.

\subsubsection{Lisímetro de pesagem}

A evapotranspiração de referência foi determinada diretamente pelo uso de um lisimetro de pesagem. O lisimetro foi construído com uma caixa de cimento amianto, com profundidade de $0,65 \mathrm{~m}$ e 0,92 $\mathrm{m}^{2}$ de área da superfície 
evaporante, apoiado sobre uma armação de madeira com três células de carga (modelo: LCCA-2K - Omega Engineering, Inc.), com capacidade total de $1.830 \mathrm{~kg}$ e exatidão de $0,037 \%$ de sua capacidade total. A caixa foi enterrada de forma a manter uma borda para evitar escorrimento de água para dentro da caixa. O enchimento foi feito com o solo retirado do local, mantendo-se a seqüência e a profundidade dos diferentes horizontes originais. O processo de drenagem era permitido pela existência de uma camada de pedra britada no fundo, sendo a água de drenagem retirada da caixa por uma tubulação de $0,05 \mathrm{~m}$ de diâmetro disposta verticalmente.

A vegetação do lisímetro era de grama batatais (Paspalum notatum), como a área em torno, e a mesma foi mantida à altura adequada (8 a $12 \mathrm{~cm}$ ). Existia uma bordadura de cerca de $10 \mathrm{~m}$ em torno do lisímetro, e a irrigação foi feita de modo a propiciar condições de evapotranspiração potencial. Foi feito o monitoramento da tensão da água no solo para que esta situação fosse mantida.

O monitoramento da tensão da água no solo foi feito através de leituras diárias de 4 tensiômetros instalados no lisímetro, nas profundidades de $15 \mathrm{e}$ $30 \mathrm{~cm}$. A leituras foram feitas com o uso de um tensímetro digital, que apresentava diretamente o valor da tensão da água no solo em mbar.

A tensão correspondente ao ponto de capacidade de campo foi determinada diretamente no campo, nos lisímetros de drenagem instalados ao lado do lisímetro de pesagem, da seguinte forma: com os drenos abertos, foi feita uma irrigação que saturou o solo e provocou drenagem. A tensão da água no solo foi acompanhada pela leitura de tensiômetros até que o processo de drenagem cessasse, e este valor de tensão foi tomado como a tensão na capacidade de campo. Os valores de tensão ficaram entre -60 e -70 mbar.

Durante o período de coleta de dados foi feita uma calibração em campo do sistema, que indicou que este funciona adequadamente, tanto para acréscimo quanto para decréscimo de peso. O procedimento e os resultados da calibração são apresentados no Apêndice I. 
A evapotranspiração ocorrida foi calculada através das informações de peso obtidas pelas três células de carga, valores que foram coletados por um "datalogger" (modelo: CR10, Campbell Scientific, Inc.). Foram armazenados valores de média do somatório do peso das três células de carga, calculados cada $30 \mathrm{~min}$, a partir de dados medidos a cada segundo.

\subsubsection{Informações climáticas}

As informações climáticas foram obtidas na estação meteorológica automática instalada na área, que possui sensores de:

- temperatura do ar e umidade relativa do ar a $2 \mathrm{~m}$ de altura (modelo: HMP35C Temperature/RH Probe - Campbell Scientific, Inc.; exatidão: temperatura $= \pm 0,1^{\circ} \mathrm{C}$; umidade relativa $= \pm 3 \%$ ).

- radiação global a $3 \mathrm{~m}$ de altura (modelo: LI200X Pyranometer - Li-cor Inc.).

- velocidade do vento a $2 \mathrm{~m}$ de altura (modelo: 014A Wind Speed Sensor - Met One Instruments; limiar de medida $\left.=0,45 \mathrm{~m} \mathrm{~s}^{-1}\right)$.

- direção do vento a $2 \mathrm{~m}$ de altura (modelo: 024A Wind Direction Sensor - Met One Instruments; limiar de medida $=0,45 \mathrm{~m} \mathrm{~s}^{-1}$; exatidão $= \pm 5^{\circ}$ ).

- precipitação a 1,5 m de altura (modelo: TE525 Tipping Bucket Rain Gauge - Weather Bureau; precisão $=0,1 \mathrm{~mm}$ ).

- radiação líquida a $1 \mathrm{~m}$ da cobertura vegetal (modelo: Q7.1 Net Radiometer - REBS; espectro: 0,25 a $60 \mu \mathrm{m}$ ).

Sobre superfície evaporante do lisímetro, foram coletadas informações de temperatura da cobertura vegetal pelo uso de um termômetro ao infravermelho (modelo: 4000-4GL Infrared Temperature Transducer - Everest Interscience Inc; resolução $=0,1^{\circ} \mathrm{C}$; exatidão $= \pm 0,5^{\circ} \mathrm{C}$ ), a $25 \mathrm{~cm}$ de altura, visando a cobertura vegetal num ângulo de $40^{\circ} \mathrm{com}$ a horizontal, no sentido Sul. O termômetro ao infravermelho possuia um ângulo de visada de $15^{\circ}$, uma 
banda de leitura de 8 a $14 \mu \mathrm{m}$, e a emissividade estimada para determinação da temperatura foi de 0,975 , valor fixo regulado no termômetro. O termômetro foi calibrado em laboratório, conforme procedimento descrito no Apêndice II, e a correção dos dados coletados foi feita pela subtração de 1,6 nos valores determinados, conforme indicado pelo resultado da calibração.

Além disso, foi instalado na área do lisímetro, um sensor de densidade de fluxo de calor no solo (modelo: HFT-3 Soil Heat Flux Plate - REBS), a $2 \mathrm{~cm}$ de profundidade. Como este sensor foi instalado posteriormente ao início da coleta de dados, foi calculada uma relação entre a densidade de fluxo de calor no solo e a radiação líquida ( $G / R n)$, a fim de estimar o valor de $G$ nos dias anteriores. Os valores encontrados para a relação $G / R n$ e utilizados na estimativa de $\mathrm{G}$ foram:

- $G / R n=0,05$ para períodos de radiação global diferente de 0

- $\mathrm{G} / \mathrm{Rn}=0,30$ para períodos de radiação global igual a 0

Todos os sensores foram conectados a um "datalogger" (modelo: CR10 Campbell Scientific, Inc.), que armazenou dados de média a cada $30 \mathrm{~min}$, das leituras feitas a cada segundo. Foram armazenados também dados de médias de temperatura do ar, umidade relativa do ar, total de chuva e radiação em períodos de $24 \mathrm{~h}$.

\subsection{Métodos}

\subsubsection{Determinação direta da evapotranspiração}

Para o cálculo da evapotranspiração obtida diretamente pelo lisímetro de pesagem, foi utilizado um fator de correção que relaciona a variação do peso com a lâmina evapotranspirada. Sendo a área da superfície evaporante do lisímetro igual a $0,92 \mathrm{~m}^{2}$, uma variação negativa do peso de $0,92 \mathrm{~kg}$ corresponde à evapotranspiração de uma lâmina de $1 \mathrm{~mm}$. Desta forma, o fator 
de correção aplicado foi de $-0,92$ (considerou-se a massa específica da água um valor constante com a variação da temperatura, e igual a $1,0 \mathrm{~g} \mathrm{~cm}^{-3}$ ).

Para a determinação da lâmina total evapotranspirada durante um período qualquer, foi feito o cálculo da diferença entre o peso no início e no final do período, e aplicado o fator de correção.

3.2.2. Estimativa da evapotranspiração de referência pelo modelo Penman-Monteith com o uso da termometria ao infravermelho

A equação original de Penman-Monteith pode ser escrita como:

$$
\lambda E=\frac{s(R n-G)+\frac{\rho c p\left(e^{*} a-e a\right)}{r a}}{s+\gamma\left(1+\frac{r c}{r a}\right)}
$$

onde $\lambda E$ é a densidade fluxo de calor latente $\left(\mathrm{kJ} \mathrm{m}^{-2} \mathrm{~s}^{-1}\right)$; Rn é a radiação líquida $\left(\mathrm{kJ} \mathrm{m}^{-2} \mathrm{~s}^{-1}\right) ; \mathrm{G}$ é a densidade de fluxo de calor no solo $\left(\mathrm{kJ} \mathrm{m}^{-2} \mathrm{~s}^{-1}\right)$; $\rho$ é a massa específica do ar atmosfériço $\left(\mathrm{kg} \mathrm{m}^{-3}\right)$; $\mathrm{cp}$ é o calor específico do ar a pressão constante $\left(\mathrm{kJ} \mathrm{kg}^{-1}{ }^{\circ} \mathrm{C}^{-1}\right)=1,013 \mathrm{~kJ} \mathrm{~kg}^{-1}{ }^{\circ} \mathrm{C}^{-1}$; $e^{*}$ a é a pressão de saturação de vapor à temperatura do ar $(\mathrm{kPa})$; ea é a pressão atual de vapor $(\mathrm{kPa})$; rc é a resistência da cobertura vegetal à difusão de vapor d'água $\left(\mathrm{s} \mathrm{m}^{-1}\right)$; ra é a resistência aerodinâmica à difusão de vapor d'água $\left(\mathrm{s} \mathrm{m}^{-1}\right) ; \gamma$ é a constante psicrométrica $\left(\mathrm{kPa}{ }^{\circ} \mathrm{C}^{-1}\right)=0,0631 \mathrm{kPa}{ }^{\circ} \mathrm{C}^{-1} ; \mathrm{s}$ é a inclinação da tangente à curva de pressão de saturação de vapor no ponto da temperatura do $\operatorname{ar}\left(\mathrm{kPa}^{\circ} \mathrm{C}^{-1}\right)$.

O valor da massa específica do ar $(\rho)$ foi calculado da seguinte forma: 


$$
\rho=\frac{P}{\operatorname{TvR}}
$$

onde $\mathrm{P}$ é a pressão atmosférica local $(\mathrm{kPa})=95,310 \mathrm{kPa}$; $\mathrm{R}$ é a constante universal dos gases para o ar úmido $\left(\mathrm{kJ} \mathrm{kg}^{-1} \mathrm{~K}^{-1}\right)=0,287 \mathrm{~kJ} \mathrm{~kg}^{-1} \mathrm{~K}^{-1}$; Tv é a temperatura virtual do ar (K). Segundo Smith (1991), Tv pode ser estimada por $\mathrm{Tv}=\mathrm{Ta}+275$, onde Ta é a temperatura do ar $\left({ }^{\circ} \mathrm{C}\right)$. A equação utilizada, portanto, fica:

$$
\rho=\frac{332,091}{T a+275}
$$

A pressão de saturação de vapor à temperatura do ar ( $\left.e^{*} a\right)$ foi calculada por:

$$
e^{*} a=0,6108 \exp \left(\frac{17,27 \mathrm{Ta}}{\mathrm{Ta}+237,3}\right)
$$

A pressão atual de vapor d'água (ea) foi calculada por:

$$
e a * a \frac{U R}{100}
$$

onde UR = umidade relativa média do ar (\%).

Para o cálculo da resistência aerodinâmica, Allen et al (1989) apresentaram as seguintes equações, salientando que o período considerado deve ser de um dia, ou maior: 


$$
r a=\frac{\ln \left(\frac{z m-d}{z o m}\right) \ln \left(\frac{z h-d}{z o h}\right)}{k^{2} U z}
$$

onde $\mathrm{zm}$ é a altura de medida da velocidade do vento $(\mathrm{m})$; zh é a altura de determinação da temperatura e da umidade relativa $(m)$; d é o deslocamento do plano zero do perfil de velocidade do vento $(\mathrm{m})$; zom é o comprimento de rugosidade equivalente para transferência de momento $(\mathrm{m})$; zoh é o comprimento de rugosidade equivalente para transferência de calor sensível e calor latente $(\mathrm{m}) ; \mathrm{k}$ é a constante de von Karman $(k=0,41)$; $U z$ é a velocidade do vento medida à altura $z\left(\mathrm{~m} \mathrm{~s}^{-1}\right)$.

$$
d=\frac{2}{3} h c
$$

onde hc é a altura média da vegetação $(\mathrm{m})$.

$$
\begin{aligned}
& \text { zom }=0,123 \mathrm{hc} \\
& \text { zoh }=0,1 \mathrm{zom} \text { ou } z o h=0,0123 \mathrm{hc}
\end{aligned}
$$

O valor da inclinação da tangente à curva de pressão de saturação de vapor no ponto da temperatura do ar (s), foi calculado pela equação:

$$
s=\frac{4098 e^{*} a}{(T a+237,3)^{2}}
$$

Com os dados coletados, foi feito o cálculo da evapotranspiração da grama utilizando o modelo de Penman-Monteith, utilizando a relação entre a 
resistência aerodinâmica e da cobertura vegetal calculada através da temperatura da cobertura vegetal, como apresentado na equação (6), na pag. 21.

3.2.3. Estimativa da evapotranspiração de referência pelo modelo Penman-Monteith Padronizado pela FAO/91

Para o uso do modelo de Penman-Monteith, Smith (1991) padronizou alguns parâmetros para períodos de um dia, com base em sua validade global. As equações das diversas variáveis da equação de Penman-Monteith são as mesmas citadas anteriormente (eq. 8 a 16). Para o cálculo da resistência da cobertura vegetal, Allen et al (1989) apresentaram as equações a seguir:

$$
\begin{aligned}
& r c=\frac{R I}{0.5 \mathrm{IAF}} \\
& \mathrm{IAF}=24 \mathrm{hc}
\end{aligned}
$$

onde RI é a média diária da resistência estomática de uma folha $\left(\mathrm{s} \mathrm{m}^{-1}\right)=$ $100 \mathrm{~s} \mathrm{~m}^{-1}$; IAF é o índice de área foliar $\left(\mathrm{m}_{\text {folha }}^{2} / \mathrm{m}^{2}\right.$ terreno $)$, e hc é a altura da cultura. Obtém-se desta forma, para a cultura de referência, o valor sugerido em Smith (1991) fixado em:

$$
\mathrm{rc}=69 \mathrm{~s} \mathrm{~m}^{-1}
$$

\subsubsection{Comparação entre os métodos}

Foram feitos estudos comparativos dos diferentes métodos de estimativa da evapotranspiração. Foram feitas regressões lineares entre os valores 
obtidos por cada método descrito acima, utilizando valores médios e totais diários, tomando as leituras diretas obtidas no lisímetro como padrão.

Como o valor do coeficiente de correlação da equação de regressão $\left(r^{2}\right)$ analisado isoladamente pode levar a interpretações inadequadas da performance do modelo estudado, utilizou-se também o índice $d$ (Id) de concordância (Willmott, 1981), descrito como:

$$
\mathrm{Id}=1-\frac{\Sigma(\mathrm{Pi}-\mathrm{Oi})^{2}}{\Sigma(|\mathrm{Pi}-\mathrm{O}|+|\mathrm{Oi}-\mathrm{O}|)^{2}}
$$

onde $\mathrm{Pi}$ são os valores previstos de evapotranspiração (evapotranspiração estimada pelos modelos em estudo - $\mathrm{mm}$ ); Oi são os valores observados de evapotranspiração (evapotranspiração medida pelo lisímetro - $\mathrm{mm}$ ); $\mathrm{O}$ é a média dos valores de evapotranspiração observados $(\mathrm{mm})$.

O valor do índice d é mais sensível a erros sistemáticos e não sistemáticos dos modelos, e reflete uma tendência quando combinado com a análise de $r^{2}$. Seu valor pode variar de 0 , para total discordância entre o modelo e a realidade, e 1, para total concordância.

Outras medidas feitas para a comparação entre os métodos estudados neste trabalho foram:

$$
\begin{array}{ll}
\text { erro sistemático: } & E s=\left(\frac{\sum(\mathrm{Pri}-\mathrm{Oi})^{2}}{\mathrm{~N}}\right)^{2} \\
\text { erro não sistemático: } & \mathrm{Eu}=\left(\frac{\sum(\mathrm{Pi}-\mathrm{Pri})^{2}}{\mathrm{~N}}\right)^{2} \\
\text { média do erro absoluto: } & \mathrm{MAE}=\frac{\sum|\mathrm{Pi}-\mathrm{O}|}{\mathrm{N}}
\end{array}
$$


onde Pri é calculado a partir dos coeficientes da equação de regressão entre os valores previstos e observados (Pri=a+b Oi). 


\section{RESULTADOS E DISCUSSÃO}

\subsection{Dados coletados}

O período de coleta de dados foi de 15/12/95 até 25/05/96, e os dados a cada $30 \mathrm{~min}$ foram analisados dia a dia. Observou-se que existem vários fatores que provocam alterações nas medidas durante períodos do dia. Esses fatores estão relacionados à sensibilidade dos equipamentos, às atividades de manutenção da área, à ocorrênica de chuva e mesmo à presença de pessoas na área. Foi possivel detectar as interferências nos dados, porém seu dimensionamento e correção são limitados, devido à sensibilidade e precisão dos equipamentos.

Outra perturbação que ocorre no sistema e que não pôde ser eliminada, foi a ocorrência de advecção. As variações de radiação solar e velocidade e direção do vento fizeram com que em alguns dias, ou períodos do dia, a área ao redor da estação meteorológica não fosse suficientemente grande para evitar o efeito de transportes horizontais de energia.

Devido a essas dificuldades, inerentes a este tipo de trabalho de campo, e por ser necessário, neste tipo de estudo, que o sistema não sofra perturbações externas que interfiram nas medidas, foi necessário a determinação de critérios para a seleção de períodos quando as interferências foram mínimas.

Com este objetivo, foram adotados os seguintes critérios para selecionar os dias a serem analisados: dias quando todos os sensores estivessem funcionando adequadamente durante as $24 \mathrm{~h}$; dias quando não foram executadas atividades na área que pudessem influenciar nas leituras dos 
sensores, como o corte da grama, drenagem do lisímetro ou mudança de sensores; dias sem a ocorrência de chuva no período de $24 \mathrm{~h}$ (dentro deste critério, considerou-se como dia sem chuva aqueles com valores medidos de chuva menor ou igual a $0,5 \mathrm{~mm}$ ); e dias quando a análise da relação entre a evapotranspiração medida pelo lisímetro e a radiação líquida total do dia $\left(E T_{\text {lis }} / \mathrm{Rn}\right.$ ) resultou em valores maiores que 0,60 , indicando que a evapotranspiração ocorrida foi potencial.

A partir destes critérios, foram selecionados 45 dias considerados adequados para estes estudos. Na Tabela 1 são apresentados os dados médios e totais de $24 \mathrm{~h}$ para os dias analisados.

As médias mensais da temperatura do ar, umidade relativa, velocidade do vento e total mensal de chuva nos meses de coleta de dados foram comparadas com as médias dos últimos 10 anos (Apêndice III). Foi possível observar que os meses em estudo podem ser considerados como típicos em relação à temperatura do ar. Comparativamente, a umidade relativa foi maior $\mathrm{e}$ a velocidade do vento foi menor que a média dos últimos 10 anos. Os meses de dezembro/95 e janeiro/96 foram 11 e 30\% mais chuvosos do que a média dos anos passados, respectivamente, enquanto que os outros meses foram mais secos ( $11 \%$ em fevereiro, $32 \%$ em março, $86 \%$ em abril e $58 \%$ em maio).

Os dados médios diários da temperatura e da umidade relativa dos dias analisados está apresentada na Figura 2. Pode-se observar que neste período a temperatura variou de 17,0 a $30,1^{\circ} \mathrm{C}$, e a umidade relativa variou de 59,0 a $90,0 \%$.

$\mathrm{Na}$ Figura 3 são apresentados os dados de radiação líquida total de $24 \mathrm{~h}$ nos dias analisados. A variação deste dado é consequência da ocorrência desde dias totalmente limpos, sem a ocorrência de nuvens, até a ocorrência de dias bastante encobertos (dias 28/01 e 02/05, respectivamente - Figura 4). 
Tabela 1. Valores médios de temperatura do ar (Ta), umidade relativa (UR), velocidade do vento $(U)$, temperatura da cobertura vegetal $(T c)$, e valores totais de radiação líquida $(R n)$, densidade de fluxo de calor no solo $(G)$ e evapotranspiração medida pelo lisímetro ( $E T_{\text {lis }}$ ), em periodos de $24 \mathrm{~h}$.

\begin{tabular}{|c|c|c|c|c|c|c|c|}
\hline Data & $\begin{array}{c}\mathrm{Ta} \\
\left({ }^{\circ} \mathrm{C}\right)\end{array}$ & $\begin{array}{l}\text { UR } \\
\text { (\%) }\end{array}$ & $\begin{array}{c}\mathrm{U} \\
\left(\mathrm{m} \mathrm{s}^{-1}\right)\end{array}$ & $\begin{array}{c}R n \\
\left(k J m^{-2} d^{-1}\right)\end{array}$ & $\frac{G}{\left(k J m^{-2} d^{-1}\right)}$ & $\begin{array}{c}\text { Tc } \\
\left({ }^{\circ} \mathrm{C}\right)\end{array}$ & $\begin{array}{c}\mathrm{ET}_{\text {lis }} \\
(\mathrm{mm})\end{array}$ \\
\hline $23 / 12$ & 25.4 & 73.0 & 2.1 & 17027.4 & 738.4 & 23.8 & 4.5 \\
\hline $31 / 12$ & 22.5 & 77.0 & 2.4 & 11498.1 & 361.3 & 21.1 & 3.7 \\
\hline $01 / 01$ & 22.1 & 79.0 & 1.4 & 8673.0 & 278.8 & 20.5 & 2.1 \\
\hline $13 / 01$ & 25.4 & 84.0 & 1.4 & 16827.4 & 717.1 & 24.5 & 4.8 \\
\hline $14 / 01$ & 26.6 & 73.0 & 1.8 & 18397.3 & 761.9 & 24.3 & 5.4 \\
\hline $18 / 01$ & 25.2 & 80.0 & 1.7 & 15888.3 & 684.9 & 23.7 & 4.2 \\
\hline $22 / 01$ & 25.9 & 75.0 & 1.8 & 19052.4 & 817.8 & 24.2 & 4.7 \\
\hline $25 / 01$ & 27.8 & 71.0 & 1.5 & 18134.4 & 774.2 & 24.8 & 5.6 \\
\hline $26 / 01$ & 27.2 & 73.0 & 1.7 & 16607.9 & 657.6 & 24.3 & 4.6 \\
\hline $28 / 01$ & 26.4 & 70.0 & 1.5 & 19285.8 & 823.0 & 23.4 & 5.6 \\
\hline $29 / 01$ & 30.1 & 59.0 & 1.7 & 18271.4 & 725.0 & 24.1 & 5.6 \\
\hline $31 / 01$ & 26.8 & 72.0 & 1.6 & 15622.3 & 597.8 & 23.6 & 4.6 \\
\hline $05 / 02$ & 25.0 & 85.0 & 1.7 & 11437.2 & 449.5 & 23.1 & 3.3 \\
\hline $22 / 02$ & 25.6 & 77.0 & 1.7 & 13758.6 & -4.1 & 23.3 & 4.0 \\
\hline $23 / 02$ & 25.4 & 79.0 & 1.4 & 12729.9 & -15.6 & 22.9 & 3.7 \\
\hline $02 / 03$ & 24.4 & 82.0 & 2.1 & 10177.7 & 134.8 & 22.7 & 3.2 \\
\hline $10 / 03$ & 22.5 & 77.0 & 3.0 & 11719.3 & -195.3 & 19.9 & 4.2 \\
\hline $11 / 03$ & 22.8 & 75.0 & 2.0 & 11642.9 & 73.5 & 20.3 & 3.9 \\
\hline $13 / 03$ & 23.1 & 87.0 & 1.6 & 13230.5 & 372.4 & 22.1 & 3.4 \\
\hline $14 / 03$ & 23.6 & 88.0 & 1.4 & 10428.6 & 278.0 & 22.4 & 2.8 \\
\hline $17 / 03$ & 23.2 & 90.0 & 1.3 & 8779.9 & 130.2 & 22.3 & 2.5 \\
\hline $21 / 03$ & 23.5 & 84.0 & 2.2 & 9620.9 & -119.3 & 21.8 & 3.1 \\
\hline $22 / 03$ & 23.6 & 82.0 & 1.8 & 10306.4 & 28.6 & 21.5 & 2.9 \\
\hline $24 / 03$ & 24.3 & 85.0 & 1.4 & 12934.8 & 299.9 & 22.9 & 3.4 \\
\hline $25 / 03$ & 24.4 & 81.0 & 1.6 & 14265.9 & 133.6 & 22.5 & 4.1 \\
\hline $26 / 03$ & 25.4 & 79.0 & 1.4 & 14183.8 & 252.7 & 23.4 & 4.2 \\
\hline $28 / 03$ & 24.5 & 85.0 & 1.2 & 11057.5 & 149.5 & 23.1 & 3.1 \\
\hline $03 / 04$ & 25.8 & 74.0 & 1.6 & 12291.9 & -24.9 & 22.9 & 3.7 \\
\hline $04 / 04$ & 25.7 & 75.0 & 1.6 & 11266.7 & -121.1 & 23.1 & 3.7 \\
\hline $06 / 04$ & 24.7 & 80.0 & 1.2 & 11838.2 & 113.3 & 22.3 & 3.2 \\
\hline $07 / 04$ & 25.2 & 77.0 & 1.8 & 12007.6 & 77.6 & 22.9 & 3.5 \\
\hline $10 / 04$ & 24.5 & 79.0 & 1.5 & 10664.3 & 193.4 & 22.8 & 2.9 \\
\hline $13 / 04$ & 23.8 & 83.0 & 1.3 & 9495.1 & 164.6 & 22.5 & 2.6 \\
\hline $15 / 04$ & 24.4 & 80.0 & 1.7 & 11237.3 & 194.1 & 22.6 & 3.4 \\
\hline $18 / 04$ & 18.3 & 73.0 & 3.2 & 9038.7 & -957.2 & 17.6 & 3.3 \\
\hline $19 / 04$ & 17.0 & 74.0 & 2.6 & 11309.3 & -851.6 & 15.8 & 3.0 \\
\hline $20 / 04$ & 18.9 & 74.0 & 2.1 & 10755.8 & -291.1 & 17.4 & 2.8 \\
\hline $26 / 04$ & 20.0 & 81.0 & 2.5 & 8189.9 & -306.0 & 18.6 & 2.1 \\
\hline $27 / 04$ & 20.0 & 74.0 & 3.1 & 8313.5 & -379.7 & 18.9 & 2.2 \\
\hline $29 / 04$ & 21.2 & 78.0 & 1.4 & 10105.1 & -66.1 & 19.5 & 2.5 \\
\hline $30 / 04$ & 20.6 & 81.0 & 1.8 & 8220.5 & -270.1 & 19.1 & 2.3 \\
\hline $02 / 05$ & 19.3 & 77.0 & 2.3 & 6517.5 & -328.3 & 17.7 & 1.8 \\
\hline $04 / 05$ & 19.2 & 76.0 & 1.4 & 10367.2 & -186.4 & 17.0 & 2.6 \\
\hline $17 / 05$ & 19.1 & 83.0 & 1.4 & 9259.5 & -238.5 & 17.1 & 2.6 \\
\hline $24 / 05$ & 18.1 & 81.0 & 2.5 & 5482.6 & -485.0 & 16.7 & 1.5 \\
\hline
\end{tabular}




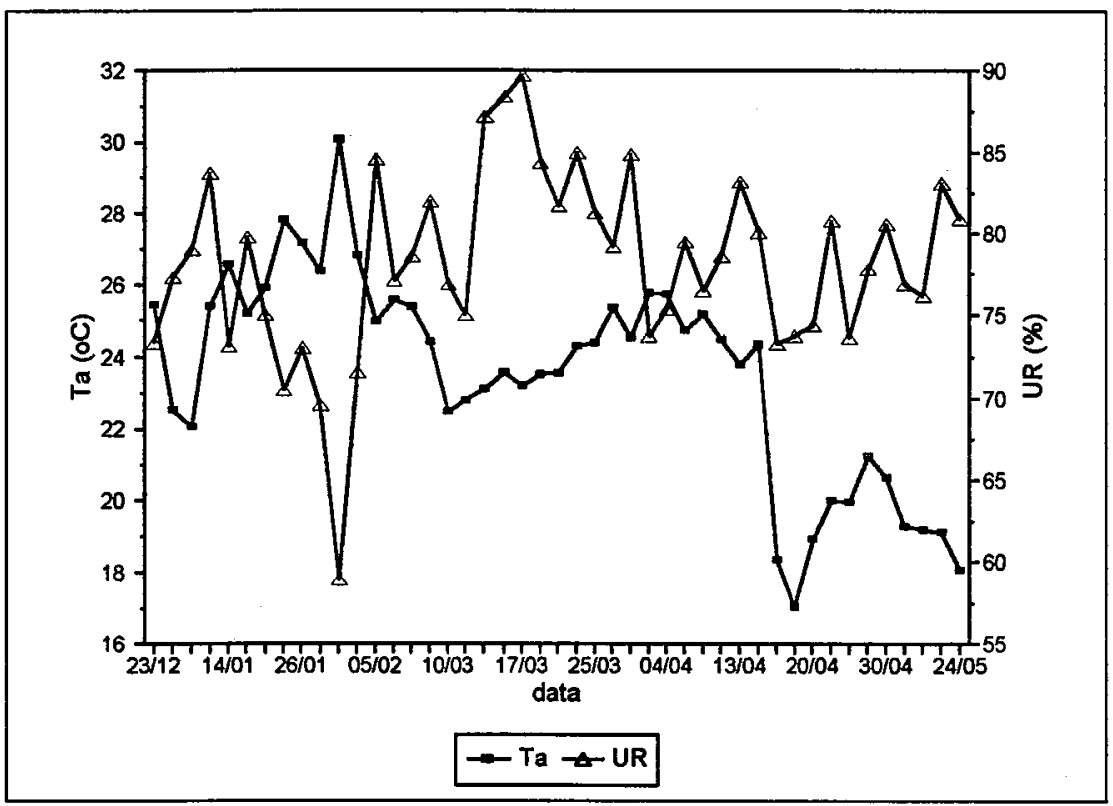

Figura 2. Temperatura média diária $\left({ }^{\circ} \mathrm{C}\right)$ e umidade relativa média diária $(\%)$ dos dias em análise.

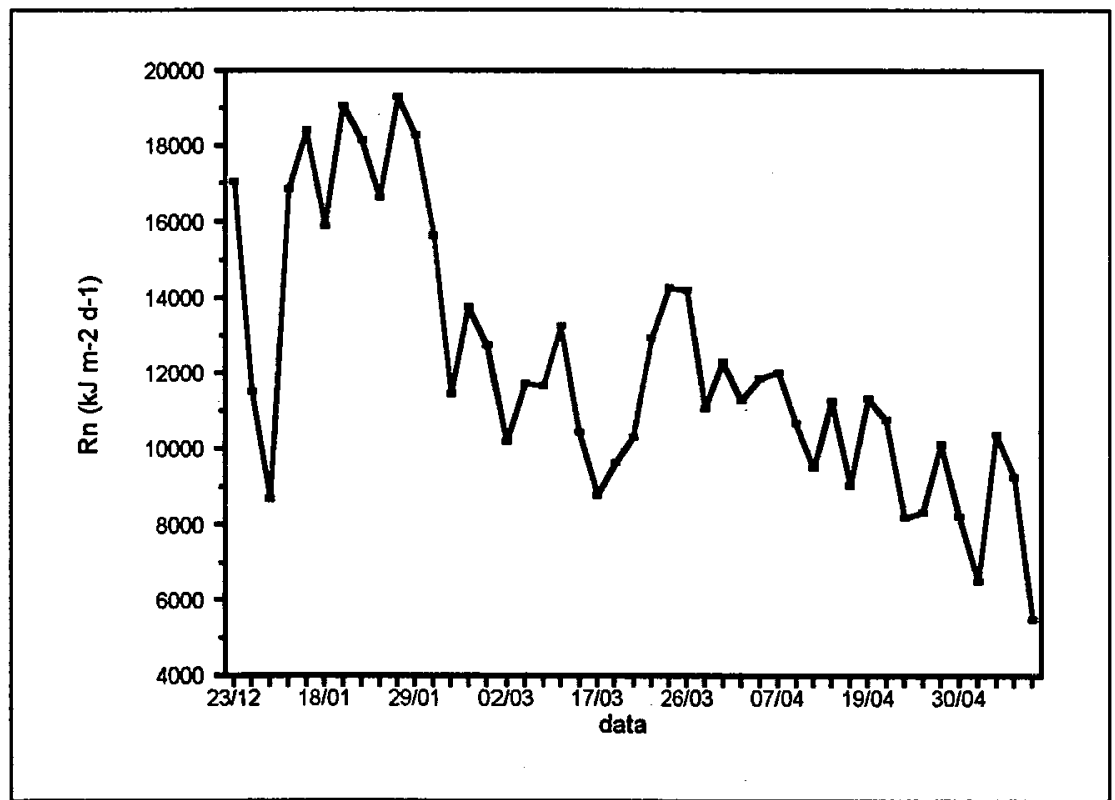

Figura 3. Radiação líquida total no período de $24 \mathrm{~h}\left(\mathrm{~kJ} \mathrm{~m}^{-2} \mathrm{~d}^{-1}\right)$ dos dias em análise. 
Vários dos dias analisados ocorreu a presença de nuvens interceptando a incidência da radiação solar em períodos do dia (dia 18/01 - Figura 5). A presença de nuvens provoca a variação do balanço de energia na superfície vegetada, o que não é considerado adequado quando se utiliza a temperatura radiante da cobertura vegetal para o cálculo de índices relacionados ao estado de água da cultura (Folegatti, 1988).

Nos diversos trabalhos que utilizam a temperatura da cobertura vegetal para o cálculo de índices de estresse ou da evapotranspiração, são utilizadas informações obtidas nos horários de maior radiação e sem a presença de nuvens, evitando assim as alterações provocadas pelo sombreamento (Jackson, 1982; Choudhury et al, 1986). Para fins deste trabalho foram utilizadas inicialmente informações médias de temperatura da cobertura vegetal nos diferentes períodos analisados ( $30 \mathrm{~min}, 24 \mathrm{~h}$ e período de luz), não tendo sido objeto de preocupação o descarte dos dias que apresentaram a ocorrência de nuvens em períodos do dia.

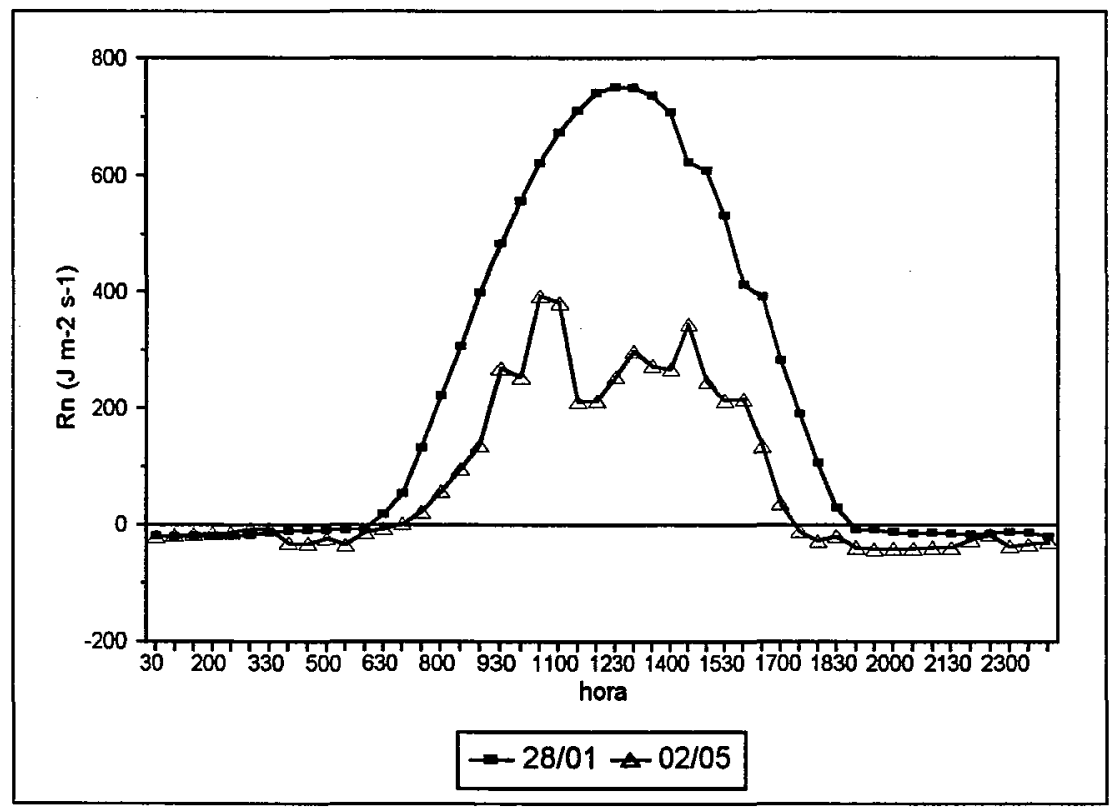

Figura 4. Variação da radiação líquida ao longo de um dia sem a ocorrência de nuvens (28/01) e de um dia encoberto (02/05). 


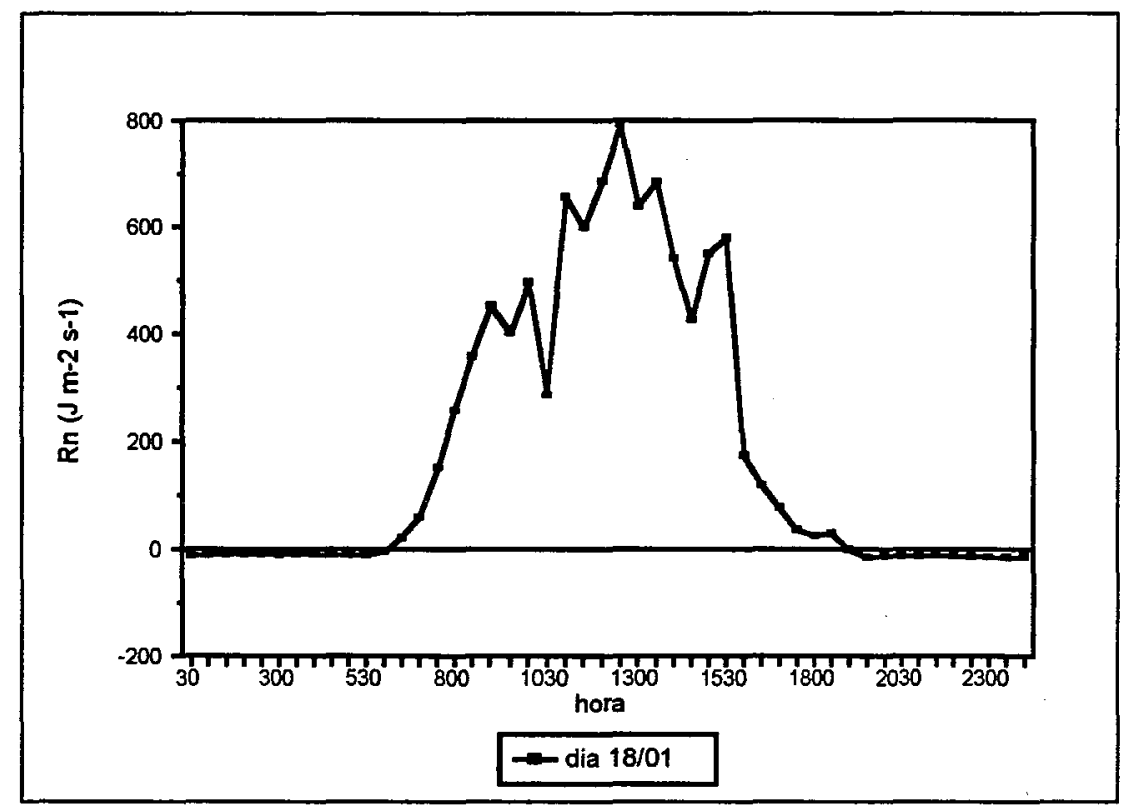

Figura 5. Variação da radiação líquida ao longo de um dia com presença de nuvens.

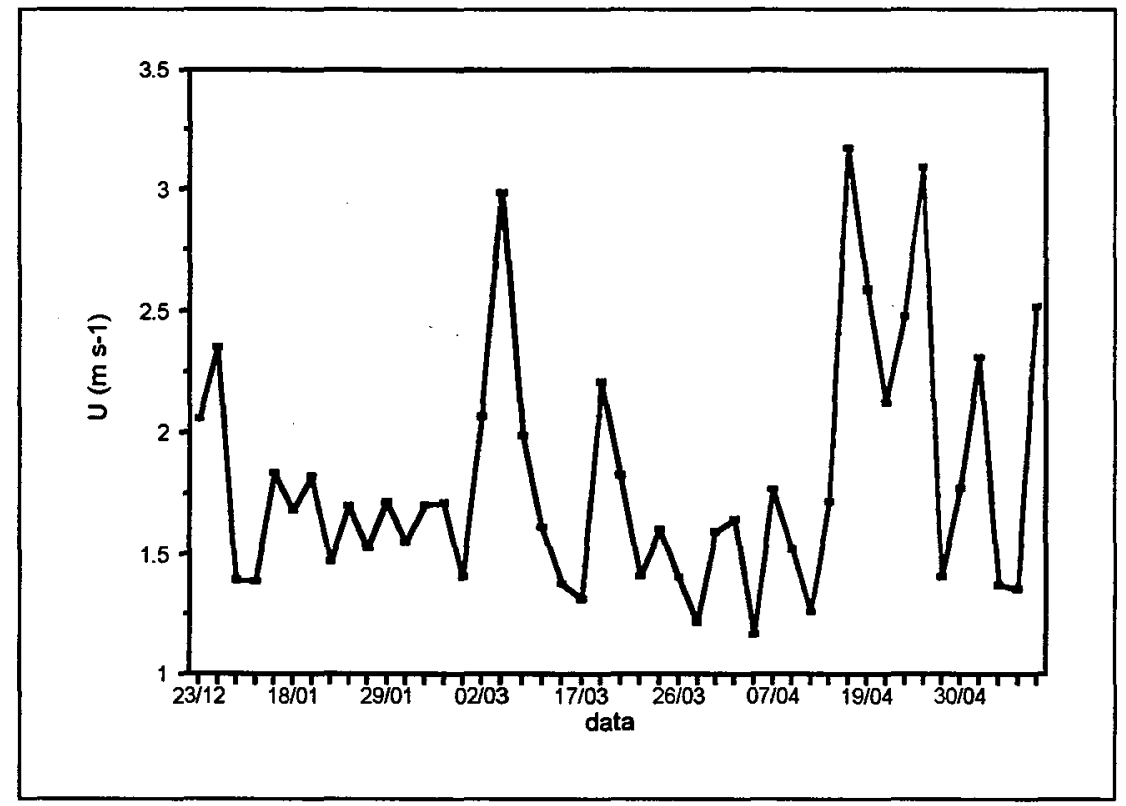

Figura 6. Velocidade do vento média diária $\left(\mathrm{m} \mathrm{s}^{-1}\right)$ dos dias em análise. 
A velocidade média do vento no período de $24 \mathrm{~h}$ nos dias em análise foi em torno de $1,8 \mathrm{~m} \mathrm{~s}^{-1}$, com exceção dos dias 18/04 e 27/04, quando foram superiores a $3,0 \mathrm{~m} \mathrm{~s}^{-1}$, como pode ser observado na Figura 6 .

\subsection{Resistência da cobertura vegetal}

O valor proposto pela $\mathrm{FAO/91}$ para a resistência da cobertura vegetal de uma cultura de referência é de $69 \mathrm{~s} \mathrm{~m}^{-1}$ (Smith, 1991), para uso na equação de Penman-Monteith. Este valor é fixado a partir de estimativas da resistência estomática e do índice de área foliar da cultura. Porém, o documento reportado por Smith (1991) indicou que devem ser desenvolvidas pesquisas no sentido de estudar se este valor é adequado às diferentes condições climáticas.

Peres (1994), trabalhando com dados de evapotranspiração do Estado de São Paulo, concluiu que o valor adequado para essas condições de estudo, seria de $80 \mathrm{~s} \mathrm{~m}^{-1}$, número encontrado através de simulações.

Neste trabalho foi possivel dar especial atenção ao cálculo de rc. Com os dados coletados, foram comparados valores de rc calculados de duas diferentes formas, em diferentes períodos de tempo. O valor de rc considerado como padrão para comparação foi o rc calculado como resíduo da equação de Penman-Monteith ( $r \mathrm{c}_{\mathrm{res}}$ ), com os dados de evapotranspiração medidos pelo lisímetro de pesagem ( $\left(E T_{\text {lis }}\right)$. A equação utilizada foi:

$$
r c_{\text {res }}=\frac{s r a\left(R n-G-E T_{\text {lis }}\right)+\rho c p\left(e^{*} a-e a\right)}{\gamma E T_{\text {lis }}}-r a
$$

com valores de $\mathrm{ET}_{\text {lis }}$ em $\mathrm{kJ} \mathrm{m}^{-2} \mathrm{~s}^{-1}$.

Utilizando a temperatura da cobertura vegetal, foi possivel o cálculo de rc a partir da seguinte equação $\left(\mathrm{rC}_{\mathrm{TC}}\right)$ : 


$$
r c_{T c}=\frac{\rho c p\left(e^{*} c-e a\right)}{\gamma\left[(R n-G)-\frac{\rho c p(T c-T a)}{r a}\right]}-r a
$$

Foi possível o cálculo e a análise de rc em diferentes períodos de tempo: $30 \mathrm{~min}, 24 \mathrm{~h}$, e periodo de luz, aqui definido como o período quando a radiação líquida foi maior que zero. Primeiramente será feita a apresentação dos resultados obtidos para os diferentes períodos de tempo, para uma discussão conjunta posterior.

\subsubsection{Cálculo de rc em períodos de $30 \mathrm{~min}$}

A variação do valor de rc calculado das duas formas em estudo pode ser observada na Figura 7, para um dia ensolarado (Fig. 7a - dia 29/01), e para um dia com ocorrência de nuvens (Fig. $7 \mathrm{~b}$ - dia 05/02). Nas Figuras $7 \mathrm{c}$ e $7 \mathrm{~d}$ podem ser observadas as variações da radiação líquida nos mesmos dias. Os valores calculados $\mathrm{rc}_{\text {res }}$ em períodos de $30 \mathrm{~min}$ apresentam grande variação ao longo do dia, que aumenta quando há ocorrência de nuvens, e apresentam valores negativos na madrugada e início da manhã. Os valores de $\mathrm{rc}_{\mathrm{Tc}}$ também variam bastante ao longo do dia, porém mantém-se menor que zero durante praticamente todo o dia. Durante a noite e madrugada, os valores de rc calculados alcançam valores extremamente altos, não representados na escala das figuras.

Foi feita uma análise da relação entre a densidade de fluxo de calor latente ( $E T_{\text {lis, }}$ em $\mathrm{kJ} \mathrm{m}^{-2} \mathrm{~s}^{-1}$ ) ocorrido e a radiação líquida $(\mathrm{Rn})$, em cada período de 30 min durante as $24 \mathrm{~h}$ dos dois dias. Quando o resultado desta relação permanece no intervalo entre 0,6 e 1,0, indica que a evapotranspiração está ocorrendo potencialmente, e não há efeito de advecção, sendo esta a situação 

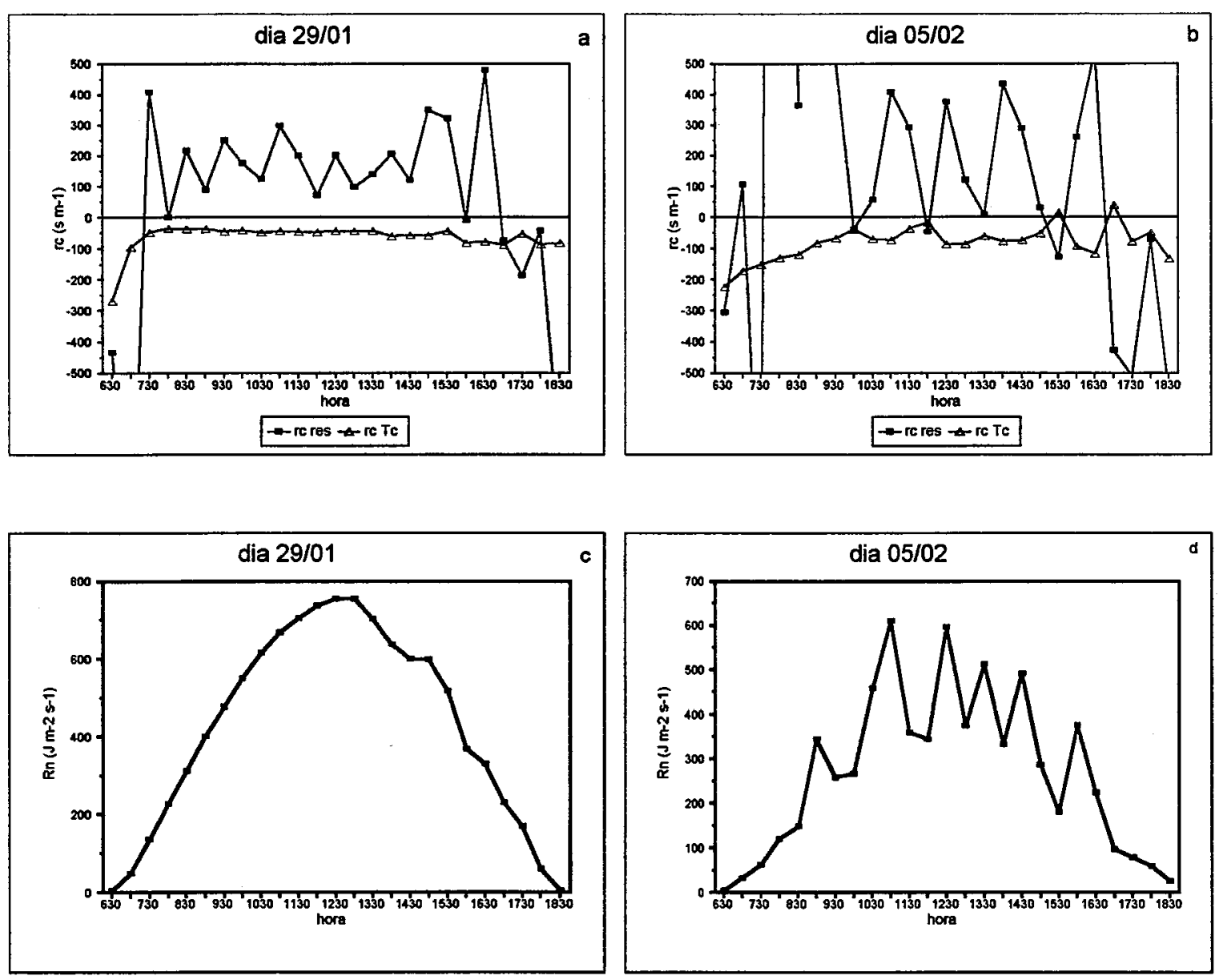

Figura 7. Variação da resistência da cobertura vegetal calculada como resíduo $\left(\mathrm{rc}_{\mathrm{res}}\right)$ e pelo uso da temperatura da cobertura vegetal $\left(\mathrm{rC}_{\mathrm{Tc}}\right)$ e variação da radiação líquida: a) e c) ao longo de um dia sem a ocorrência de nuvens; b) e d) ao longo de um dia com a ocorrência de nuvens.

que se deseja neste estudo. Pode-se observar na Figura 8, que quando o dia apresenta-se ensolarado, sem a presença de nuvens (Fig 8 a - dia 29/01), a relação mantém-se no intervalo entre 0,6 e 1,0 durante o dia, indicando a ocorrência de evapotranspiração potencial. Na madrugada e durante o final da tarde e noite, a relação resulta em valores fora deste intervalo, indicando a ocorrência de advecção ou de evapotranspiração não potencial. Quando se analisa a variação durante um dia com presença intermitente de nuvens (Fig. 

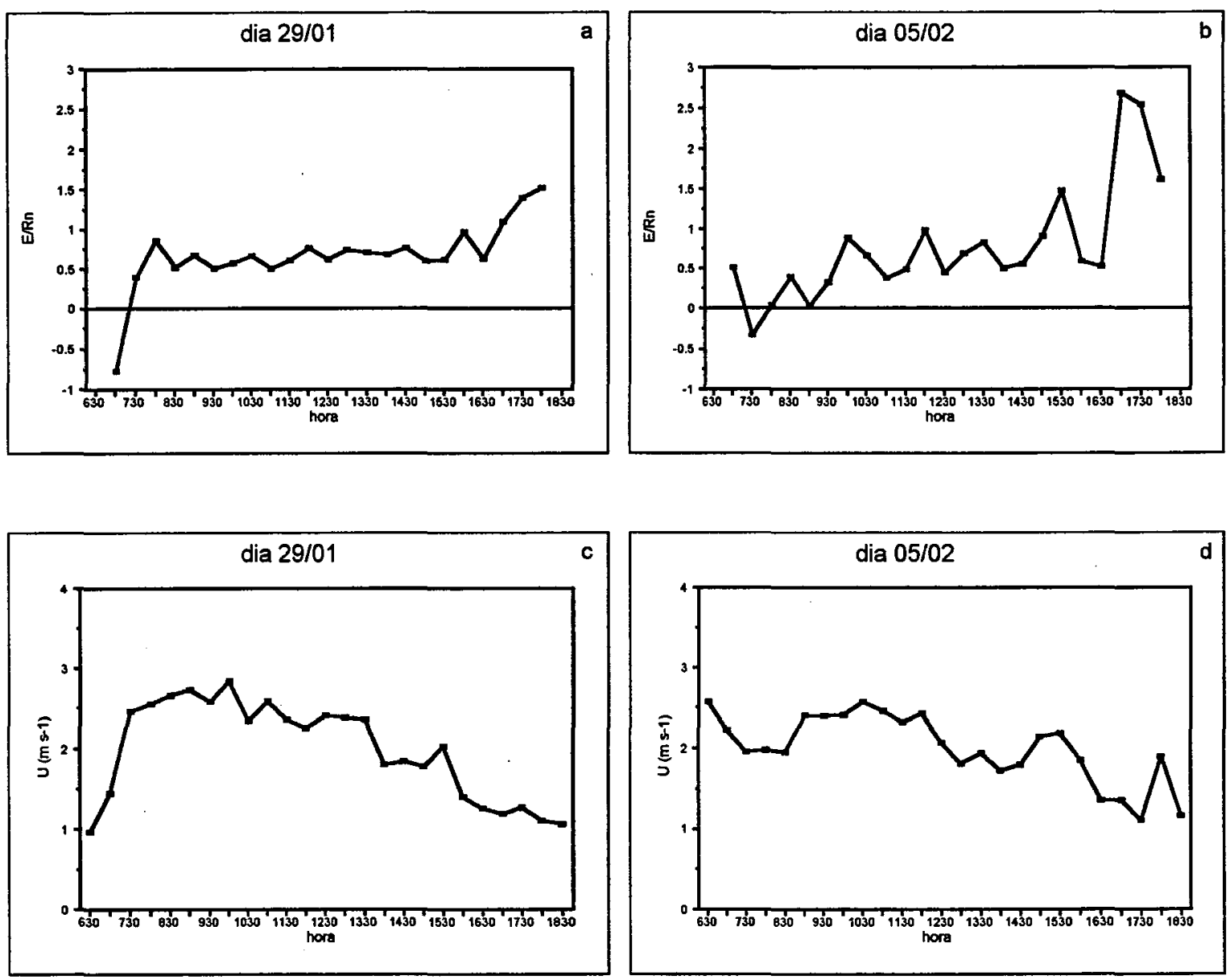

Figura 8. Variação da relação entre a densidade de fluxo de calor latente medido e a radiação líquida, e variação da velocidade do vento: a) e c) em um dia sem a ocorrência de nuvens; b) e d) em um dia com a ocorrência de nuvens.

$8 b$ - dia 05/02), em períodos de $30 \mathrm{~min}$ a relação apresenta uma maior oscilação, saindo do intervalo de interesse. Este fato indica que a interceptação da radiação pelas nuvens alterou o balanço de energia, favorecendo a ocorrência da advecção, e interferindo na evapotranspiração medida. Durante a madrugada e início da noite, o fator que pode estar influenciando na variação da relação é a velocidade do vento. Porém, não foi observada relação entre essas variáveis (Fig. $8 \mathrm{c}$ e $8 \mathrm{~d}$ ). 
Para períodos de $30 \mathrm{~min}$, a oscilação tanto dos valores da relação $E T_{\text {lis }} / R n$ quanto de $\mathrm{rc}_{\text {res }}$ é decorrente dos resultados de $\mathrm{ET}_{\text {lis. }}$. Nestes períodos, o lisímetro apresentou uma oscilação que pode ser devido ao vento.

Os valores de $\mathrm{rc}_{\mathrm{Tc}}$ calculados também apresentam grandes oscilaçōes, e permaneceram negativos durante todo o período da madrugada e manhã, passando a valores positivos no final da tarde.

\subsubsection{Cálculo de rc em periodos de 24 horas}

Calculando $\mathrm{rc}_{\mathrm{res}}$ a partir dos valores médios diários das variáveis climáticas, foram encontrados valores que variaram de 53 até $256 \mathrm{~s} \mathrm{~m}^{-1}$, com uma média aritmética de $144 \mathrm{~s} \mathrm{~m}^{-1}$ para os dias analisados. Utilizando médias diárias de temperatura da cobertura vegetal para o cálculo de $\mathrm{rc}_{T c}$, foram encontrados valores negativos para praticamente todos os dias analisados, com exceção de 2 dias (Tabela 2). A representação gráfica dos valores calculados de rc pode ser observada na Figura 9.

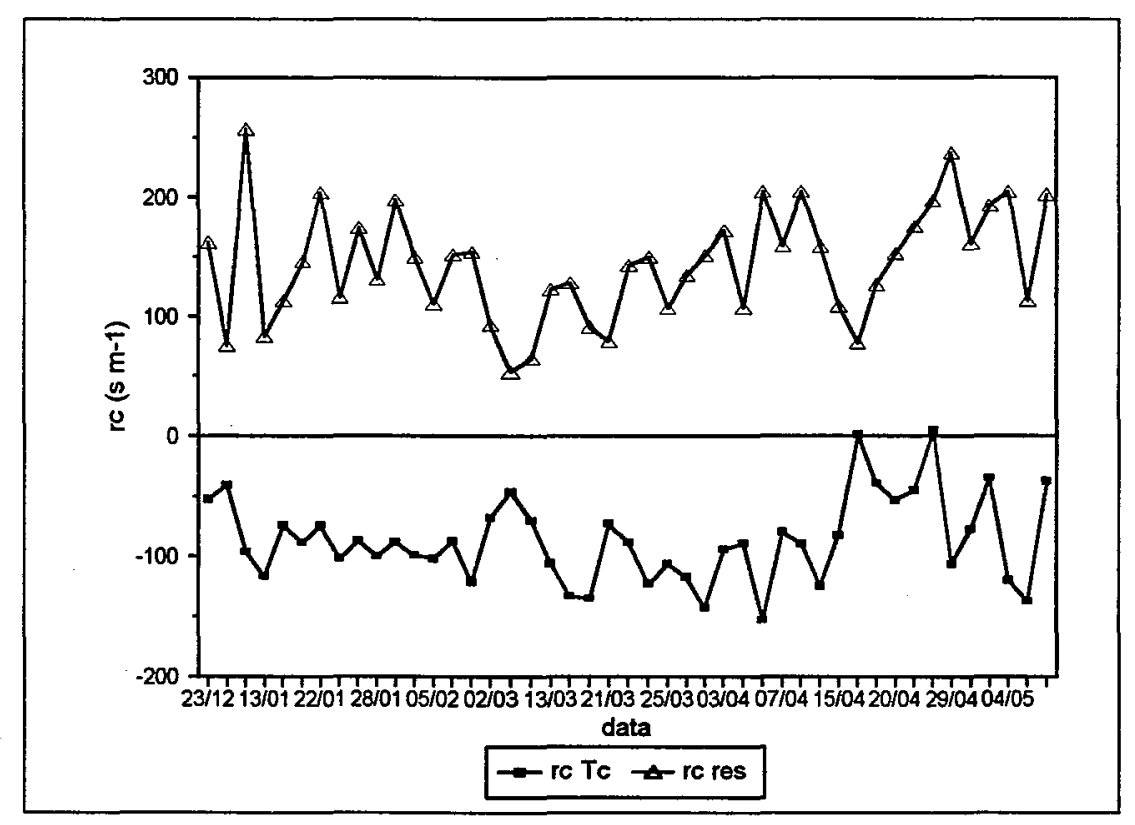

Figura 9. Resistência da cobertura vegetal $\left(\mathrm{rc}_{\mathrm{res}}\right.$ e $\left.\mathrm{rC}_{\mathrm{Tc}}\right)$ calculada com valores médios de $24 \mathrm{~h}$, para os dias em análise. 
Tabela 2. Valores de resistência da cobertura vegetal calculados pelo uso de informaçōes médias de $24 \mathrm{~h}$.

\begin{tabular}{|c|c|c|}
\hline Data & $\begin{array}{c}\mathrm{rC}_{\mathrm{Tc}} \\
\left(\mathrm{s} \mathrm{m}^{-1}\right)\end{array}$ & $\begin{array}{c}r c_{r e s} \\
\left(\mathrm{~s} \mathrm{~m}^{-1}\right)\end{array}$ \\
\hline $23 / 12$ & -53 & 162 \\
\hline $31 / 12$ & -41 & 75 \\
\hline $01 / 01$ & -96 & 257 \\
\hline $13 / 01$ & -117 & 83 \\
\hline $14 / 01$ & -75 & 113 \\
\hline $18 / 01$ & -89 & 147 \\
\hline $22 / 01$ & -75 & 204 \\
\hline $25 / 01$ & -102 & 116 \\
\hline $26 / 01$ & -87 & 174 \\
\hline $28 / 01$ & -100 & 131 \\
\hline $29 / 01$ & -88 & 198 \\
\hline $31 / 01$ & -99 & 150 \\
\hline $05 / 02$ & -102 & 110 \\
\hline $22 / 02$ & -88 & 152 \\
\hline $23 / 02$ & -122 & 155 \\
\hline $02 / 03$ & -68 & 93 \\
\hline $10 / 03$ & -46 & 53 \\
\hline $11 / 03$ & -71 & 64 \\
\hline $13 / 03$ & -106 & 123 \\
\hline $14 / 03$ & -133 & 129 \\
\hline $17 / 03$ & -135 & 91 \\
\hline $21 / 03$ & -73 & 79 \\
\hline $22 / 03$ & -89 & 143 \\
\hline $24 / 03$ & -123 & 150 \\
\hline $25 / 03$ & -106 & 107 \\
\hline $26 / 03$ & -117 & 135 \\
\hline $28 / 03$ & -143 & 152 \\
\hline $03 / 04$ & -95 & 172 \\
\hline $04 / 04$ & -89 & 107 \\
\hline $06 / 04$ & -153 & 205 \\
\hline $07 / 04$ & -80 & 160 \\
\hline $10 / 04$ & -90 & 205 \\
\hline $13 / 04$ & -125 & 159 \\
\hline $15 / 04$ & -83 & 109 \\
\hline $18 / 04$ & 1 & 77 \\
\hline $19 / 04$ & -39 & 127 \\
\hline $20 / 04$ & -53 & 153 \\
\hline $26 / 04$ & -45 & 176 \\
\hline $27 / 04$ & 5 & 197 \\
\hline $29 / 04$ & -107 & 237 \\
\hline $30 / 04$ & -78 & 162 \\
\hline $02 / 05$ & -35 & 193 \\
\hline $04 / 05$ & -120 & 205 \\
\hline $17 / 05$ & -137 & 113 \\
\hline $24 / 05$ & -37 & 203 \\
\hline
\end{tabular}




\subsubsection{Cálculo de rc em períodos de luz}

$\mathrm{Na}$ análise do cálculo de rc para períodos de luz, foi feita novamente a análise da relação $\lambda E / R n$ ocorrida nestes períodos (critério de seleção dos dias a serem analisados, utilizado inicialmente). Desta forma, o número de dias analisados neste item passou para 32 dias. Os valores médios e totais dos períodos de luz dos dias analisados são apresentados na Tabela 3.

Tabela 3. Valores médios de temperatura do ar (Ta), umidade relativa (UR), velocidade do vento $(U)$, temperatura da cobertura vegetal (TC), e valores totais de radiação líquida $(R n)$, densidade de fluxo de calor no solo $(G)$ e evapotranspiração medida pelo lisimetro ( $\left(\mathrm{ET}_{\text {lis }}\right)$, em períodos de luz.

\begin{tabular}{cccccccc}
\hline Data & $\begin{array}{c}\text { Ta } \\
\left({ }^{\circ} \mathrm{C}\right)\end{array}$ & $\begin{array}{c}\text { UR } \\
(\%)\end{array}$ & $\begin{array}{c}\mathrm{U} \\
\left(\mathrm{m} \mathrm{s}^{-1}\right)\end{array}$ & $\begin{array}{c}\mathrm{Rn} \\
\left(\mathrm{kJ} \mathrm{m}^{-2} \mathrm{~d}^{-1}\right)\end{array}$ & $\begin{array}{c}\mathrm{G} \\
\left(\mathrm{kJ} \mathrm{m}^{-2} \mathrm{~d}^{-1}\right)\end{array}$ & $\begin{array}{c}\text { Tc } \\
\left({ }^{\circ} \mathrm{C}\right)\end{array}$ & $\begin{array}{c}\mathrm{ET}_{\text {lis }} \\
(\mathrm{mm})\end{array}$ \\
\hline $23 / 12$ & 27.5 & 64.0 & 2.9 & 17523.2 & 876.2 & 26.7 & 4.41 \\
$31 / 12$ & 24.4 & 71.0 & 2.5 & 12408.0 & 620.4 & 24.1 & 3.45 \\
$13 / 01$ & 27.6 & 74.0 & 1.7 & 17367.8 & 868.4 & 27.8 & 4.51 \\
$14 / 01$ & 29.0 & 60.0 & 1.8 & 19082.1 & 954.1 & 27.5 & 5.10 \\
$18 / 01$ & 27.2 & 68.0 & 2.4 & 16345.6 & 817.3 & 26.6 & 4.36 \\
$22 / 01$ & 28.8 & 62.0 & 2.2 & 19639.7 & 982.0 & 27.7 & 4.78 \\
$25 / 01$ & 30.2 & 61.0 & 1.7 & 18690.3 & 934.5 & 27.9 & 4.97 \\
$26 / 01$ & 30.1 & 62.0 & 1.5 & 17335.4 & 866.8 & 27.4 & 4.60 \\
$28 / 01$ & 29.0 & 59.0 & 1.8 & 19881.9 & 994.1 & 26.6 & 5.25 \\
$29 / 01$ & 30.3 & 57.0 & 2.0 & 19087.5 & 954.4 & 27.0 & 5.41 \\
$31 / 01$ & 29.4 & 61.0 & 1.8 & 16417.0 & 820.9 & 26.9 & 4.38 \\
$05 / 02$ & 26.7 & 78.0 & 2.0 & 11956.8 & 597.8 & 24.9 & 3.22 \\
$02 / 03$ & 26.2 & 76.0 & 2.1 & 10864.1 & 500.1 & 24.8 & 2.94 \\
$10 / 03$ & 24.8 & 67.0 & 3.5 & 13694.4 & 348.0 & 22.7 & 4.21 \\
$11 / 03$ & 25.3 & 65.0 & 1.8 & 12967.4 & 568.3 & 23.2 & 3.52 \\
$13 / 03$ & 25.8 & 76.0 & 1.8 & 14197.4 & 773.1 & 26.0 & 3.67 \\
$17 / 03$ & 25.0 & 81.0 & 1.6 & 9441.0 & 475.0 & 24.6 & 2.40 \\
$21 / 03$ & 25.9 & 76.0 & 3.0 & 10558.3 & 321.6 & 24.8 & 2.93 \\
$22 / 03$ & 25.9 & 73.0 & 2.2 & 11592.7 & 496.1 & 25.1 & 3.07 \\
$25 / 03$ & 27.1 & 69.0 & 2.4 & 15239.7 & 690.6 & 26.6 & 4.12 \\
$26 / 03$ & 28.6 & 67.0 & 1.6 & 15063.3 & 779.5 & 27.6 & 4.02 \\
$28 / 03$ & 27.1 & 74.0 & 1.4 & 12026.8 & 611.9 & 26.9 & 3.06 \\
$03 / 04$ & 28.8 & 59.0 & 1.6 & 13611.5 & 620.6 & 26.9 & 3.60 \\
$04 / 04$ & 28.7 & 63.0 & 1.6 & 12810.7 & 494.5 & 26.9 & 3.74 \\
$06 / 04$ & 27.3 & 67.0 & 1.4 & 12941.3 & 703.7 & 26.7 & 3.52 \\
$07 / 04$ & 28.5 & 62.0 & 1.8 & 13135.6 & 667.0 & 26.9 & 3.47 \\
$10 / 04$ & 27.7 & 67.0 & 1.5 & 11523.4 & 774.6 & 26.8 & 3.18 \\
$13 / 04$ & 25.8 & 74.0 & 1.2 & 10305.9 & 517.2 & 25.5 & 2.73 \\
$15 / 04$ & 27.1 & 67.0 & 2.2 & 11969.2 & 613.1 & 25.8 & 3.19 \\
$02 / 05$ & 21.3 & 69.0 & 2.9 & 7779.8 & 217.5 & 21.5 & 2.04 \\
$17 / 05$ & 22.0 & 71.0 & 1.9 & 10479.2 & 354.0 & 22.2 & 2.68 \\
$26 / 05$ & 19.8 & 66.0 & 1.1 & 9687.0 & 337.9 & 21.4 & 3.20 \\
\hline & & & & & & &
\end{tabular}


Os valores de $\mathrm{rc}_{\text {res }}$ calculados com valores médios do período de luz variaram de 146 até $496 \mathrm{~s} \mathrm{~m}^{-1}$, com média de $265 \mathrm{~s} \mathrm{~m}^{-1}$, valores bastante superiores aos calculados anteriormente. No cálculo de $\mathrm{rC}_{\mathrm{Tc}}$ com valores médios do período de luz, foram encontrados novamente resultados negativos em 20 dos dias analisados. Os valores de $\mathrm{rC}_{\mathrm{res}}$ e $\mathrm{rC}_{\mathrm{Tc}}$ calculados para os períodos de luz podem ser observados na Tabela 4, e sua representação gráfica, na Figura 10.

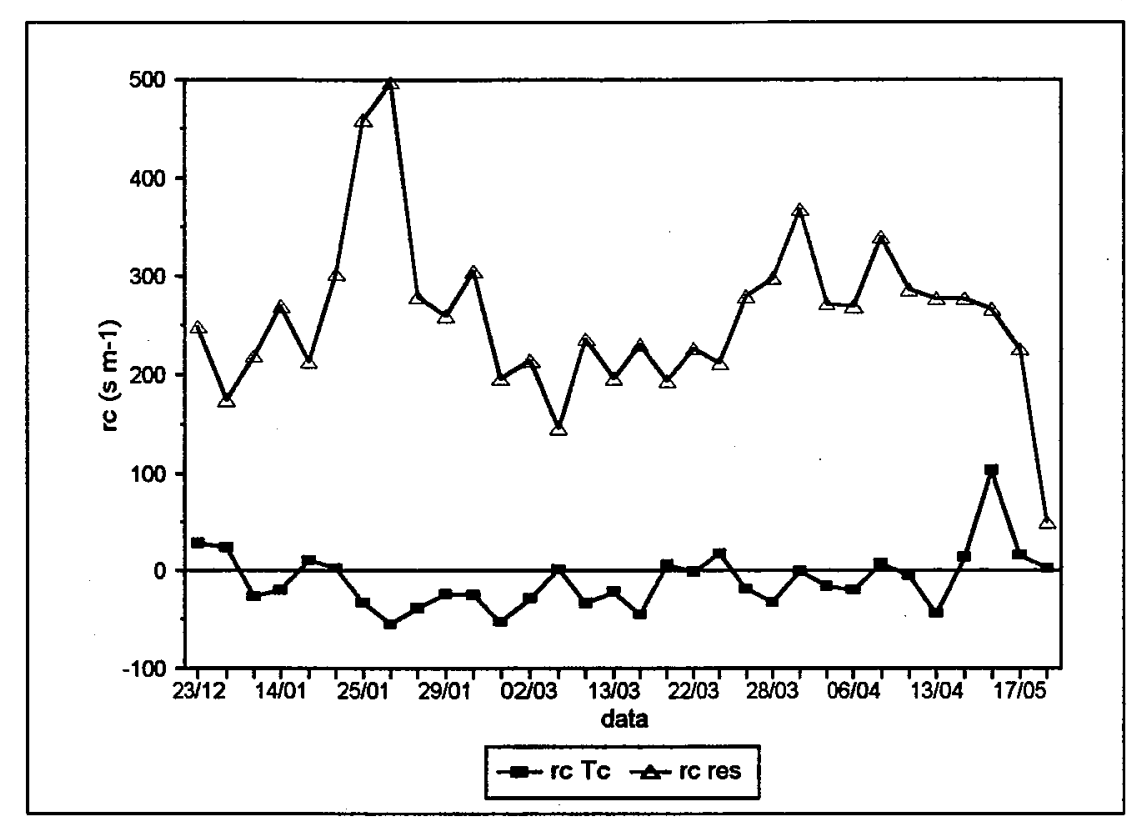

Figura 10. Resistência da cobertura vegetal $\left(\mathrm{rc}_{\mathrm{res}}\right.$ e $\mathrm{rC}_{\mathrm{Tc}_{\mathrm{c}}}$ ) calculada com valores médios dos períodos de luz, para os dias em análise

\subsubsection{Considerações sobre o cálculo de rc}

O cálculo de rc em diferentes períodos de tempo apresentou resultados bastante diversos, para o mesmo dia analisado. A discussão deve então ser sobre qual o período mais adequado a ser utilizado para seu cálculo.

No cálculo de $\mathrm{rc}_{\mathrm{res}}$, quando foram utilizadas informações de $30 \mathrm{~min}$, ocorreu grande variação dos resultados. Esta variação está relacionada com a flutuação do peso do lísímetro, ou seja, da evapotranspiração medida em 
períodos curtos de tempo. Este fato indica que o equipamento utilizado para medir a evapotranspiração, no caso o lisimetro de pesagem, não é adequado para medidas em períodos curtos de tempo (30 min).

Tabela 4. Valores de resistência da cobertura vegetal calculada pelo uso de informações médias de períodos de luz.

\begin{tabular}{lrr}
\hline Data & $\begin{array}{r}\mathrm{rc}_{\text {Tc }} \\
\left(\mathrm{s} \mathrm{m}^{-1}\right)\end{array}$ & $\begin{array}{r}\mathrm{rc}_{\text {res }} \\
\left(\mathrm{s} \mathrm{m}^{-1}\right)\end{array}$ \\
\hline $23 / 12$ & 28 & 249 \\
$31 / 12$ & 23 & 175 \\
$13 / 01$ & -27 & 219 \\
$14 / 01$ & -20 & 270 \\
$18 / 01$ & 11 & 213 \\
$22 / 01$ & 2 & 302 \\
$25 / 01$ & -33 & 459 \\
$26 / 01$ & -55 & 497 \\
$28 / 01$ & -39 & 279 \\
$29 / 01$ & -24 & 260 \\
$31 / 01$ & -25 & 304 \\
$05 / 02$ & -53 & 196 \\
$02 / 03$ & -29 & 215 \\
$10 / 03$ & 1 & 146 \\
$11 / 03$ & -33 & 236 \\
$13 / 03$ & -22 & 196 \\
$17 / 03$ & -45 & 230 \\
$21 / 03$ & 6 & 194 \\
$22 / 03$ & -2 & 227 \\
$25 / 03$ & 17 & 211 \\
$26 / 03$ & -19 & 279 \\
$28 / 03$ & -33 & 298 \\
$03 / 04$ & -1 & 368 \\
$04 / 04$ & -16 & 272 \\
$06 / 04$ & -20 & 269 \\
$07 / 04$ & 7 & 339 \\
$10 / 04$ & -5 & 286 \\
$13 / 04$ & -44 & 277 \\
$15 / 04$ & 13 & 277 \\
$02 / 05$ & 103 & 266 \\
$17 / 05$ & 16 & 226 \\
$26 / 05$ & 2 & 50 \\
\hline & &
\end{tabular}

O balanço de energia, quando se considera períodos de $24 \mathrm{~h}$, é menor do que para períodos de luz, assim como o déficit de pressão de vapor e a resistência aerodinâmica. São essas diferenças que levam aos menores 
valores de $\mathrm{rc}_{\mathrm{res}}$ encontrados nos períodos de $24 \mathrm{~h}$. A evapotranspiração é um processo que ocorre basicamente durante o periodo de ocorrência de luz. Durante o período noturno ocorre saída de energia do sistema (Rn negativo), muito pequena se comparada com os valores diurnos. Porém, sendo o modelo de Penman-Monteith uma equação que considera, além do balanço de energia, os parâmetros aerodinâmicos que influenciam a evapotranspiração (representados basicamente pela resistência aerodinâmica), o mais adequado seria o cálculo de $\mathrm{rc}_{\text {res }}$ a partir de valores médios de $24 \mathrm{~h}$ de medida.

O valor de $\mathrm{rc}_{\text {res }}$ médio, calculado a partir dos dados médios de $24 \mathrm{~h}$, foi de $144 \mathrm{~s} \mathrm{~m}^{-1}$, maior que o dobro do valor proposto pela FAO/91 (Smith, 1991), e cerca de $45 \%$ maior que o valor encontrado por Peres (1994). No estudo feito por Peres (1994), o maior valor de rc estudado na simulação feita para estimar a evapotranspiração, foi de $80 \mathrm{~s} \mathrm{~m}^{-1}$, sendo este valor o que melhor se ajustou aos seus dados reais. A partir dos resultados aqui obtidos, é possivel que talvez fossem encontrados melhores ajustes da estimativa de evapotranspiração no estudo daquele autor, se fossem utilizados valores maiores de rc.

O resultado aqui obtido também é bastante superior aos valores indicados em Hatfield (1988) e Monteith (1985), que são de 20 e $50 \mathrm{~s} \mathrm{~m}^{-1}$, indicando que estes valores propostos não representam a situação de evapotranspiração potencial.

Quanto ao cálculo de $\mathrm{rC}_{\mathrm{Tc}}$, os períodos de tempo aqui estudados resultaram em valores negativos, incoerentes fisicamente, sendo que a rc é um fator de resistência da planta à difusão de vapor, não assumindo valores negativos. A resistência da cobertura vegetal deve ser um valor positivo, que representa a dificuldade que a planta oferece ao transporte de vapor d'água do interior de suas células para a atmosfera. A planta sempre oferece alguma resistência à evapotranspiração, ainda que esteja totalmente túrgida e com total disponibilidade de água, quando rc tende a 0 (Jackson, 1982). Não foi encontrado nenhum resultado semelhante na literatura consultada. Também 
não foi encontrada explicação para estes resultados, nem tampouco relação entre estes $e$ as diferentes variáveis climáticas medidas.

Outra forma de cálculo de $\mathrm{rC}_{\mathrm{Tc}_{\mathrm{C}}}$ foi a partir do uso de valores diários de $\mathrm{Rn}$ e $G$, e valores instantâneos de $T a, U R$ e $U$, nos horários de maior radiação (como é comum encontrar nos trabalhos que utilizam a temperatura da cobertura vegetal no cálculo de índices de estresse hídrico e na estimativa de ETo). Os valores de $\mathrm{rC}_{T c}$ calculados foram positivos, para a maioria dos horários dos dias analisados, o que pode ser observado na Figura 11, e na Tabela 5. Isso indica que o uso de valores médios de Tc em períodos maiores de tempo devem ser melhor estudados.
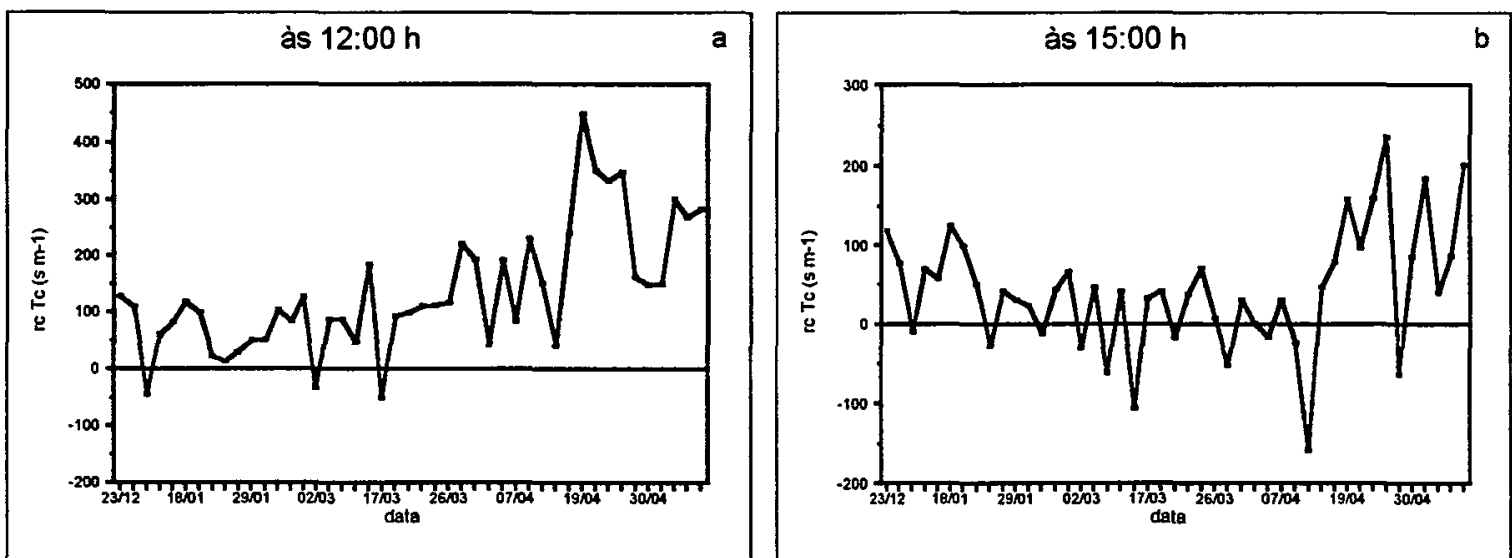

Figura 11. Resistência da cobertura vegetal ( $\mathrm{rc}_{\mathrm{res}}$ e $\mathrm{rC}_{\mathrm{Tc}_{\mathrm{c}}}$ ) calculada para os dias em análise, com dados médios diários de $R n$ e $G$, e dados instantâneos de temperatura da cobertura vegetal: a) às $12: 00 \mathrm{~h} ;$ b) às $15: 00 \mathrm{~h}$. 
Tabela 5. Valores da resistência da cobertuta vegetal calculados pelo uso da temperatura da cobertura vegetal obtida em horários de maior radiação, para os dias analisados.

\begin{tabular}{|c|c|c|c|c|c|}
\hline \multirow[t]{2}{*}{ Data } & \multicolumn{5}{|c|}{$r c_{T c}\left(s^{-1}\right)$} \\
\hline & $11 \mathrm{~h}$ & $12 \mathrm{~h}$ & $13 \mathrm{~h}$ & $14 \mathrm{~h}$ & $15 \mathrm{~h}$ \\
\hline $23 / 12$ & 46 & 128 & 161 & 116 & 118 \\
\hline $31 / 12$ & 66 & 110 & 119 & 286 & 77 \\
\hline $01 / 01$ & 49 & -45 & -18 & 6 & -10 \\
\hline $13 / 01$ & 32 & 60 & 87 & 152 & 70 \\
\hline $14 / 01$ & 75 & 82 & 95 & 103 & 57 \\
\hline $18 / 01$ & 71 & 118 & 135 & 98 & 124 \\
\hline $22 / 01$ & 64 & 98 & 77 & 137 & 99 \\
\hline $25 / 01$ & -40 & 22 & 61 & 93 & 51 \\
\hline $26 / 01$ & 7 & 13 & 44 & 4 & -28 \\
\hline $28 / 01$ & 20 & 29 & 46 & 48 & 42 \\
\hline $29 / 01$ & 31 & 49 & 48 & 33 & 30 \\
\hline $31 / 01$ & 65 & 51 & 14 & 4 & 23 \\
\hline $05 / 02$ & -39 & 103 & -44 & -25 & -12 \\
\hline $22 / 02$ & 46 & 83 & 94 & 96 & 44 \\
\hline $23 / 02$ & -7 & 127 & 17 & 67 & 66 \\
\hline $02 / 03$ & -3 & -34 & 3 & 143 & -30 \\
\hline $10 / 03$ & 74 & 87 & 42 & 20 & 46 \\
\hline $11 / 03$ & 89 & 86 & -36 & -59 & -62 \\
\hline $13 / 03$ & -90 & 48 & 106 & 63 & 40 \\
\hline $14 / 03$ & 102 & 185 & 137 & -112 & -106 \\
\hline $17 / 03$ & 161 & -50 & -65 & -77 & 32 \\
\hline $21 / 03$ & 50 & 93 & 47 & 51 & 41 \\
\hline $22 / 03$ & 52 & 98 & -35 & 9 & -17 \\
\hline $24 / 03$ & 52 & 111 & 101 & 88 & 37 \\
\hline $25 / 03$ & 90 & 112 & 116 & 103 & 71 \\
\hline $26 / 03$ & 65 & 116 & 122 & 95 & 7 \\
\hline $28 / 03$ & 91 & 221 & 69 & -36 & -52 \\
\hline $03 / 04$ & 107 & 194 & 128 & 104 & 30 \\
\hline $04 / 04$ & -98 & 42 & 147 & 79 & 1 \\
\hline $06 / 04$ & 81 & 192 & 165 & 119 & -16 \\
\hline $07 / 04$ & 22 & 83 & 56 & 91 & 31 \\
\hline $10 / 04$ & 141 & 230 & 192 & 169 & -24 \\
\hline $13 / 04$ & 172 & 151 & 253 & 0 & -158 \\
\hline $15 / 04$ & 211 & 40 & 64 & 108 & 47 \\
\hline $18 / 04$ & 586 & 240 & 315 & 215 & 79 \\
\hline $19 / 04$ & 333 & 448 & 395 & 268 & 158 \\
\hline $20 / 04$ & 293 & 351 & 342 & 170 & 96 \\
\hline $26 / 04$ & 163 & 334 & 191 & 114 & 159 \\
\hline $27 / 04$ & 256 & 349 & 286 & 99 & 236 \\
\hline $29 / 04$ & 133 & 162 & 252 & 70 & -64 \\
\hline $30 / 04$ & 197 & 149 & 187 & 280 & 85 \\
\hline $02 / 05$ & 369 & 151 & 116 & 201 & 185 \\
\hline $04 / 05$ & 287 & 301 & 247 & 31 & 40 \\
\hline $17 / 05$ & 254. & 268 & 230 & 207 & 87 \\
\hline $24 / 05$ & 231 & 284 & 709 & 423 & 201 \\
\hline
\end{tabular}




\subsubsection{Escolha do valor de $\mathrm{rc}_{\mathrm{Tc}}$ a ser utilizado na estimativa da evapotranspiração}

Os valores de $\mathrm{rC}_{\mathrm{Tc}}$ calculados para os horários de maior radiação foram comparados com os valores de $\mathrm{rc}_{\mathrm{res}}$ de $24 \mathrm{~h}$ para a escolha do horário de cálculo a ser utilizado na estimativa da evapotranspiração. Os resultados das regressões lineares feitas, tomando rc $_{\text {res }}$ como padrão, constam da Tabela 6. Os valores negativos de $\mathrm{rc}_{\mathrm{Tc}}$ encontrados foram descartados no cálculo das regressōes.

Tabela 6. Parâmetros das equações de regressão entre $\mathrm{rc}_{\mathrm{res}}$ e $\mathrm{rc}_{\mathrm{Tc}}$ calculados nos horários de maior radiação $(y=a+b x)$.

\begin{tabular}{ccrc}
\hline horário & $\mathbf{a}$ & \multicolumn{1}{c}{$\mathrm{b}$} & $\mathrm{r}^{2}$ \\
\hline $11: 00 \mathrm{~h}$ & $-0,061$ & 143,323 & 0,001 \\
$12: 00 \mathrm{~h}$ & 0,722 & 43,430 & 0,096 \\
$13: 00 \mathrm{~h}$ & 0,895 & 19,722 & 0,091 \\
$14: 00 \mathrm{~h}$ & 0,151 & 136,486 & 0,006 \\
$15: 00 \mathrm{~h}$ & 0,554 & $-0,721$ & 0,169 \\
\hline
\end{tabular}

Pode-se observar que os coeficientes de correlação encontrados foram muito baixos, nunca superiores a $17 \%$, indicando a grande dispersão dos pontos em torno da reta de regressão. O cálculo para o horário das $15: 00 \mathrm{~h}$ foi o que apresentou o maior valor de $r^{2}$, seguido do horário das 12:00 h. Desta forma, os valores de $\mathrm{rc}_{\mathrm{Tc}}$ calculados nestes horários foram utilizados para a estimativa da evapotranspiração.

\subsection{Estimativa da evapotranspiração de referência}

A evapotranspiração de referência foi estimada de três formas, e estas comparadas aos valores medidos ( $E T_{\text {lis }}$ ). A estimativa de $E T o$ pelo uso da temperatura da cobertura vegetal foi feita utilizando os valores de $\mathrm{rC}_{\mathrm{Tc}}$ calculados com Tc dos horários das 12:00 h $\left(\mathrm{ET}_{\mathrm{Tc12}_{2}}\right)$ e das 15:00 h $\left(\mathrm{ET}_{\mathrm{Tc15}}\right)$, e valores de $\mathrm{Rn}$ e $\mathrm{G}$ do período de $24 \mathrm{~h}$. Os dias que apresentaram valores 
negativos nessa situação foram descartados. A outra forma de estimar ETo foi a partir da parametrização proposta pela $\mathrm{FAO/91}\left(\mathrm{ET}_{\mathrm{FAO}}\right)$.

Os valores encontrados de evapotranspiração estimada e medida podem ser observados na Tabela 7. Na Figura 12 está a representação gráfica da variação dos valores nos dias analisados. A Figura 13 apresenta a relação entre os dados medidos e estimados, onde pode-se tomar como referencial a linha 1:1. Como pode ser observado, os valores diários de ETo estimada pelos três métodos superestimaram a ETo medida na maioria dos dias. Tomando a evapotranspiração medida como padrão, foram feitas as regressões lineares, e calculados os outros parâmetros de comparação, que constam da Tabela 8.

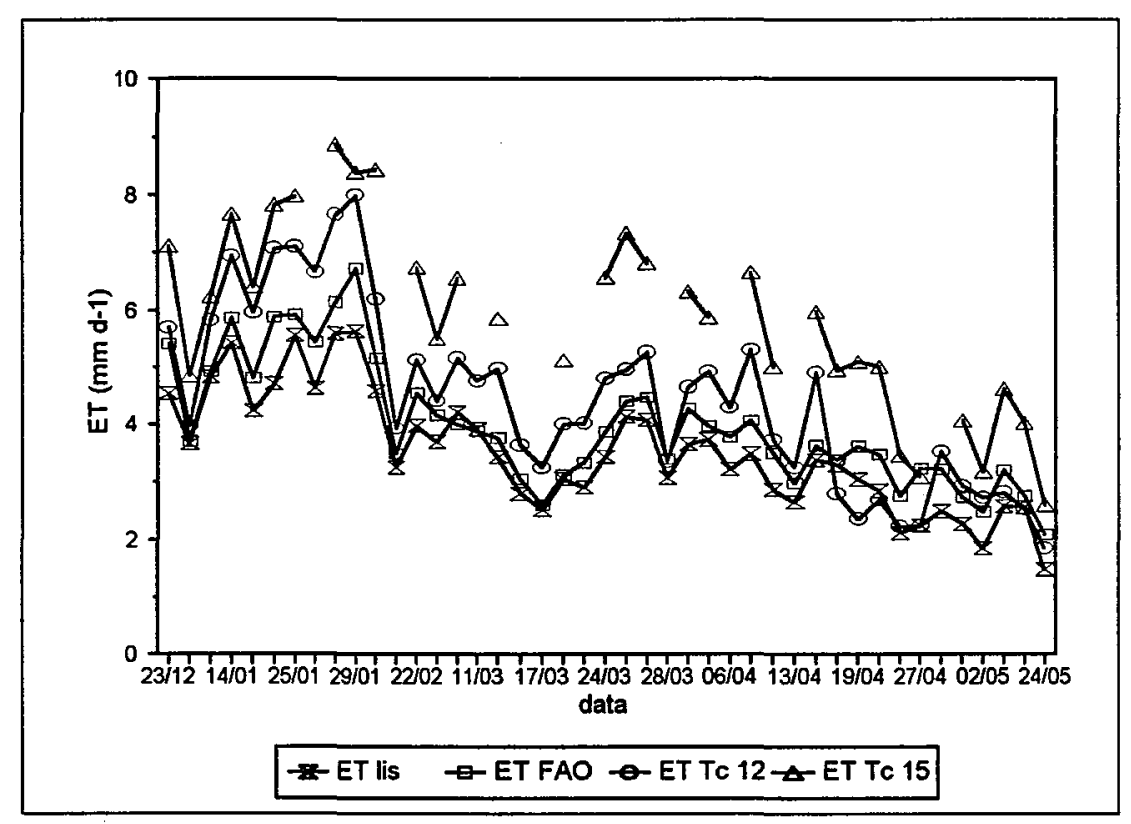

Figura 12. Evapotranspiração medida ( $E T_{\text {lis }}$ ), e estimadas pela parametrização proposta pela $F A O / 91$ ( $E T_{F A O}$ ) e pelo uso da temperatura da cobertura vegetal ( $E T_{T_{c 12}}$ e $E T_{T c 15}$ ), para os dias em análise. 
Tabela 7. Valores medidos de evapotranspiração ( $E T_{\text {lis }}$, estimados pela parametrização proposta pela $\mathrm{FAO} / 91$ ( $\mathrm{ET}_{\mathrm{FAO}}$ ), e pelo uso da temperatura da cobertura vegetal ( $E T_{\text {Tc12 }}$ e $\left.E T_{\text {Tc15 }}\right)$.

\begin{tabular}{|c|c|c|c|c|}
\hline Data & $\begin{array}{c}E T_{\text {lis }} \\
\left(\mathrm{mm} \mathrm{d}^{-1}\right)\end{array}$ & $\begin{array}{c}E T_{F A O} \\
\left(m d^{-1}\right)\end{array}$ & $\begin{array}{c}E T_{\mathrm{Tc12}} \\
\left(\mathrm{mm} \mathrm{d}^{-1}\right)\end{array}$ & $\begin{array}{c}E T_{\mathrm{Tc} 15} \\
\left(\mathrm{~mm} \mathrm{~d}^{-1}\right)\end{array}$ \\
\hline $23 / 12$ & 4.54 & 5.42 & 5.70 & 7.11 \\
\hline $31 / 12$ & 3.66 & 3.71 & 3.96 & 4.85 \\
\hline $13 / 01$ & 4.84 & 4.94 & 5.83 & 6.24 \\
\hline $14 / 01$ & 5.43 & 5.86 & 6.94 & 7.67 \\
\hline $18 / 01$ & 4.23 & 4.81 & 5.96 & 6.40 \\
\hline $22 / 01$ & 4.71 & 5.89 & 7.07 & 7.82 \\
\hline $25 / 01$ & 5.56 & 5.93 & 7.11 & 7.98 \\
\hline $26 / 01$ & 4.63 & 5.44 & 6.66 & \\
\hline $28 / 01$ & 5.60 & 6.14 & 7.65 & 8.88 \\
\hline $29 / 01$ & 5.63 & 6.73 & 7.99 & 8.38 \\
\hline $31 / 01$ & 4.59 & 5.17 & 6.20 & 8.43 \\
\hline $05 / 02$ & 3.25 & 3.49 & 3.93 & \\
\hline $22 / 02$ & 3.97 & 4.55 & 5.12 & 6.74 \\
\hline $23 / 02$ & 3.69 & 4.16 & 4.41 & 5.50 \\
\hline $10 / 03$ & 4.21 & 4.00 & 5.16 & 6.56 \\
\hline $11 / 03$ & 3.92 & 3.88 & 4.76 & \\
\hline $13 / 03$ & 3.43 & 3.77 & 4.97 & 5.86 \\
\hline $14 / 03$ & 2.79 & 3.05 & 3.64 & \\
\hline $17 / 03$ & 2.51 & 2.59 & 3.25 & \\
\hline $21 / 03$ & 3.05 & 3.12 & 4.00 & 5.13 \\
\hline $22 / 03$ & 2.90 & 3.33 & 4.02 & \\
\hline $24 / 03$ & 3.43 & 3.86 & 4.81 & 6.57 \\
\hline $25 / 03$ & 4.13 & 4.40 & 4.96 & 7.34 \\
\hline $26 / 03$ & 4.07 & 4.47 & 5.27 & 6.82 \\
\hline $28 / 03$ & 3.06 & 3.40 & 3.35 & \\
\hline $03 / 04$ & 3.65 & 4.27 & 4.65 & 6.33 \\
\hline $04 / 04$ & 3.73 & 3.97 & 4.92 & 5.87 \\
\hline $06 / 04$ & 3.21 & 3.77 & 4.29 & \\
\hline $07 / 04$ & 3.48 & 4.06 & 5.31 & 6.65 \\
\hline $10 / 04$ & 2.86 & 3.50 & 3.72 & 4.99 \\
\hline $13 / 04$ & 2.64 & 2.98 & 3.25 & \\
\hline $15 / 04$ & 3.38 & 3.63 & 4.91 & 5.98 \\
\hline $18 / 04$ & 3.29 & 3.39 & 2.78 & 4.95 \\
\hline $19 / 04$ & 3.04 & 3.61 & 2.35 & 5.10 \\
\hline $20 / 04$ & 2.84 & 3.47 & 2.68 & 5.01 \\
\hline $26 / 04$ & 2.11 & 2.76 & 2.22 & 3.44 \\
\hline $27 / 04$ & 2.24 & 3.23 & 2.24 & 3.08 \\
\hline $29 / 04$ & 2.49 & 3.21 & 3.52 & \\
\hline $30 / 04$ & 2.27 & 2.72 & 2.92 & 4.06 \\
\hline $02 / 05$ & 1.84 & 2.47 & 2.72 & 3.17 \\
\hline $04 / 05$ & 2.57 & 3.20 & 2.81 & 4.62 \\
\hline $17 / 05$ & 2.56 & 2.76 & 2.52 & 4.02 \\
\hline $24 / 05$ & 1.47 & 2.08 & 1.85 & 2.59 \\
\hline
\end{tabular}




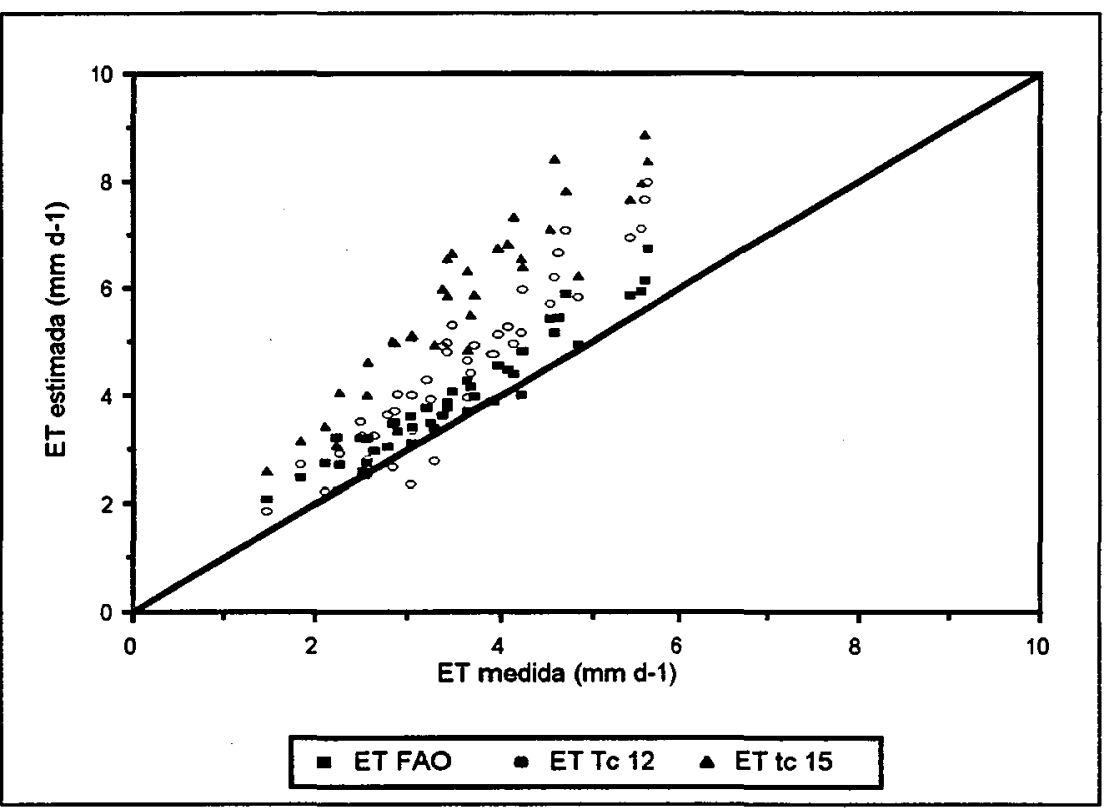

Figura 13. Comparação entre os valores medidos da evapotranspiração (linha 1:1), e os valores estimados pela parametrização proposta pela $F A O / 91$ ( $\left.E T_{F A O}\right)$, e pelo uso da temperatura da cobertura vegetal ( $E T_{T_{c 12}}$ e $\left.E T_{T_{c 15}}\right)$.

Tabela 8. Parâmetros para comparação entre os métodos de estimativa da evapotranspiração, tomando como padrão a evapotranspiração medida pelo lisimetro $(y=a x+b)$ : indice $d$ (Id). erro sistemático (Es, em $\mathrm{mm} \mathrm{d}^{-1}$ ), erro não sistemático $\left(E u, e m \mathrm{~mm} \mathrm{~d}^{-1}\right.$ ) e média do erro absoluto (MAE, em $\left.\mathrm{mm} \mathrm{d}^{-1}\right)$.

\begin{tabular}{|c|c|c|c|c|c|c|c|}
\hline modelo & a & b & $r^{2}$ & Id & Es & $\mathrm{Eu}$ & MAE \\
\hline$E T_{F A O}$ & 1,012 & 0,426 & 0,928 & 0,953 & 0,475 & 0,274 & 0,479 \\
\hline $\mathrm{ET}_{\mathrm{Tc12}}$ & 1,454 & $-0,655$ & 0,889 & 0,821 & 1,136 & 0,341 & 1,022 \\
\hline $\mathrm{ET}_{\text {Tc15 }}$ & 1,418 & 0,693 & 0,874 & 0,637 & 2,289 & 0,386 & 2,200 \\
\hline
\end{tabular}

Os coeficientes de correlação das equações de regressão $\left(r^{2}\right)$ das três formas de estimativa de ETo utilizados foram altos, indicando pouca dispersão em torno da reta de regressão. Os outros parâmetros de comparação indicam que a concordância entre os valores medidos e estimados é considerada excelente para o modelo parametrizado pela $\mathrm{FAO} / 91$ ( $\mathrm{Id}=0,953$ ), ótima para o modelo que utiliza a temperatura da cobertura vegetal no horário das 12:00 h (Id = 0,821), e boa para o mesmo modelo, no horário das 15:00 h. A melhor performance do modelo da FAO/91 pode ser também observada a partir dos 
valores dos erros sistemático e não sistemático, que são menores. Os valores dos erros sistemático e não sistemático indicam que os modelos superestimam a evapotranspiração ocorrida.

A partir desses resultados, é possivel afirmar que o modelo PenmanMonteith parametrizado pela FAO/91 pode ser utilizado na estimativa da evapotranspiração de referência, nas condições deste estudo, confirmando os resultados encontrados por Peres (1994), para a estimativa de ETo.

A estimativa da evapotranspiração pelo uso da termometria ao infravermelho levou a resultados que tiveram performances inferiores, superestimando a evapotranspiração medida, em média, em 27 e $67 \%$ para os horários de 12:00 h e 15:00 h respectivamente. Porém a performance geral do método, às $12: 00 \mathrm{~h}$, foi boa, e pode ser utilizada na estimativa da evapotranspiração de referência. 


\section{CONCLUSÕES}

A partir dos resultados obtidos neste trabalho, conclui-se que o uso da temperatura da cobertura vegetal na estimativa do parâmetro de resistência da cobertura vegetal utilizando valores médios de temperatura em $30 \mathrm{~min}, 24 \mathrm{~h}$ ou em períodos de luz não conduz a resultados coerentes, sendo necessário, portanto, maiores estudos para o entendimento da limitação de sua aplicação. Quando utilizados valores médios diários de radiação líquida e da densidade de fluxo de calor no solo, e a temperatura da cobertura vegetal, temperatura do ar, umidade relativa e velocidade do vento de períodos de $30 \mathrm{~min}$, nos horários do dia de maior radiação, foi possível encontrar valores de rc coerentes.

Os valores de rc calculados como resíduo foram superiores ao valor padronizado proposto pela FAO/91.

A estimativa da evapotranspiração de referência feita com valores de $\mathrm{rc}_{\mathrm{Tc}}$ calculados a partir de informaçōes do horário de $12: 00 \mathrm{~h}$, e pela parametrização proposta pela FAO/91 superestimaram a evapotranspiração medida. Quanto à performance geral dos modelos de estimativa, a proposta da FAO/91 e o uso da temperatura da cobertura vegetal apresentaram excelente e ótima concordâncias com os valores medidos, respectivamente, indicando que sua utilização é adequada na estimativa da evapotranspiração de referência. 


\section{REFERÊNCIAS BIBLIOGRÁFICAS}

ALLEN, R. G. A Penman for all seasons. Journal of Irrigation and Drainage Engineering, v.112, n.4, p.348-69, Nov. 1986.

ALLEN, R. G.; JENSEN, M. E.; WRIGHT, J. L.; BURMAN, R. D. Operational estimates of reference evapotranspiration. Agronomy Journal, V.81, n.4, p.650-62, July/Aug. 1989.

ALLEN, R. G.; PRUEGER, J. R.; HILL, R. W. Evapotranspiration from isolated stands of hydrophytes: cattail and bulrush. Transactions of the ASAE, v.35, n.4, p.1191-8, July/Aug. 1992.

AMORIM NETO, M. S.; GOMIDE, R. L.; SEDIYAMA, G. C.; BRITO, R. A. L.; MAGALHÃES, P. C.; BORGES, J. C. F. Aplicação da termometria a infravermelho para detecção de status hídrico do feijoeiro irrigado. In: CONGRESSO BRASILEIRO DE AGROMETEOROLOGIA, 11., Campina Grande, 1995. Anais. Campina Grande: Sociedade Brasileira de Agrometeorologia, 1995a. p.139-41.

AMORIM NETO, M. S.; GOMIDE, R. L.; SEDIYAMA, G. C.; BRITO, R. A. L.; MAGALHÃES, P. C.; BORGES, J. C. F. Índice de estresse hídrico da cultura do feijoeiro irrigado. In: CONGRESSO BRASILEIRO DE AGROMETEOROLOGIA, 11., Campina Grande, 1995. Anais. Campina Grande: Sociedade Brasileira de Agrometeorologia, 1995b. p.137-8.

ASTON, A. R.; VAN BAVEL, C. H. M. Soil surface water depletion and leaf temperature. Agronomy Journal, v.64, n.3, p.368-73, May/June 1972.

BAILEY, W. G.; DAVIES, J. A. Bulk stomatal resistance control on evaporation. Boundary Layer Meteorology, v.20, n.4, p.401-15, June 1981. 
BEN-ASHER, J. PHENE, C. J.; KINARTI, A. Canopy temperature to assess daily evapotranspiration and management of high frequency drip irrigation systems. Agricultural Water Management, v.22, p.379-90, 1992.

BEN-ASHER, J.; MEEK, D. W.; HUTMACHER, R. B.; PHENE, C. J. Computational approach to assess actual transpiration from aerodynamic and canopy resistance. Agronomy Journal, v.81, n.5, p.776-82, Sep./Oct. 1989.

BLAD, B. L.; ROSENBERG, N. J. Measurement of crop temperature by leaf thermocouple, infrared thermometry and remotely sensed thermal imagery. Agronomy Journal, v.68, n.4, p.635-41, July/Aug. 1976.

BOISSARD, P.; GUYOT, G.; JACKSON, R. D. Factors affecting the radiative temperature of a vegetative canopy. In: EASTER SCHOOL IN AGRICULTURAL SCIENCE, 48., Nottingham, 1989. Applications of remote sensing in agriculture. Cambridge: Cambridge University Press, 1990. p.45-72.

CHOUDHURY, B. J.; REGINATO, R. J.; IDSO, S. B. An analysis of infrared temperature observations over wheat and calculation of latent heat flux. Agricultural and Forest Meteorology, v.37, n.1, p.75-88, 1986.

CLAWSON, K. L.; BLAD, B. L. Infrared thermometry for scheduling irrigation of corn. Agronomy Journal, v.74, n.2, p.311-6, Mar.IApr. 1982.

CLAWSON, K. L.; JACKSON, R. D.; PINTER JR., P. J. Evaluating plant water stress with canopy temperature differences. Agronomy Journal, v.81, n.6, p.858-63, Nov./Dez. 1989.

COSTA, A. B. G.; STEINMETZ, S. Uso da termometria ao infravermelho para caracterizar a necessidade de irrigação do feijoeiro (Phaseolus vulgaris, L.). I. Desempenho do indice baseado na diferença de temperatura com uma parcela de referência. In: CONGRESSO BRASILEIRO DE 
AGROMETEOROLOGIA, 11., Campina Grande, 1995. Anais. Campina Grande: Sociedade Brasileira de Agrometeorologia, 1995. p.108-9.

DOORENBOS, J.; PRUITT, W. O. Guidelines for predicting crop water requirements. Rome: FAO, 1975. 179p. (FAO Irrigation and Drainage Paper, 24).

EHRLER, W. L. Cotton leaf temperatures as related to soil water depletion and meteorological factors. Agronomy Journal, v.65, n.3, p.404-9, May/June 1973.

FERREIRA, J. A. S.; SILVA, B. B.; SOBRINHO, J. E.; MOURA NETO, E. L.; MAIA NETO, J. M. Determinação da resistência estomática do meloeiro através do método de O'Toole \& Real. In: CONGRESSO BRASILEIRO DE AGROMETEOROLOGIA, 11., Campina Grande, 1995. Anais. Campina Grande: Sociedade Brasileira de Agrometeorologia, 1995. p.99-101

FOLEGATTI, M. V. Avaliação do desempenho de um "scheduler" na detecção do estresse hídrico em cultura do feijoeiro (Phaseolus vulgaris, L.) irrigada com diferentes lâminas. Piracicaba, 1988. 188p. Tese (Doutorado) - Escola Superior de Agricultura "Luiz de Queiroz", Universidade de São Paulo.

FOLEGATTI, M. V. Utilização da temperatura radiante do dossel vegetativo na caracterização do estresse hídrico da cultura do feijoeiro irrigado com diferentes lâminas de água In: CONGRESSO BRASILEIRO DE AGROMETEOROLOGIA, 11., Campina Grande, 1995. Anais. Campina Grande: Sociedade Brasileira de Agrometeorologia, 1995. p. 74-6.

FUCHS, M.; TANNER, C. B. Infrared Thermometry of vegetation. Agronomy Journal, v.58, n.6, p. 597-601, nov/dez 1966.

GATES, D. M. Characteristics of soil and vegetated sufaces to reflected and emitted radiation. In: INTERNATIONAL SYMPOSIUM OF REMOTE SENSING ENVIRONMENT, 3. Proceedings. 1964, p. 573-600. 
GEISER, K. M.; SLACK, D. C.; ALLRED, E. R.; STANGE, K. W. Irrigation scheduling using crop canopy-air temperature difference. Transactions of the ASAE, v.25, n.3, p.689-94, May/June 1982.

GRANT, D. R. Comparison of evaporation from barley with Penman estimates. Agricultural. Meteorology, v.15, p.49-60, 1975.

HATFIELD, J. L. The utilization of thermal infrared radiation measurements from grain sorghum crops as a method of assessing their irrigation requirements. Irrigation Science, v.3, n.4, p.259-68, Jan. 1983.

HATFIELD, J. L. Wheat canopy resistance determined by energy balance techniques. Agronomy Journal, v.77, n.2, p.279-83, Mar./Apr. 1985.

HATFIELD, J. L. Research priorities in ET: evolving methods. Transactions of the ASAE, v.31, n.2, p.491-95, Mar./Apr. 1988.

HATFIELD, J. L.; PERRIER, A.; JACKSON, R. D. Estimation of evapotranspiration at one time-of-day using remotely sensed surface temperatures. Agricultural Water Management, v.6, p.341-50, 1983.

HATFIELD, J. L.; WANJURA, D. F.; BARKER, G. L. Canopy temperature response to water stress under partial canopy. Transactions of the ASAE, v.28, n.5, p.1607-11, Sep./Oct. 1985.

HEERMANN, D. F.; MARTIN, D. L.; JACKSON, R. D.; STEGMAN, E. C. Irrigation scheduling controls and techniques. In: STEWART, B. A; NIELSEN, D. R., ed. Irrigation of agricultural crops. Madison: ASAICSSAISSSA, 1990. p.509-35.

HEILMAN, J. L.; HEILMAN, W. E.; MOORE, D. G. Remote sensing of canopy temperature at incomplete cover. Agronomy Journal, v.73, n.3, p.4036, May/June 1981.

IDSO, S. B.; JACKSON, R. D.; REGINATO, R. J. Remote sensing of crop yields. Science, v.196, p.19-25, Apr. 1977.

IDSO, S. B.; PINTER JR., P. J.; REGINATO, R. J. Non-water-stressed baselines: the importance of site selection for air temperature and air 
vapour pressure deficit measurements. Agricultural and Forest Meteorology, v.53, n.1/2, p.73-80; Nov. 1990.

IDSO, S. B.; REGINATO, R. J.; JACKSON, R. D.; PINTER JR., P. J. Foliage and air temperature: evidence for a dynamic "equivalent point". Agricultural Meteorology, v. 24, n.3, p.223-6, July 1981b.

IDSO, S. B.; REGINATO, R. J.; REICOSKY, D. C.; HATFIELD, J. L. Determining soil-induced plant water potential depressions in alfafa by means of infrared thermometry. Agronomy Journal, v.73, n.5, p.826-30, Set./Oct. 1981c.

IDSO, S. B.; JACKSON, R. D.; PINTER JR., P. J.; REGINATO, R. J.; HATFIELD, J. L. Normalizing the stresse-degree-day parameter for environmental variability. Agricultural Meteorology, v.24, n.1, p.45-55, May. 1981a.

JACKSON, R. D. Canopy temperature and crop water stress. In: HILLEL, D., ed. Advances in Irrigation. New York: Academic Press, 1982. v.1, p.43-85.

JACKSON, R. D.; REGINATO, R. J.; IDSO, S. B. Wheat canopy temperature: a practical tool for evaluating water requirements. Water Resources Research, v.13, n.3, p.651-6, June 1977.

JACKSON, R. D.; IDSO, S. B.; REGINATO, R. J.; PINTER Jr, P. J. Canopy temperature as a crop water stress indicator. Water Resources Research, v.17, n.4, p.1133-8, Aug. 1981.

LINACRE, E. T. A note on a feature of leaf and air temperature. Agricultural Meteorology, v.1, n.1, p.66-72, Mar. 1964.

LINACRE, E. T. Further notes on a feature of leaf and air temperature. Theoretical and Applied Climatology, v.15. p.422-6, 1967.

LORENZ, D. Temperature measurements of natural surfaces using infrared radiometers. Appl. Opt., v.7, p.1705-10, 1968. 
LUCHIARI Jr. A.; RIHA, S. J. Bulk surface resistance and its effect on evapotranspiration rates in irrigated wheat. Agronomy Journal, v.83, n.5, p.888-95, Sep./Nov. 1991.

MONTEITH, J. L. Evaporation and environment. Symposium of the Society for Experimental Biology. London, v.19, p.205-34, 1965.

MONTEITH, J. L. Principles of environmental physics. New York: American Elsevier Pub., Inc., 1973. 241p.

MONTEITH, J. L. The development and extension of Penman's evaporation formula. In: HILLEL, D., ed. Applications of soil physics. New York: Academic Press, 1980. cap. 10, p. 247-53.

MONTEITH, J. L. Evaporation from land surfaces: progress in analysis and prediction since 1948. In: NATIONAL CONFERENCE ON ADVANCES IN EVAPOTRANSPIRATION, Chicago, 1985. Proceedings. St. Joseph: ASAE, 1985. p.4-12.

MONTEITH, J. L.; SZEICZ, G. Radiative temperature in the heat balance of natural surfaces. Quartely Journal of Royal Meteorological Society, v.88, n.378, p.496-507, Oct. 1962.

O'TOOLE, J. C.; REAL, J. G. Estimation of aerodynamic and crop resistances from canopy temperature. Agronomy Journal, v.78, n.2, p.305-10, Mar.IApr. 1986.

OMETTO, J. C. Registros e estimativas de parâmetros meteorológicos da região de Piracicaba, SP. Piracicaba: FEALQ, 1989. 76p.

OKE, T. R. Boundary layer climates. 2.ed. London: Routledge, 1992. 435p.

PAZZETTI, G. A.; OLIVA, M. A.; LOPES, N. F. Aplicação da termometria ao infravermelho à irrigação do feijoeiro: crescimento e produtividade. Pesquisa Agropecuária Brasileira, v.28, n.12, p.1371-7, Dec. 1993.

PENMAN, H. L. Natural evaporation from open water, bare soil and grass. Proceedings of the Royal Society, v.198, p.116-40, 1948. 
PENNINGTON, D. A.; HEATHERLY, L. Effects of changing solar radiation on canopy-air temperatures of cotton and soybean. Agricultural and Forest Meteorology, v.46, n.1/2, p.1-14, Apr. 1989.

PERES, J. G. Avaliação do modelo de Penman-Monteith, padrão FAO, para estimar a evapotranspiração de referência nas condições climáticas do estado de São Paulo. Piracicaba, 1994. 115 p. Tese (Doutorado) Escola Superior de Agricultura "Luiz de Queiroz", Universidade de São Paulo.

PERRIER, A. Mesure des températures de surface par radiométrie infrarouge. In: HALLAIRE, M.; PERRIN DE BRICHAMBAUT, C.; GOILOOT, C. ed. Techniques d'étude des facteurs physiques de la biosphère. Paris: Institut National de la Recherche Agronomique, 1970. p.169-178.

RUSSEL, G. Crop evaporation, surface resistance and soil water status. Agricultural Meteorology, v.21, n.3/4, p.213-26, Dec. 1980.

SHARMA, M. L. Estimating evapotranspiration. In: HILLEL, D., ed. Advances in irrigation. New York: Academic Press, 1983. v.3, p.213-81.

SMITH, M., ed. Report on the expert consultation on procedures for revision of FAO guidelines for prediction of crop water requirements. Rome: $F A O, 1991$. 45p.

STEINMETZ, S.; COSTA, A. B. G. Uso da termometria ao infravermelho para caracterizar a necessidade de irrigação do feijoeiro (Phaseolus vulgaris, L.). I. Desempenho do índice baseado na variabilidade da temperatura do dossel vegetativo. In: CONGRESSO BRASILEIRO DE AGROMETEOROLOGIA, 11., Campina Grande, 1995. Anais. Campina Grande: Sociedade Brasileira de Agrometeorologia, 1995. p.504-5.

STOCKLE, C. O.; DUGAS, W. A. Evaluating canopy temperature-based indices for irrigation scheduling. Irrigation Science, v.13, n.1, p.31-7, Mar. 1992. 
SUMAYAO, C. R.; KANEMASU, E. T.; BRAKKE, T. W. Using leaf temperature to assess evapotranspiration and advection. Agricultural Meteorology, v.22, n.2, p.153-66, Nov. 1980.

WIEGAND, C. L.; NANKEN, L. N. Influences of plant moisture stress, solar radiation, and air temperature on cotton leaf temperature. Agronomy Journal, v.58, n.6, p.582-6, Nov./Dec. 1966.

WILLMOTT, C. J. On the validation of models. Physical Geography, v.2, p.184-94, 1981. 


\section{APÊNDICES}




\section{Apêndice l. Calibração do lisímetro de pesagem}

No dia 04/02/96 foi feita a calibração do lisimetro de pesagem em campo. O horário escolhido para a calibração foi antes do amanhecer, quando a variação de peso por evapotranspiração ou orvalho foi considerada desprezível.

Em laboratório foram confeccionados pesos conhecidos, de 500 e $1000 \mathrm{~g} \pm 0,1 \mathrm{~g}$, em pacotes impermeáveis cheios de pedrisco seco ao ar. No campo, primeiramente, os pesos foram sendo acrescentados ao lisimetro, variando o peso total de 0,5 a $11,5 \mathrm{~kg}$, de $1 \mathrm{em} 1 \mathrm{~kg}$. A seguir os pesos foram retirados, de $1 \mathrm{em} 1 \mathrm{~kg}$. $O$ intervalo de tempo entre cada peso acrescentado ou retirado foi de $3 \mathrm{~min}$. A média da massa entre o início e o final dos intervalos de tempo foi comparado com a massa real presente sobre o lisímetro.

A Figura 14 apresenta a variação da massa e da temperatura na altura das células de carga durante o período de calibração.

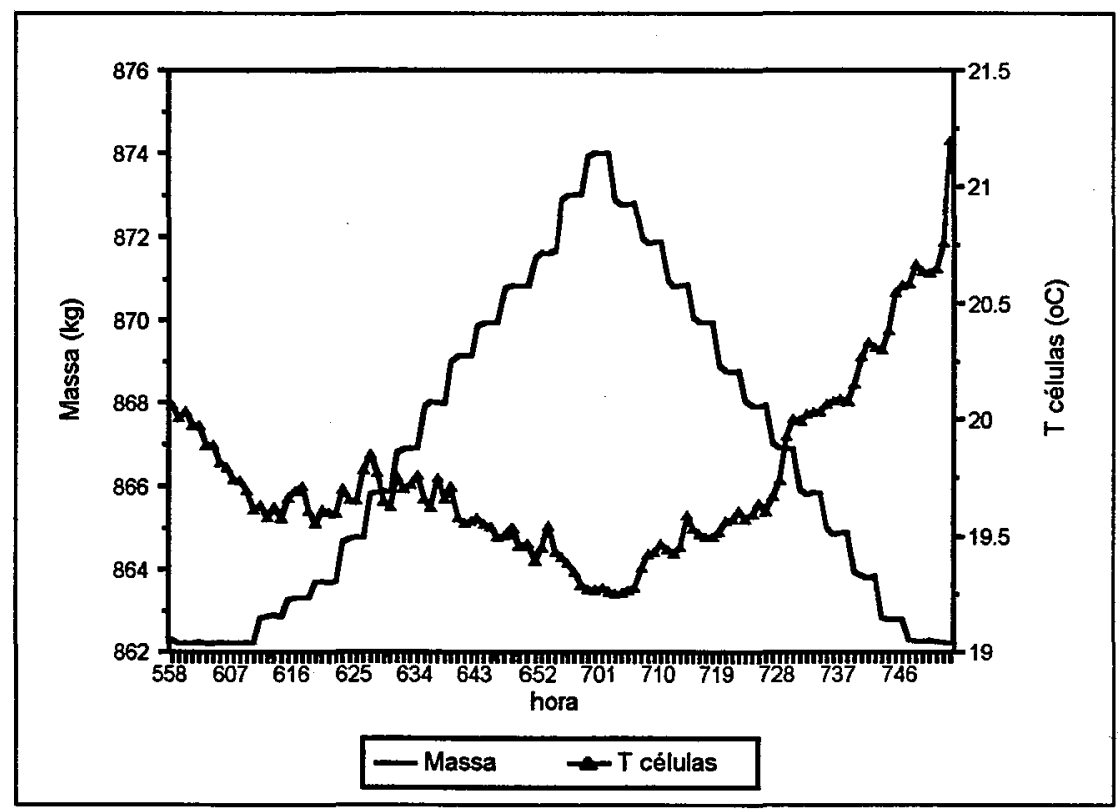

Figura 14. Variação da massa do lisimetro e da temperatura na altura das células de carga durante o período de calibração. 
A Tabela 9 apresenta os valores de massa medida e massa real durante os dois procedimentos, acréscimo e decréscimo de massa. A partir dos dados de massa medida e massa padrão acrescentada ou retirada, foram feitas regressões lineares e o cálculo do índice d para comparar os valores reais ao valores observados. Na Figura 15 pode-se observar a representação gráfica da relação entre as massas reais e observadas nos dois procedimentos, comparados com a reta $1: 1$, e a Tabela 10 apresenta os valores dos parâmetros das retas de regressão e os valores do índice d.

Tabela 9. Massa medida e massa real durante o procedimentos de acréscimo e decréscimo de peso.

\begin{tabular}{cccc}
\hline \multicolumn{2}{c}{ acréscimo de peso } & \multicolumn{2}{c}{ decréscimo de peso } \\
\hline $\begin{array}{c}\text { P medido } \\
(\mathrm{kg})\end{array}$ & $\begin{array}{c}\text { P padrão } \\
(\mathrm{kg})\end{array}$ & $\begin{array}{c}\text { P medido } \\
(\mathrm{kg})\end{array}$ & $\begin{array}{c}\text { P padrão } \\
(\mathrm{kg})\end{array}$ \\
\hline 0.646 & 0.5 & 11.763 & 11.5 \\
1.480 & 1.5 & 10.596 & 10.5 \\
2.513 & 2.5 & 9.680 & 9.5 \\
3.646 & 3.5 & 8.656 & 8.5 \\
4.646 & 4.5 & 7.776 & 7.5 \\
5.767 & 5.5 & 6.580 & 6.5 \\
6.870 & 6.5 & 5.740 & 5.5 \\
7.696 & 7.5 & 4.726 & 4.5 \\
8.606 & 8.5 & 3.650 & 3.5 \\
9.376 & 9.5 & 2.696 & 2.5 \\
10.746 & 10.5 & 1.636 & 1.5 \\
11.763 & 11.5 & 0.590 & 0.5 \\
\hline
\end{tabular}

Tabela 10. Parâmetros das equações de regressão linear $(y=a x+b)$ entre pesos reais e medidos, e indice $\mathrm{d}$ (Id).

\begin{tabular}{lcccc} 
& $\mathrm{a}$ & $\mathrm{b}$ & $\mathrm{r}^{2}$ & Id \\
\cline { 2 - 5 } & 1,0097 & 0,0881 & 0,9957 & 1,00 \\
acréscimo de peso & 1,0051 & 0,1437 & 0,9997 & 1,00 \\
\hline
\end{tabular}




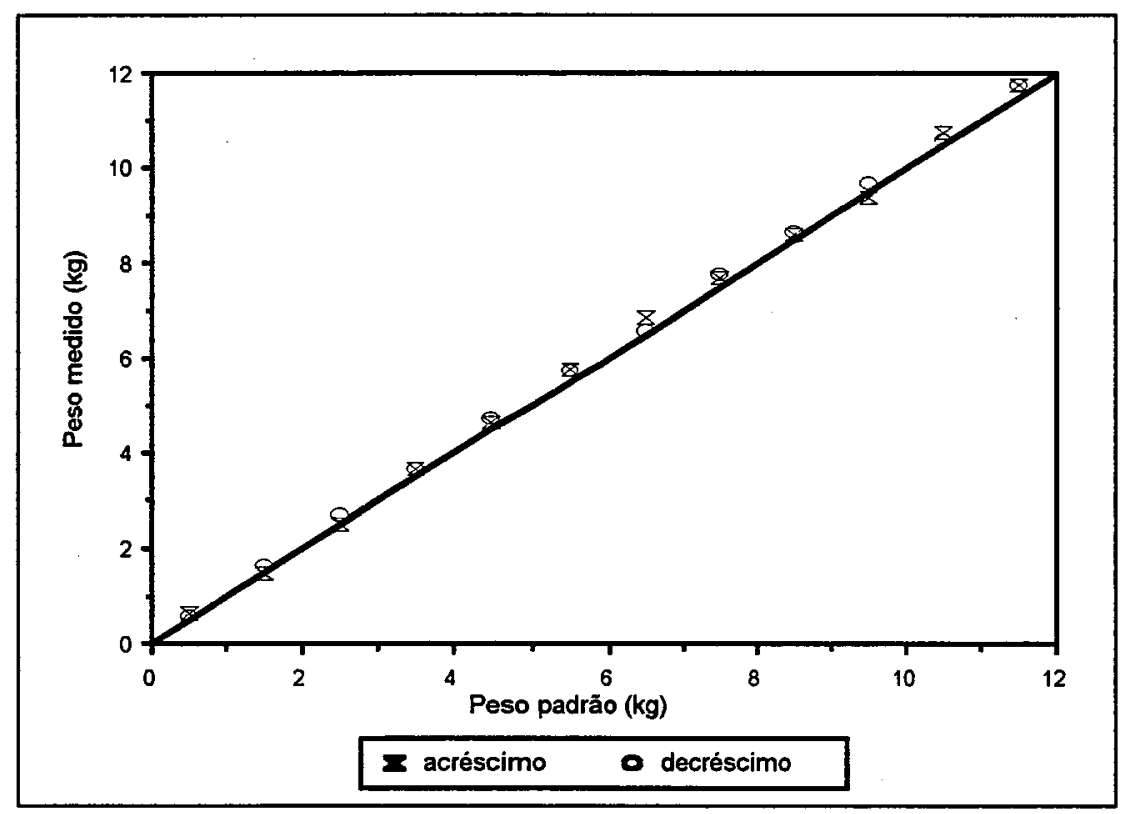

Figura 15. Relação entre valores reais e medidos pelo lisímetro de pesagem, em comparação com a reta 1:1. 


\section{Apêndice II. Calibração do Termômetro ao Infravermelho}

PERRIER (1970) propôs um sistema simples para calibração de
dispositivos que medem a temperatura de superficies por radiação ao infravermelho. Consiste basicamente de uma esfera inteiramente negra, mergulhada num banho de temperatura uniforme e conhecida, permitindo desta forma representar um corpo negro perfeito $(\varepsilon=1)$. O sensor é disposto de forma a medir a temperatura da esfera, e desta forma pode-se comparar as medidas de temperatura.

O sistema construído constituiu-se de uma esfera de cobre oca, com 12 $\mathrm{cm}$ de diâmetro, pintada interna e externamente de preto fosco, com um orifício para a colocação do sensor. A esfera foi acoplada à tampa de uma caixa de isopor com capacidade para $8 \mathrm{I}$. Três termopares foram também acoplados à tampa da caixa, com as juntas sensoras próximas à esfera, para indicarem a temperatura da água, considerada como temperatura padrão. Foi colocada no interior da caixa uma pequena bomba para promover a circulação da água, com o objetivo de uniformizar a temperatura em todos os pontos. A temperatura média obtida pelos termopares foi medida a cada $10 \mathrm{~s}$, e a temperatura obtida pelo termômetro ao infravermelho foi medida a cada minuto. Os valores médios de 2 min de medida foram armazenados em um "datalogger" modelo CR10 Campbell. A Figura 16 apresenta um esquema do sistema construído.

A calibração foi feita com a colocação de água quente na caixa, permitindo seu resfriamento e a seguir, com a colocação de água gelada e permitindo seu aquecimento. Os processos de resfriamento e aquecimento da água foi bastante lento (cerca de $24 \mathrm{~h}$ cada processo), permitindo a obtenção de dados suficientes de temperaturas para sua comparação. A variação da temperatura durante a calibração foi de cerca de $6^{\circ} \mathrm{C}$ até $52^{\circ} \mathrm{C}$. 


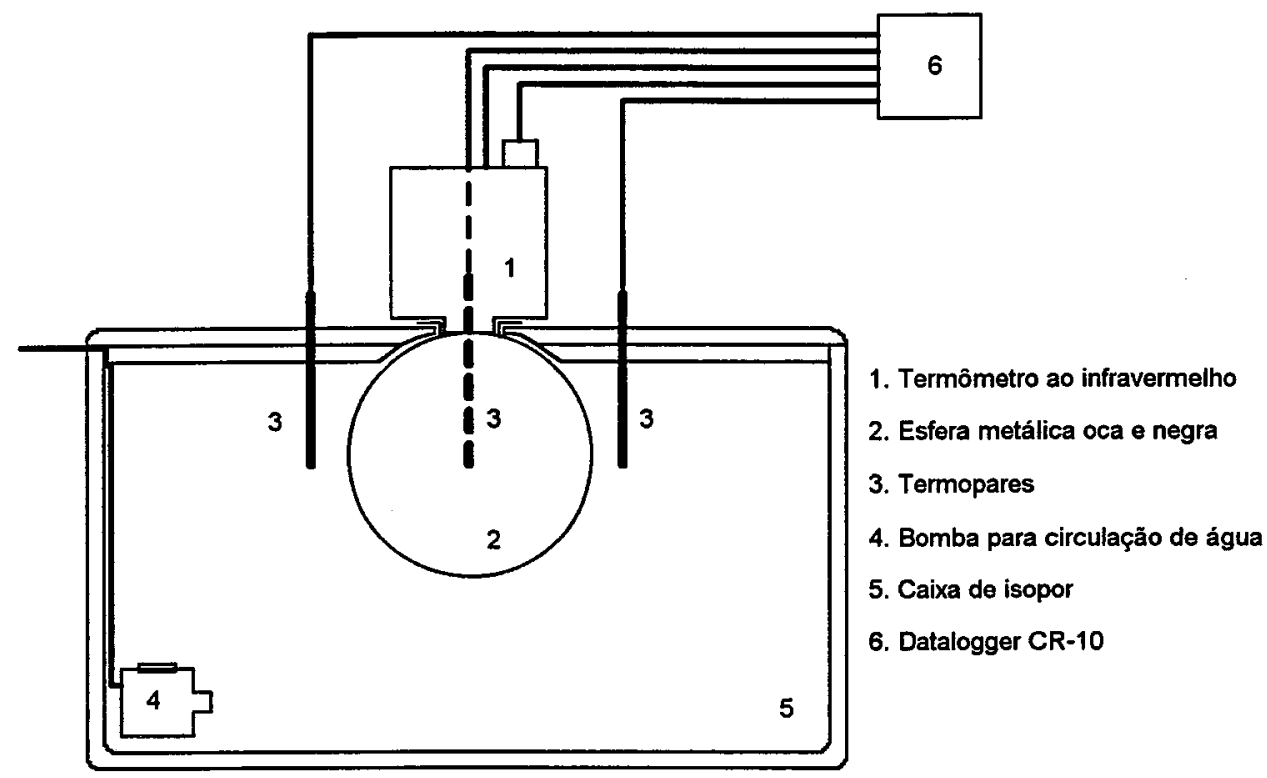

Figura 16. Esquema de montagem do sistema para calibração do termômetro ao infravermelho.

Na Figura 17 pode-se observar o gráfico de calibração, e a respectiva equação de regressão.

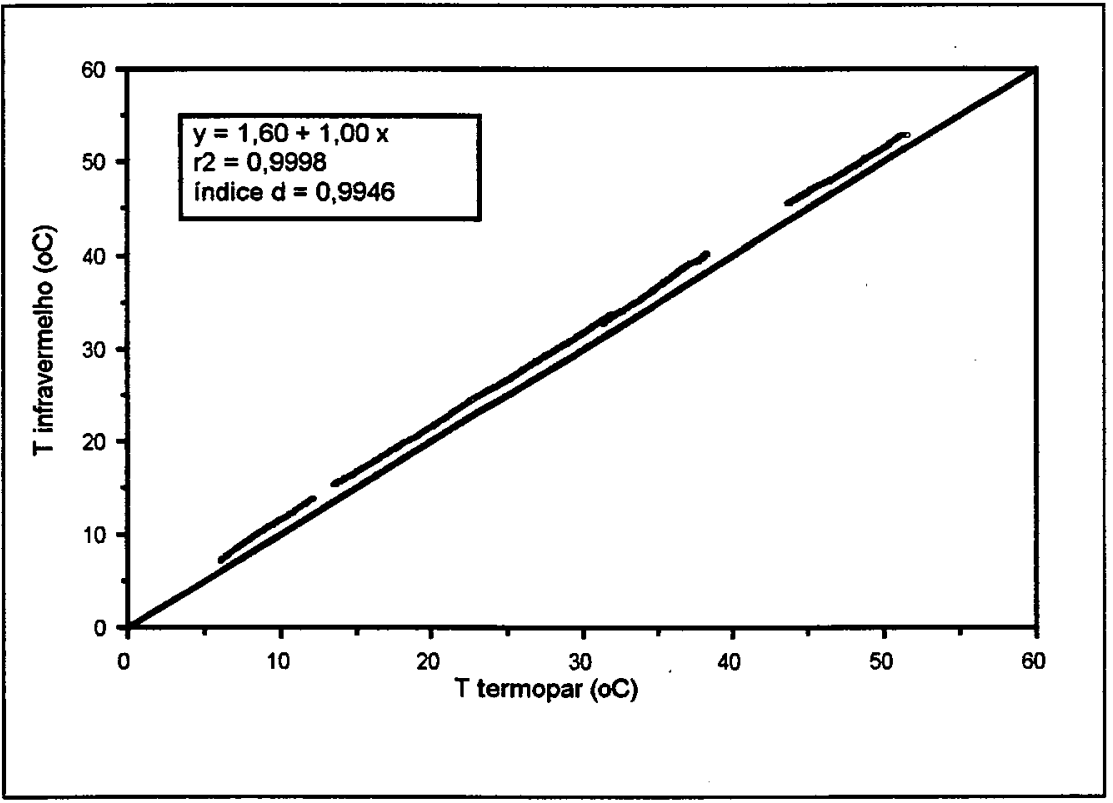

Figura 17. Representação gráfica da calibração do termômetro ao infravermelho. 


\section{Apêndice III. Comparação entre as médias mensais dos últimos 10 anos e as médias mensais do período de estudo}

Tabela 11. Comparação entre dados climáticos médios mensais dos últimos 10 anos e a média mensal durante o periodo de coleta de dados: temperatura do ar (Ta), umidade relativa (UR), velocidade do vento (U) e chuva (C).

\begin{tabular}{|c|c|c|c|c|c|c|c|c|}
\hline & \multicolumn{2}{|c|}{$\mathrm{Ta}\left({ }^{\circ} \mathrm{C}\right)$} & \multicolumn{2}{|c|}{ UR (\%) } & \multicolumn{2}{|c|}{$\mathrm{U}\left(\mathrm{m} \mathrm{s}^{-1}\right)$} & \multicolumn{2}{|c|}{$\mathrm{C}(\mathrm{mm})$} \\
\hline & $\begin{array}{c}\text { média } \\
10 \text { anos }\end{array}$ & $\begin{array}{c}\text { mês em } \\
\text { estudo }\end{array}$ & $\begin{array}{c}\text { média } \\
10 \text { anos }\end{array}$ & $\begin{array}{l}\text { mês em } \\
\text { estudo }\end{array}$ & $\begin{array}{c}\text { média } \\
10 \text { anos }\end{array}$ & $\begin{array}{c}\text { mês em } \\
\text { estudo }\end{array}$ & $\begin{array}{c}\text { média } \\
10 \text { anos }\end{array}$ & $\begin{array}{l}\text { mês em } \\
\text { estudo }\end{array}$ \\
\hline dez & 24,5 & 23,8 & 74,2 & 76,0 & 2,7 & 2,0 & 174,5 & 195,9 \\
\hline jan & 25,3 & 25,0 & 76,6 & 81,5 & 2,3 & 1,5 & 219,1 & 312,4 \\
\hline fev & 24,9 & 24,5 & 77,8 & 84,3 & 2,2 & 1,7 & 216,4 & 193,2 \\
\hline mar & 24,3 & 23,8 & 77,4 & 86,1 & 2,1 & 1,6 & 219,8 & 150,0 \\
\hline$a b r$ & 23,0 & 22,3 & 76,0 & 78,7 & 2,1 & 1,6 & 86,7 & 11,9 \\
\hline mai & 19,8 & 18,4 & 77,5 & 83,0 & 1,9 & 1,3 & 82,9 & 35,9 \\
\hline
\end{tabular}

